FERNANDO RYOJI KAKUGAWA

ATENDIMENTO PARA COMPOSIÇÃO DE SERVIÇOS JUSTO E TRANSACIONAL COM ORIGEM EM MÚLTIPLOS DOMÍNIOS

São Paulo

2016 
FERNANDO RYOJI KAKUGAWA

\section{ATENDIMENTO PARA COMPOSIÇÃO DE SERVIÇOS JUSTO E TRANSACIONAL COM ORIGEM EM MÚLTIPLOS DOMÍNIOS}

Tese apresentada à Escola Politécnica da Universidade de São Paulo para obtenção do título de Doutor em Ciências.

São Paulo

2016 


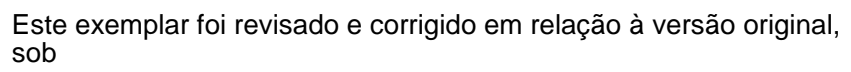

Assinatura do orientador:

\section{Kakugawa, Fernando}

Atendimento para composição de serviços justo e transacional com origem em múltiplos domínios / F. Kakugawa -- versão corr. -- São Paulo, 2016. $136 \mathrm{p}$.

Tese (Doutorado) - Escola Politécnica da Universidade de São Paulo. Departamento de Engenharia de Computação e Sistemas Digitais.

1.Sistemas distribuídos 2.Protocolos de comunicação 3.Interoperabilidade 4.Web Services 5.Controle de concorrência I.Universidade de São Paulo. Escola Politécnica. Departamento de Engenharia de Computação e Sistemas Digitais II.t. 
FERNANDO RYOJI KAKUGAWA

\section{ATENDIMENTO PARA COMPOSIÇÃO DE SERVIÇOS JUSTO E TRANSACIONAL COM ORIGEM EM MÚLTIPLOS DOMÍNIOS}

Tese apresentada à Escola Politécnica da Universidade de São Paulo para obtenção do título de Doutor em Ciências.

Área de concentração:

Engenharia de Computação

Orientadora:

Profa. Dra. Liria Matsumoto Sato

São Paulo 


\section{AGRADECIMENTOS}

Agradeço a Deus pela graça da vida e pelos dons recebidos, os quais proporcionaram a conclusão deste trabalho. É uma graça concretizar um sonho, que anos atrás era algo muito distante da minha realidade.

A minha orientadora Profa. Dra. Liria Matsumoto Sato, pela convivência, a paciência, a amizade e o amor que conduz tudo em sua vida. A sua orientação foi primordial em todas as etapas do trabalho.

A minha esposa Andréa Kakugawa, pelo suporte emocional e incondicional, pois em todas as situações de stress e agonia, ela oferecia amor e compreensão. A sua presença foi fundamental para concluir esta jornada.

A minha mãe, Rosa Kakugawa, com seu amor, seu apoio e sua presença na vida de todos os filhos. O seu exemplo e o esforço em sempre fazer o correto são uma referência em minha vida.

Aos grandes amigos Francisco Isidro Massetto, pelos auxílios técnicos para a realização deste trabalho, e Augusto Mendes Gomes Jr, disponibilizando uma carga de trabalho que sempre possibilitou o balanceamento entre as atividades do doutorado e as atividades docente na universidade que trabalhamos. O ombro amigo que eles sempre disponibilizaram foi essencial para o desenvolvimento deste trabalho.

Aos sobrinhos Gabriella, Júlia, Luiza, Julinha e Enzo, porque o convívio com essas crianças renova a minha visão de vida e me fortalecia ao longo do processo.

Ao LAHPC que disponibilizou os recursos necessários para condução deste trabalho. $\mathrm{E}$ as pessoas que fazem parte do laboratório, auxiliando em questões técnicas e construindo um ambiente descontraído e favorável para o desenvolvimento dos trabalhos. 
"Aí onde estão as nossas aspirações, o nosso trabalho, os nossos amores - aí está o lugar do nosso encontro cotidiano com Cristo. É no meio das coisas mais materiais da terra que nos devemos santificar, servindo a Deus e a todos os homens. Na linha do horizonte, meus filhos, parecem unir-se o céu e a terra. Mas não: onde de verdade se juntam é no coração, quando se vive santamente a vida diária ..."

São Josemaria Escrivá de Balager 


\section{RESUMO}

O uso de Web Services tem aberto novas possibilidades de desenvolvimento de software, entre elas a composição de serviços. A composição de serviços apresenta novas questões no ambiente computacional, entre elas a execução integral, garantindo consistência e contemplando o controle de concorrência. O workflow é um conjunto de tarefas e interações organizadas de modo que forneça uma funcionalidade ao sistema, provendo a automatização de processos complexos, através da composição de serviços. Tal composição deve ser executada de forma transacional, processando as operações com consistência. A execução de workflows oriundos de domínios diferentes, faz com que os serviços que estão sendo utilizados, não possuam ciência do contexto da execução, podendo gerar atendimentos que não sejam justos, causando situações de deadlock e de starvation. Este trabalho apresenta estratégias para a execução de workflows em domínios distintos, que requisitam múltiplos serviços de um mesmo conjunto, sem a necessidade de um coordenador central, de forma transacional. $O$ atendimento a requisição contempla uma política justa na utilização do recurso que impede a ocorrência de deadlock ou de starvation para os workflows em execução. Os experimentos realizados neste trabalho mostram que o sistema desenvolvido, aplicando as estratégias propostas, executa as composições de serviços de maneira transacional, atendendo as requisições com justiça, livre de deadlock e starvation, mantendo o sistema independente e autônomo.

Palavras Chave: Sistemas Distribuídos. Protocolos de Comunicação.

Interoperabilidade. Web Service. Controle de Concorrência. 


\section{ABSTRACT}

Web Services are increasing software development possibilities, among then service composition. Service composition introduces new issues on computational environment, such as the whole service execution, ensuring consistency and concurrency control. Workflow is a set of organized tasks and interactions in order to provide functionality to the system, automating complex process through composition service. Such composition must be performed by transactional support, performing operations consistently. The workflow execution from different domain clients sharing the same composition make these clients ignore the execution context. It may cause inconsistencies, from unfair attendance to deadlock or starvation. This work depicts strategies for workflow execution from different domains, requesting multiple services from the same composition, without a centralized coordinator, in transactional way. The request attendance contains a fair policy for resource usage and consumption to avoid deadlock and starvation. Applying the proposed strategy on the experiments performed in this work, it confirms that the developed system executes service composition with transactional support, avoiding deadlock or starvation, keeping the whole system autonomous and independent.

Keywords: Distributed Systems. Communications Protocols. Interoperability. Web Service. Concurrency Control. 


\section{LISTA DE ILUSTRAÇÕES}

Figura 2.1 - Diagrama de estados para transação …………..............................25

Figura 2.2 - Exemplo de transação aninhada..................................................27

Figura 2.3 - O relógio lógico em cada nó ..........................................................

Figura 2.4 - O algoritmo de Lamport corrige os relógios ........................................32

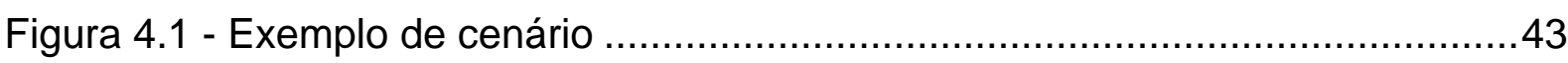

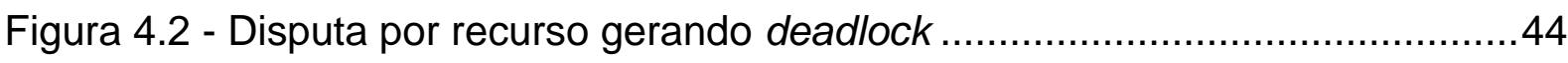

Figura 4.3 - Atualização de relógio lógico .........................................................46

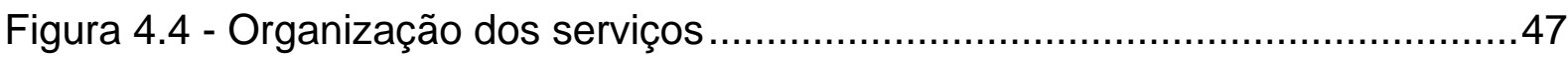

Figura 4.5 - Workflow para execução das requisições ..........................................49

Figura 4.6 - Fluxo de execução ao receber requisição.........................................52

Figura 4.7 - Fluxo de execução para verificar disponibilidade................................54

Figura 4.8 - Fluxo da operação Request_Resources ........................................57

Figura 4.9 - Diagrama de sequência de mensagens da função req_resource ..........58

Figura 4.10 - Fluxo da operação Query_Resources.............................................59

Figura 4.11 - Diagrama de sequência de mensagens da função que_resource .......59

Figura 4.12 - Fluxo da operação Rollback_Resources.........................................60

Figura 4.13 - Diagrama de sequência de mensagens da função rol_resource .........61

Figura 4.14 - Fluxo da operação Commit_Resources ...........................................61

Figura 4.15 - Diagrama de sequência de mensagens da função com_resource.......62

Figura 4.16 - Diagrama de sequência de mensagens da função rev_resource ........63

Figura 4.17 - Diagrama de sequência de mensagens da função fin_commit............63

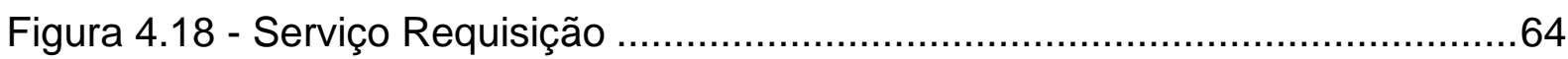

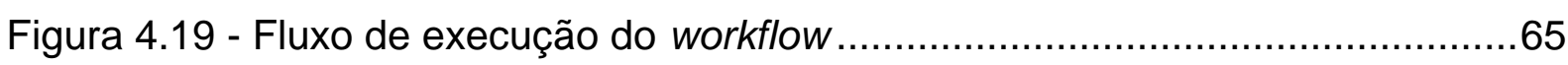

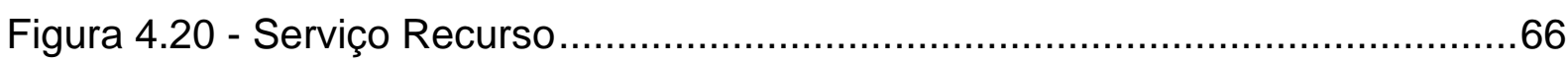

Figura 4.21 - Algoritmo thread Executa Operação .................................................68

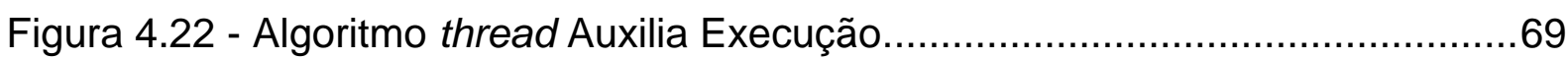

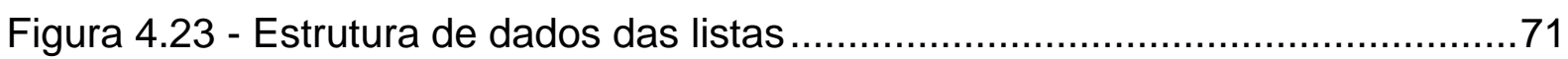

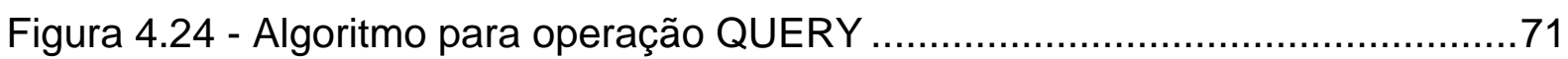

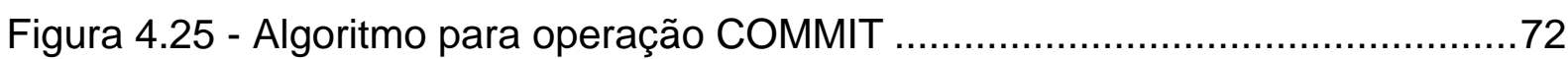

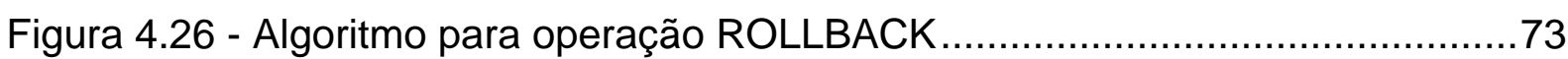

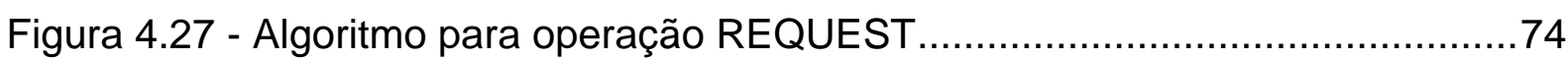

Figura 4.28 - Algoritmo para operação REQUEST_STEP2 …................................75

Figura 4.29 - Algoritmo para operação REVOKE ……….....................................75 
Figura 4.30 - Algoritmo para operação FINALIZE_COMMIT ..................................75

Figura 4.31 - Descrição dos elementos da proposta ..............................................76

Figura 4.32 - Descrição das informações contidas na mensagem ...........................76

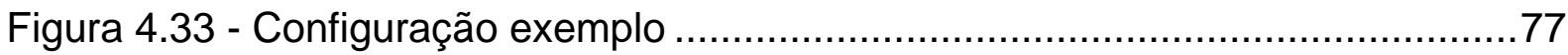

Figura 4.34 - Solicitação de reserva com operação REQUEST ..............................78

Figura 4.35 - Confirmação da operação REQUEST ............................................78

Figura 4.36 - Confirmação de reserva com a operação COMMIT ............................79

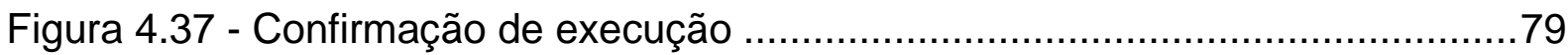

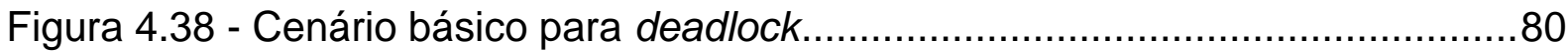

Figura 4.39 - Servidor Requisição disputando Servidor Recurso ............................81

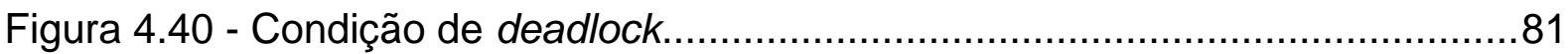

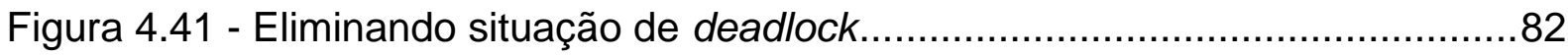

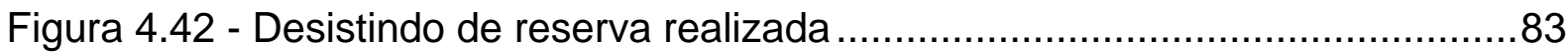

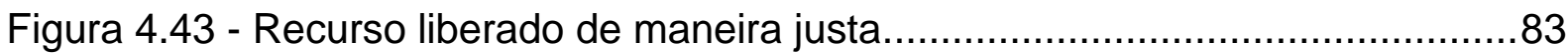

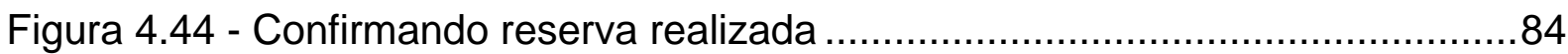

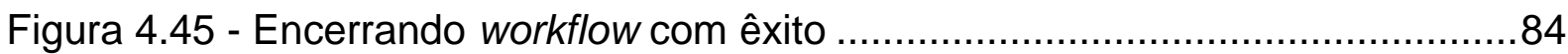

Figura 4.46 - Diagrama de estados para o Servidor Requisição no atendimento a uma requisição.

Figura 4.47 - Diagrama de estados para o Servidor Recurso ao receber requisição 87 Figura 4.48 - Diagrama de estados para o Servidor Recurso ao verificar

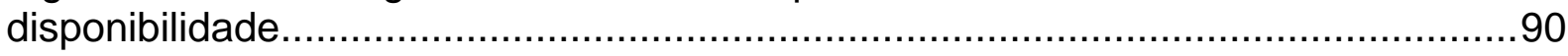

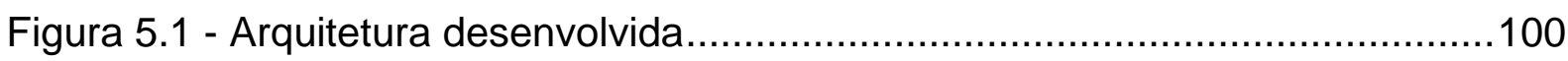

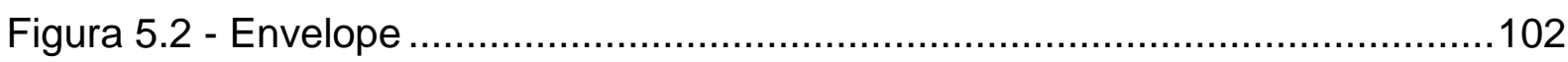

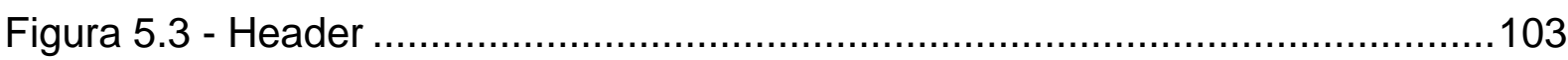

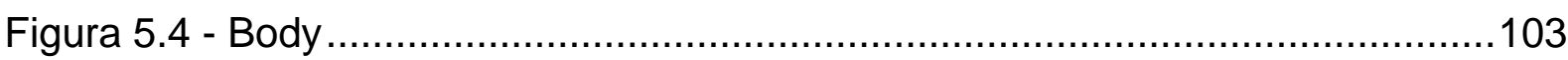

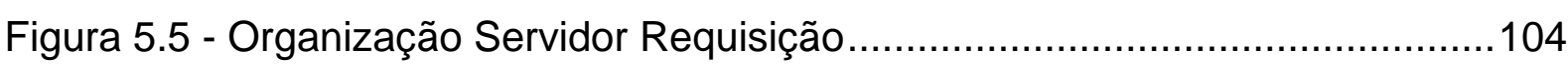

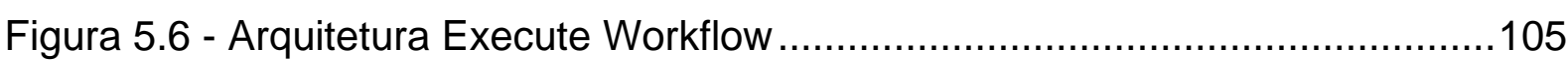

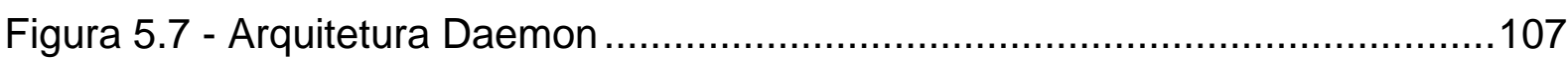

Figura 5.8 - Organização Servidor Recurso ………......................................107

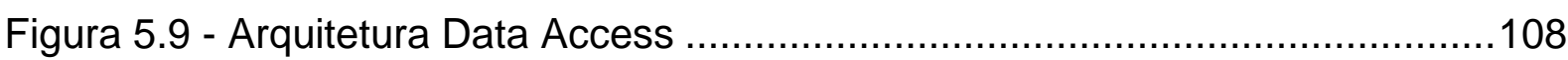

Figura 5.10 - Arquitetura Dispatcher .........................................................109

Figura 6.1 - Topologia de testes...............................................................111

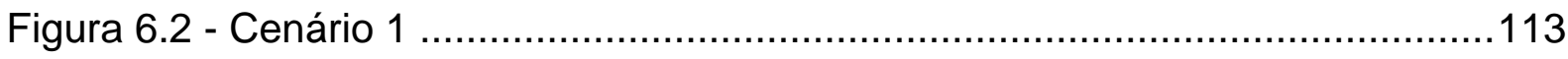

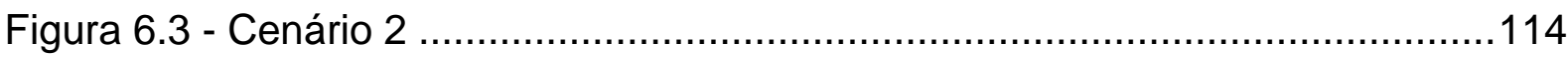

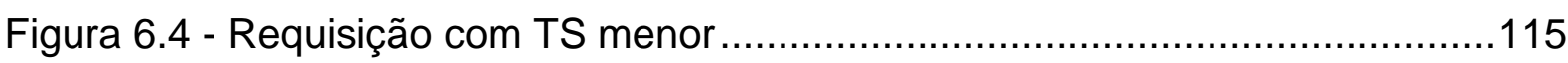

Figura 6.5 - Promovendo justiça....................................................................116 
Figura 6.6 - Suse04 confirmando reserva ....................................................

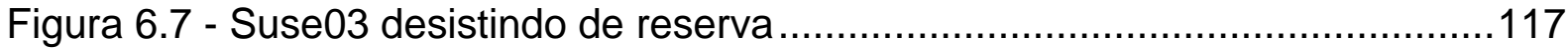

Figura 6.8 - Requisições em tempos distintos..............................................118

Figura 6.9 - Configuração de deadlock .......................................................118

Figura 6.10 - Resolvendo deadlock .........................................................119

Figura 6.11 - Suse04 confirma e Suse03 tem requisição negada ........................120

Figura 6.12 - Suse04 desfaz e Suse03 confirma.............................................121 


\section{LISTA DE TABELAS}

Tabela 5.1 - Informações sobre os serviços disponibilizados 101 


\section{LiSTA DE ABREVIATURAS e SigLAS}

2PC Two Phase Commit

ACID Acrônimo de Atomicidade, Consistência, Isolação e Durabilidade

$\mathrm{AL} \quad$ Arrival List

API Application Programming Interface

BUFFER Armazenamento temporário do sistema

CL Committing List

ETH Instituto de Sistema de Informação de Zurique - Eidgenössischen Technischen Hochschule Zürich

HTTP Hypertext Transfer Protocol

ITA Instituto Tecnológico da Aeronáutica

LPW List of Prewrite

OASIS Organization for the Advanced of Structured Information Standart

OGSA Open Grid Service Architecture

P2P Peer to Peer

QTD Quantidade total do recurso

REST Representational State Transfer

$\mathrm{RL} \quad$ Reservation List

RQT Servidor Requisição

RSC Servidor Recurso

SGBD Sistema Gerenciador de Banco de Dados

SOAP Simple Object Access Protocol

TS Timestamp

URI Uniform Resource Identifier

W3C World Wide Web Consortium

WF Workflow 
WL Wait List

WS-AT Web Service AtomicTransaction

WS-BA Web Service Business Activity

WS-BPEL Web Service Business Process Execution Language

WS-C Web Service Coordination

WS-TX Web Service Transaction

XML eXtensible Markup Language 


\section{SUMÁRIO}

1 INTRODUÇÃO

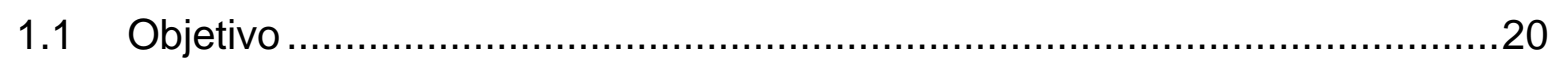

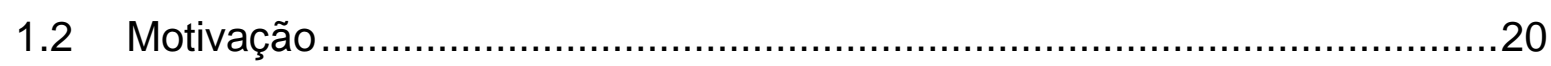

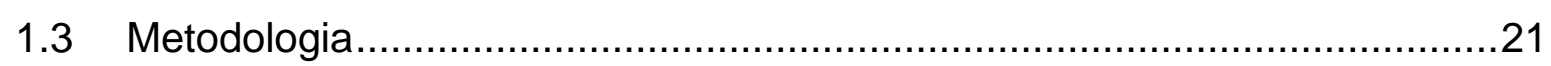

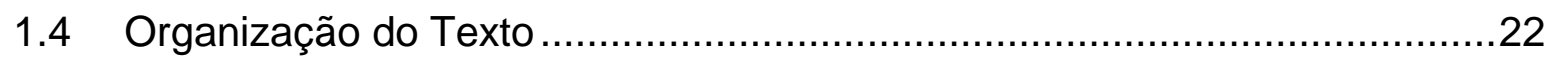

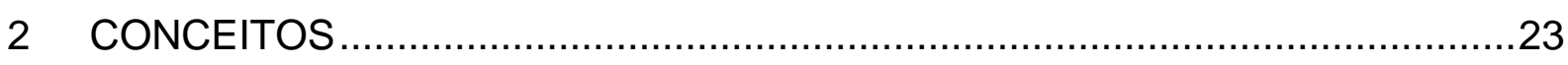

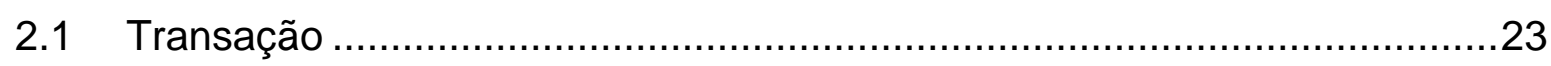

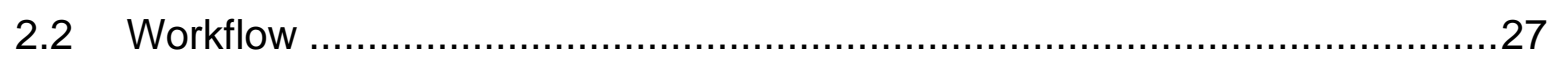

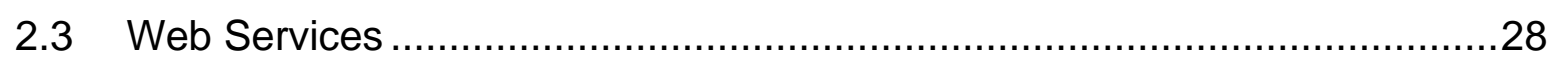

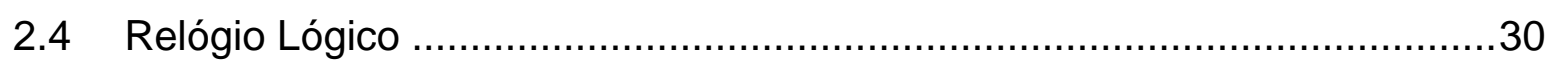

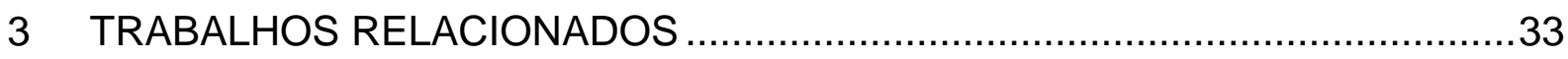

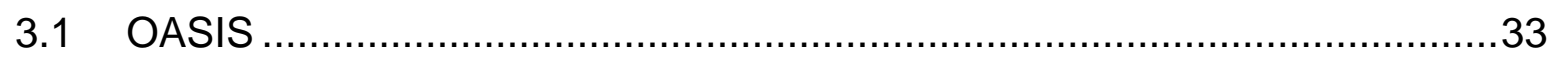

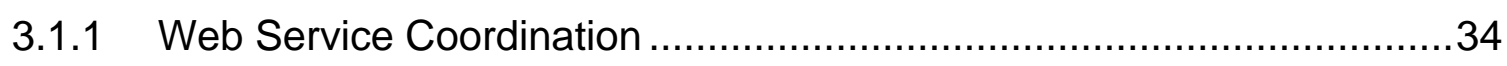

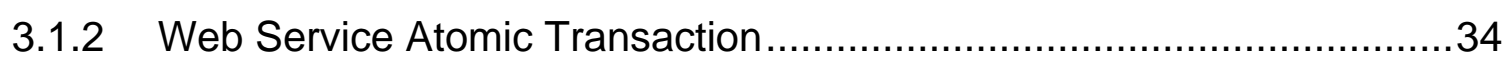

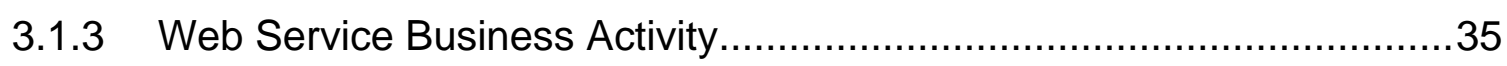

3.2 Transação em Ambiente de Grade Computacional com Controle de Concorrência Descentralizado

3.3 Protocolo Baseado em Timestamp e Two Phase Commit para Web Services 38

3.4 Considerações Sobre o Capítulo .39

4 ATENDIMENTO DE REQUISIÇÕES ORIUNDAS DE MÚLTIPLOS DOMÍNIOS EXECUTANDO COMPOSIÇÕES DE SERVIÇOS PROVIDOS POR SERVIDORES DISTINTOS

4.1 Requisições de Múltiplos Domínios para Executar Composições de Serviços Providos Por Servidores Distintos

4.2 Descrição do Sistema e dos Mecanismos para Coordenação das Requisições e do Gerenciamento dos Recursos 44

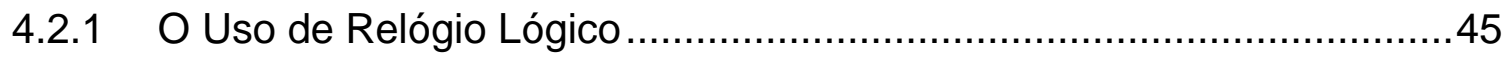

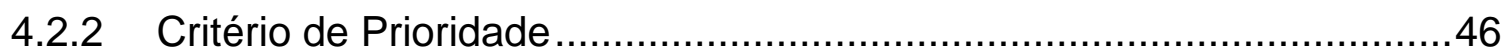

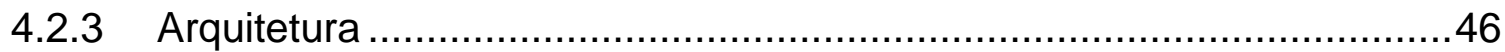

4.2.4 Descrição do Mecanismo para Execução de Requisições de Múltiplos Domínios com Composição de Serviços de Servidores Distintos

4.2.4.1 Operações no Servidor de Requisição para execução das requisições 48

4.2.4.2 Operações no Servidor Recurso. .50 
4.2.4.3 Protocolo de execução de cada operação no Servidor Requisição 57

4.2.5 Serviço Requisição .64

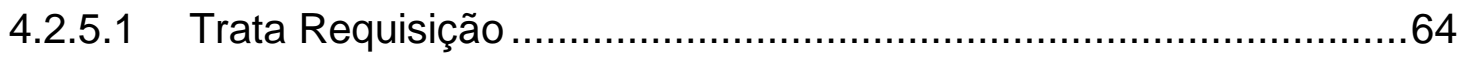

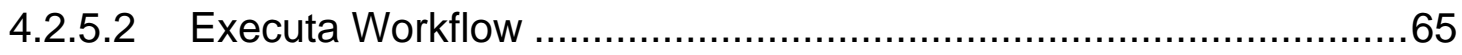

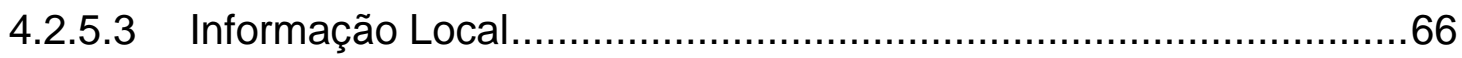

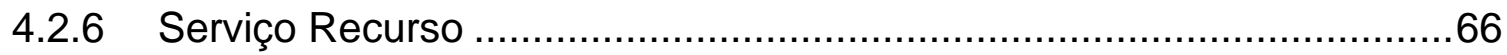

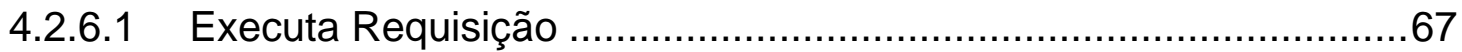

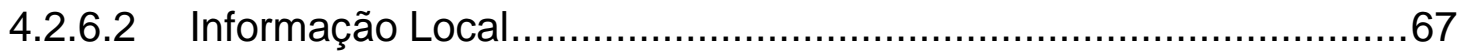

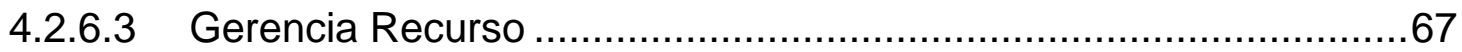

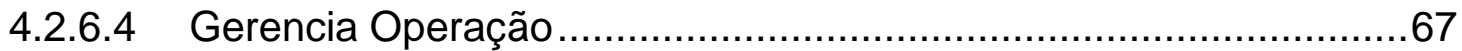

4.2.7 Exemplo Ilustrando o Funcionamento da Solução.................................76

4.2.8 Exemplo Ilustrando o Problema de Deadlock e a Solução .....................80

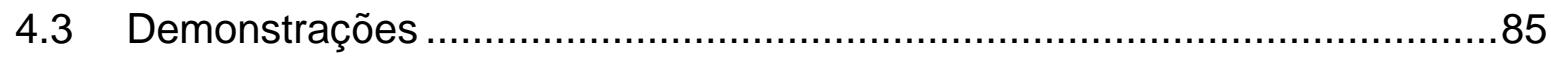

4.3.1 Demonstração da Justiça no Atendimento ………..............................93

4.3.2 Demonstração da Não Ocorrência de Deadlock....................................94

4.3.3 Demonstração da Não Ocorrência de Starvation ................................97

4.4 Considerações Sobre a Proposta ............................................................98

5 SISTEMA PARA EXECUÇÃO JUSTA DE COMPOSIÇÃO DE SERVIÇOS REMOTOS ORIUNDOS DE DOMÍNIO DISTINTO ……..................................100

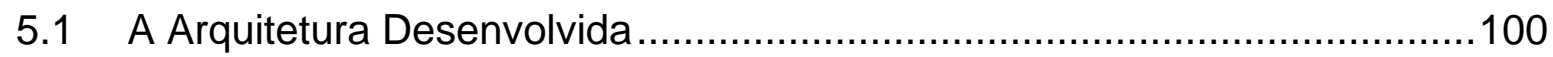

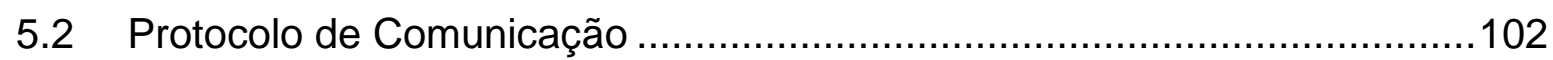

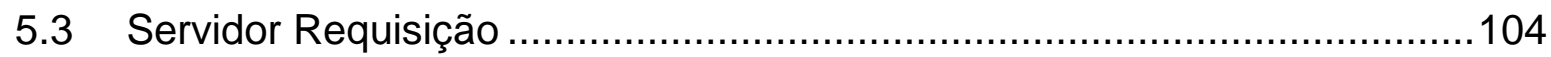

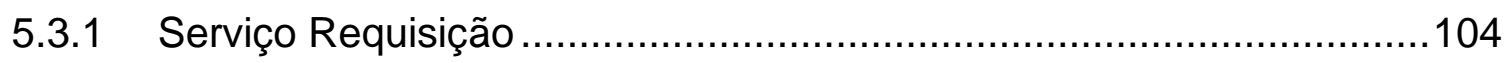

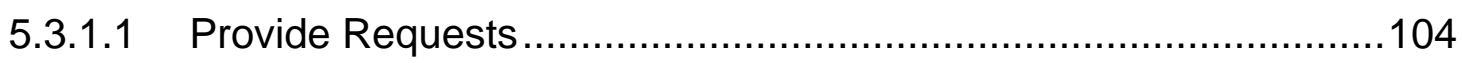

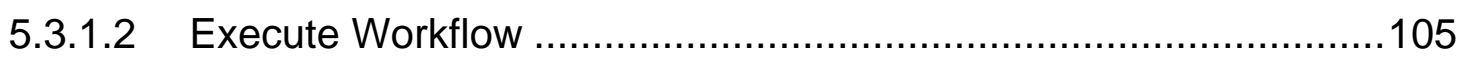

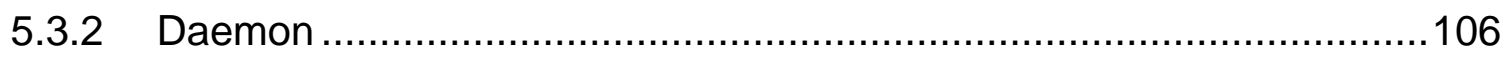

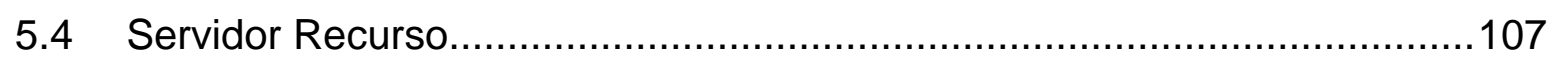

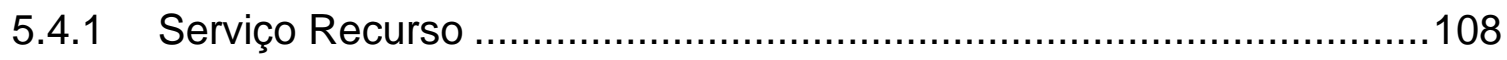

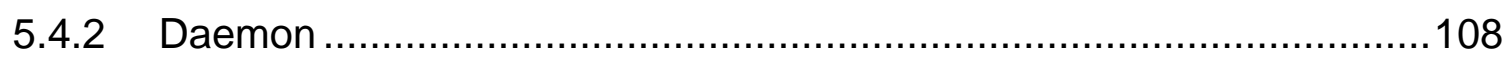

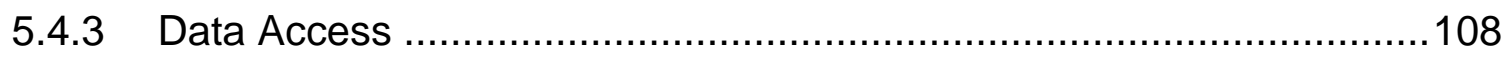

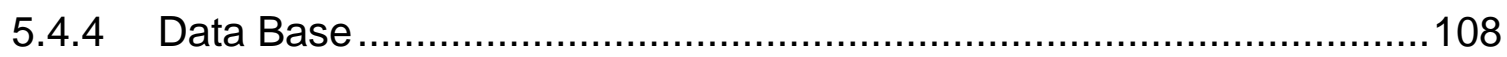

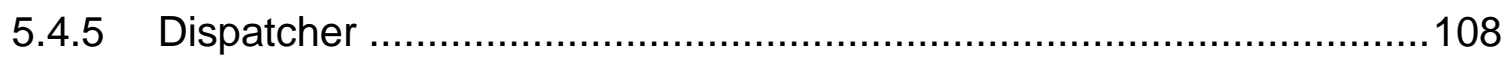

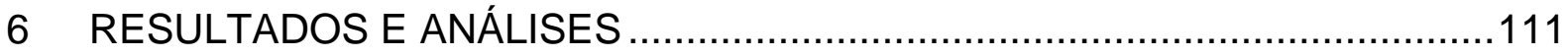

6.1 Metodologia Utilizada nos Testes.....................................................111

6.2 Descrição dos Cenários de Teste .....................................................112 


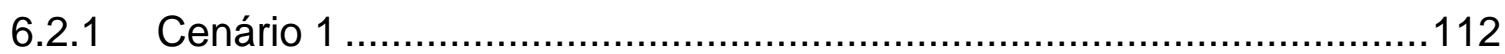

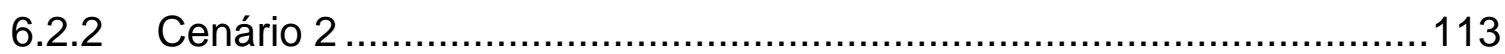

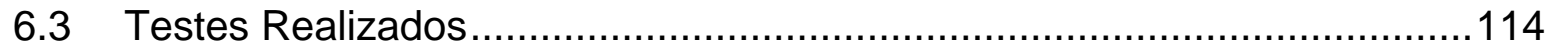

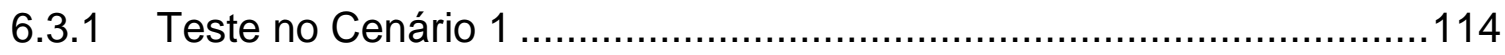

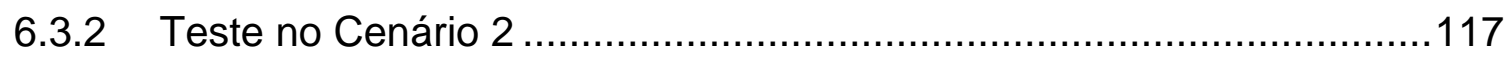

6.4 Considerações Sobre os Resultados ...............................................121

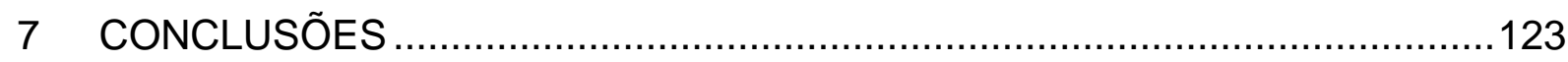

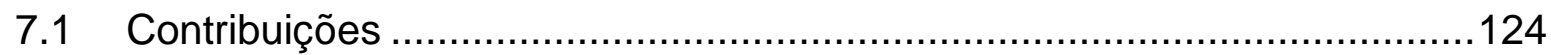

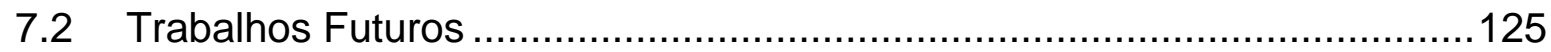

8 REFERÊNCIAS BIBLIOGRÁFICAS .........................................................126

Apêndice A - Cenário 1, log em Suse01 …………….....................................129

Apêndice B - Cenário 1, log em Suse02 ………………..............................131

Apêndice C - Cenário 2, log em Suse01 para COMMIT de Suse04.......................133

Apêndice D - Cenário 2, log em Suse02 para COMMIT de Suse04.......................134

Apêndice E - Cenário 2, log em Suse01 para ROLLBACK de Suse04 …................135

Apêndice F - Cenário 2, log em Suse02 para ROLLBACK de Suse04 …...............136 


\section{INTRODUÇÃO}

Web Services é uma tecnologia para sistemas distribuídos que tem o intuito de oferecer uma plataforma comum, possibilitando a execução composta de diferentes aplicações, independente de sistema operacional e linguagem de programação, permitindo que haja interações entre máquinas sem a necessidade de intervenção humana (COULOURIS, DOLLIMORE, et al., 2011). Através de Web Service é possível interoperar sistemas heterogêneos utilizando uma interface de comunicação comum, realizando troca de mensagens com um formato texto auto descritivo e padronizado (TANENBAUM e STEEN, 2007).

A tecnologia oferece como característica o baixo acoplamento, minimizando a dependência entre os serviços. Isto é devido a outra característica básica que confere a autonomia entre os serviços, onde cada serviço é concebido de maneira independente (ERL, 2009).

Um Web Service é composto por um conjunto de operações, que proporciona o acesso a qualquer recurso computacional, tais como objetos, banco de dados e funções, podendo ser utilizado por qualquer computador conectado à Internet. O serviço pode ser qualquer rotina, que cada organização desenvolve para atender a uma necessidade específica, independente da linguagem de programação que foi utilizada para o seu desenvolvimento. Web Services é um paradigma importante (COULOURIS, DOLLIMORE, et al., 2011), oferecendo a infraestrutura básica para áreas como a de grade computacional (FOSTER e KESSELMAN, 2004) e também para área de computação em nuvem (ARMBRUST, FOX, et al., 2009).

Com este paradigma, abrem-se novas possibilidades de desenvolvimento de software, surgindo novas aplicações, as quais são constituídas de composição de serviços, visto que o uso de serviço permite a interoperabilidade. Agilizar o desenvolvimento de aplicações realizando o reuso de rotinas já desenvolvidas e disponibilizada através de um serviço, facilita a integração entre sistemas, e esta é outra característica atraente no uso de Web Services (GOTTSCHALK, GRAHAM, et al., 2002).

Neste cenário de associação entre sistemas computacionais heterogêneos surgem novas questões, entre elas a execução dos serviços compostos de maneira 
integral, garantindo a consistência de dados. Estas questões devem contemplar aspectos como o controle de concorrência e a não ocorrência de deadlock e de starvation durante a execução para processar algum serviço. Políticas que permitam a execução completa, de maneira justa e consistente, devem ser definidas.

É fundamental que haja uma coordenação para a composição de serviços. O uso de workflows para a execução de composição de serviços tem se mostrado adequado permitindo consistência, contemplando políticas como o controle de execução transacional. O conceito de transação é definido como um conjunto de operações de leitura/escrita executadas sobre base de dados (WANG, VONK, et al., 2008), provendo uma unidade de computação consistente e confiável, devendo ser integral e completa, de maneira que assegure a execução destas operações em sua totalidade (OZSU e VALDURIEZ, 1999). O uso de um sistema de processamento de transação mostra-se adequado na instituição de políticas para articular workflows, fornecendo mecanismos para execução concorrente e promovendo a restauração de falhas.

As propriedades ACID são essenciais no processamento de transações, pois são eficientes na execução das denominadas flat transactions, as quais são operações realizadas em sistemas de banco de dados local e tradicional, possuindo características como tempo de execução relativamente curto, pouco uso de bloqueios, pequena quantidade de transações concorrentes e a localização dos seus dados não afetam de maneira negativa no desempenho do sistema (WANG, VONK, et al., 2008).

Workflows, para a execução de composição de serviços, implementa transações adaptadas para ambiente distribuído, uma vez que possui como característica o longo tempo de execução, se comparado a execuções em banco de dados local, tornando complexo o seu gerenciamento. Alguns aspectos merecem consideração, uma vez que são ingredientes que apresentam uma nova dimensão para uma situação: a quantidade de recursos computacionais envolvidos, a autonomia de cada recurso e sua distribuição geográfica. Estes aspectos expõem o desafio de coordenar execuções concorrentes e distribuídas, as quais inviabilizam de certa maneira aplicar as propriedades ACID (BERNSTEIN e KIFER, 2001). Para contemplar esses novos requisitos, é necessário flexibilizar as propriedades ACID (ELMAGARMID, RUSINKIEWICZ e SHETH, 1999). Exemplos de flexibilização de propriedades ACID podem ser observados em transações aninhadas (OZSU e 
VALDURIEZ, 1999) (GARCIA-MOLINA e SALEM, 1987), as quais dividem uma transação em subtransações.

A execução de workflow com composição de serviços prevê estas situações, possibilitando executar, com comportamento transacional, as operações solicitadas de maneira consistente. Mas o uso de workflows oriundos de domínio diferente, os quais utilizam serviços em comum, faz com que os serviços, que foram concebidos de forma autônoma, não possuam ciência do contexto da execução, uma vez que não realizam comunicação entre si para detectar dependência de serviços entre eles, podendo gerar conflito ou atendimentos que não sejam justos.

Em estratégias que adotam o instante de recebimento da requisição, ao invés do instante do envio da requisição, como um dos critérios de prioridade, leva a um atendimento injusto pois requisições solicitadas em momentos anteriores a outras poderão ser atendidas com menor prioridade. Este aspecto também pode ocasionar situação de deadlock entre workflows oriundos de servidores distintos, que concorrem ao mesmo serviço, já que em sistemas distribuídos requisições originadas do mesmo local atingem o destino em tempos distintos, considerando o tráfego na rede ou a distribuição geográfica. Neste caso, um serviço $X$ pode receber a solicitação de uma requisição $A$ e a seguir a solicitação de uma requisição $B$, e um serviço $Y$ pode receber uma solicitação de uma requisição $B$ e a seguir solicitação de uma requisição $A$. Desta forma a requisição $A$ terá $o$ atendimento do serviço $X$ e aguardará ser atendida pelo serviço $\mathrm{Y}$, e a requisição $\mathrm{B}$ terá o atendimento do serviço $\mathrm{Y}$ e aguardará ser atendida pelo serviço $\mathrm{X}$, criando-se uma situação de deadlock.

O problema de deadlock pode ser solucionado abortando toda a execução corrente e reiniciando o workflow. Mas esta ocorrência pode persistir de maneira indefinida e configurar a situação de starvation. Caso a situação não configure em starvation, a política de reenvio entre as execuções envolvidas no impasse pode permitir que uma outra requisição, que não estava envolvida, seja atendida pelo serviço, durante o reenvio entre os que estavam no impasse, gerando um atendimento injusto. 


\subsection{OBjetivo}

Este trabalho tem como objetivo apresentar uma estratégia para a execução de workflows produzidos em domínios distintos, que requisitam múltiplos serviços de um mesmo conjunto sem a necessidade de um coordenador central. Tais serviços provêm a alocação de quantidades de seus respectivos recursos que serão consumidas no atendimento das requisições.

O workflow deve executar sua composição de serviços de maneira transacional. O serviço solicitado deve receber informações que possibilite 0 gerenciamento autônomo de forma justa para executar as requisições, impedindo a ocorrência de deadlock e starvation na execução dos workflows.

A independência entre os serviços é mantida, pois não há comunicação entre os serviços. O tratamento das requisições para cada serviço é realizado através de mecanismo de controle local.

A justiça é garantida através do mecanismo de atendimento e do critério de prioridade adotado.

\subsection{Motivação}

Um dos princípios básicos de Web Services é o baixo acoplamento através de independência e autonomia dos serviços. Isto significa que um serviço não deve influenciar na execução de outro serviço, ou seja, eles são concebidos de forma autônoma e seu comportamento deve seguir esta premissa.

Organizações como o OASIS - Organization for the Advanced of Structured Information Standarts (OASIS, 2013) e o W3C - World Wide Web Consortium (W3C, 2013) vem investindo esforços no intuito de apresentar soluções para estes novos desafios. O OASIS tem apresentado diversas especificações com o objetivo de aprimorar os Web Services como o WS-Coordination (OASIS, 2009e), para disponibilizar um serviço de coordenação para a execução de diversos serviços de forma transacional, o WS-AtomicTransaction (OASIS, 2009c) para a execução de transação de curta duração e o WS-BusinessActivity (OASIS, 2009d) para transpor os obstáculos das transações de longa duração. Estas pesquisas procuram atender 0 gerenciamento transacional na execução de composição de serviços no domínio 
determinado pelo contexto do coordenador. Caso um workflow utilize os serviços determinados por um coordenador e outro workflow não esteja registrado no serviço de coordenação, e utilizem serviços em comum, não há um controle para evitar conflitos entre os workflows.

Turker (TURKER, HALLER, et al., 2005) apresenta uma proposta de gerenciamento de transações em ambiente de grade computacional de maneira que os serviços, de forma autônoma, possam detectar conflitos e tratá-los sem a necessidade de um coordenador global. Através de comunicação P2P (Peer-To-Peer) entre os serviços, os conflitos são tratados, o que faz com que percam independência, pois necessitam interferir na execução de outros serviços.

Maciel (MACIEL e HIRATA, 2010) realizou uma pesquisa que propõe um protocolo baseado em 2PC (Two Phase Commit) e no uso de relógio lógico para gerenciar transações que utilizam serviços comuns sem a necessidade de um coordenador. O protocolo proporciona autonomia entre os serviços determinando quem pode utilizar os serviços, proporcionando execução de forma transacional, evitando a ocorrência de deadlock entre as transações distintas. A política adotada para evitar deadlock pode causar uma situação em que uma solicitação nunca será atendida, uma vez que o tratamento realizado é através de reenvio de requisições até que seja atendido.

\subsection{Metodologia}

O início deste trabalho se deu através de pesquisas de revisão bibliográfica sobre os conceitos envolvidos e autores que propõem solucionar problemas semelhantes.

Definiu-se as políticas e as estratégias iniciais, de como os mecanismos podem fornecer os critérios necessários para a resolução do problema.

A partir destas informações, realizou-se a especificação do protocolo entre as entidades envolvidas no sistema. Com as entidades estabelecidas definiu-se a arquitetura e os elementos necessários para criar os mecanismos de atendimento às requisições.

A seguir, implementou-se a arquitetura proposta e realizou-se testes e análises para verificar se $o$ atendimento dos aspectos a serem contemplados foi atingido. 


\subsection{Organização do TeXto}

Este trabalho está organizado em oito capítulos.

O capítulo 2 apresenta os conceitos envolvidos neste trabalho para uma melhor contextualização do problema e da proposta apresentada.

O capítulo 3 faz uma revisão sobre algumas soluções pesquisadas apresentando suas abordagens e aspectos divergentes com este trabalho.

O capítulo 4 apresenta a proposta deste trabalho, mostrando qual o cenário do problema e a descrição da proposta.

O capítulo 5 apresenta a descrição do sistema implementado a partir da arquitetura e das estratégias apresentadas no capítulo 4.

O capítulo 6 apresenta os resultados obtidos, os testes realizados, descrevendo o propósito dos cenários utilizados e análises destes resultados.

O capítulo 7 apresenta a conclusão do trabalho e propostas para trabalhos futuros. 


\section{CONCEITOS}

Para melhor compreensão da tese, é apresentado, neste capítulo, os principais conceitos utilizados neste trabalho.

\subsection{Transação}

Existem diversas definições para transação, e foram escolhidas as que melhor expõem o conceito para compreender a proposta deste trabalho.

Ozsu (OZSU e VALDURIEZ, 1999) define transação como uma unidade de computação consistente e confiável, constituída de sequências de operações de leitura e escrita sobre dados, juntamente com etapas de computação.

Elmasri (ELMASRI e NAVATHE, 2005), determina que uma transação é uma unidade lógica de processamento no banco de dados, a qual possui uma ou mais operações de acesso que podem ser de inserção, exclusão, alteração ou recuperação.

Tanenbaum (TANENBAUM e STEEN, 2007) apresenta uma descrição bem sucinta e direta, onde após definir o escopo de uma transação, através de um Início e um Fim, todas as operações inclusas neste escopo são executadas, ou nenhuma é executada através da característica tudo-ou-nada.

Baseado nestas definições, será adotado que transação é um conjunto de uma ou $n$ operações envolvendo leitura e/ou escrita de dados. Caso realize todas as operações é considerada como sucesso na execução, e caso não complete uma ou mais operações é considerada como insucesso na execução. A transação sobre dados deve ser coerente, onde o processo de execução da transação deve iniciar e terminar em um destes estados.

Para que a transação realize uma execução consistente e confiável ela deve atender as propriedades definidas através do acrônimo ACID, as quais fundamentam o controle de concorrência na execução, assegurando que seja realizada de maneira transacional (ZARRAS e ISSARNY, 1998). As propriedades definidas por ACID são descritas a seguir: 
- Atomicidade - uma transação deve ser uma unidade atômica, seguindo o conceito de tudo ou nada, ou seja, a unidade é executada em sua totalidade, caso não consiga executar tudo implicará no efeito de não ser executada.

- Consistência - uma transação deve preservar o estado de consistência dos dados, garantindo que uma transação iniciará a partir de um estado consistente e, após sua execução, resultará em outro estado consistente.

- Isolamento - transações devem ser operações isoladas uma das outras, onde as execuções que ocorrem simultaneamente devem ter os dados isolados uns dos outros sem que haja interferências entre as execuções.

- Durabilidade - após a execução de uma transação, as atualizações realizadas sobre os dados devem ser persistidas no sistema, mantendo o dado de forma durável para que em caso de falha o dado esteja disponível de maneira persistente.

Estas propriedades são fundamentais para proporcionar a consistência e a confiabilidade de uma transação, mas praticá-las de maneira estrita através de procedimento de tudo ou nada é viável em sistemas de bancos de dados tradicional com armazenamento local. Isto porque, neste ambiente, o tempo de execução é relativamente curto, a quantidade de transação concorrente é relativamente pequena e a transação, normalmente, é somente em um único sistema de banco de dados (WANG, VONK, et al., 2008).

Para os ambientes mais complexos, como um banco de dados distribuídos, as propriedades ACID não podem ser atendidas em sua totalidade, no entanto, continuam necessárias para garantir consistência na execução da transação. Desta forma as propriedades ACID devem ser relaxadas, de maneira que, através do relaxamento de algumas das propriedades, conforme a necessidade, permitam a execução em ambientes mais complexos mantendo o propósito original (OZSU e VALDURIEZ, 1999). Uma maneira de oferecer as características ACID, neste contexto, é apresentada por Elmagarmid (ELMAGARMID, RUSINKIEWICZ e SHETH, 1999) que associa as transações a duas dimensões diferentes, através do conceito de serialização e confiabilidade, com a finalidade de oferecer a computação consistente e confiável, as quais estão descritas a seguir: 
- serialização: é sustentada através de mecanismos de controle de concorrência onde há a garantia de que cada execução do usuário é única no momento atual, característica esta atribuída a atomicidade e isolamento;

- confiabilidade: garante que consultas ou atualizações, em que as operações realizadas manipulam as bases de dados, são executadas de maneira integral, característica esta atribuída a consistência e durabilidade.

O relaxamento das propriedades ACID não implica necessariamente em algo prejudicial ao sistema de banco de dados, mas uma maneira de privilegiar alguns aspectos em detrimento a outros conforme a necessidade de cada ambiente, elegendo quais são suas prioridades, resolvendo alguns problemas e implicando em outros (ZARRAS e ISSARNY, 1998).

Uma característica intrínseca à transação está no fato dela sempre terminar, mesmo havendo falhas. A Figura 2.1 ilustra o diagrama de estados de uma transação que possui somente um estado final (Encerrado), independentemente se a execução foi ou não realizada com sucesso (ELMASRI e NAVATHE, 2005). A transação estará no estado Consolidada se suas operações são realizadas na totalidade e, no entanto, caso a transação tenha o impedimento para executar no mínimo uma operação, ela é abortada de maneira que a execução é interrompida e todas as ações executadas, até então, serão desfeitas deixando o banco de dados no estado anterior ao início da execução.

Figura 2.1 - Diagrama de estados para transação

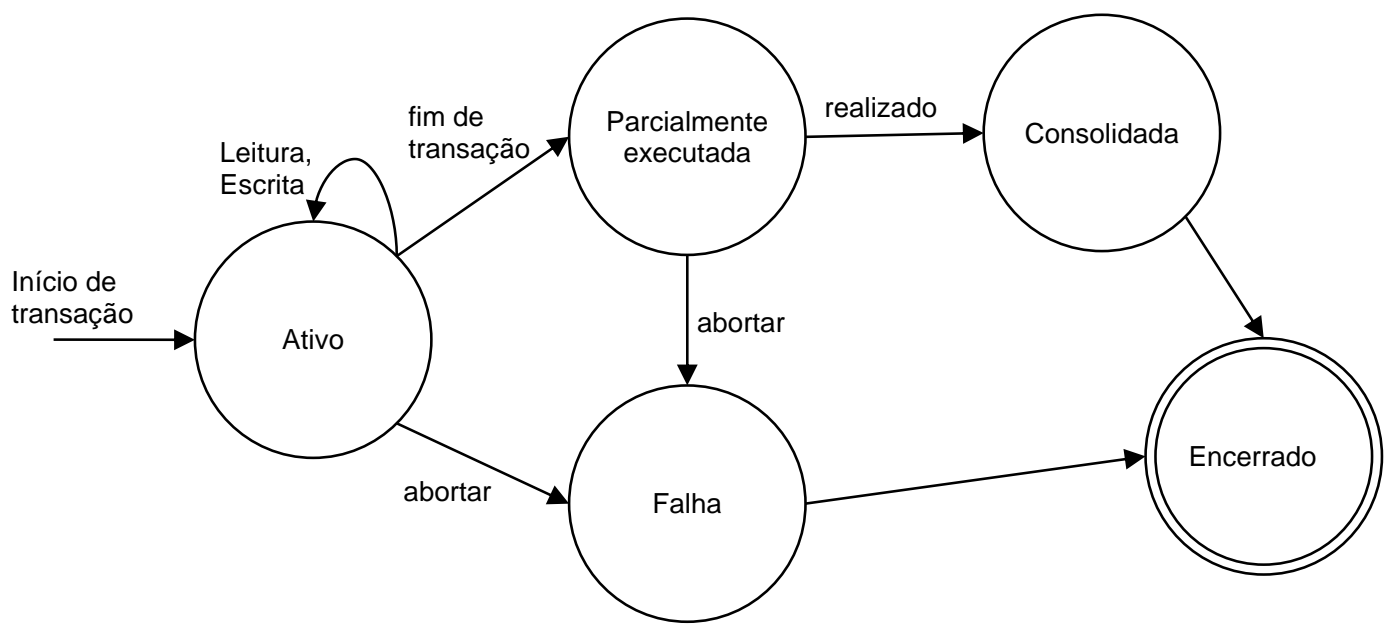

Fonte: (ELMASRI e NAVATHE, 2005) 
As transações são classificadas, basicamente, de duas maneiras, através do tempo de execução da transação ou através da estrutura de composição. As transações classificadas pelo tempo de execução estão divididas em (LIMTHANMAPHON e ZHANG, 2004):

- transação de curta duração: são aquelas que possuem tempo de execução muito curto (na ordem de segundos) e acessa uma quantidade relativamente pequena de dados;

- transação de longa duração: são aquelas que possuem longo tempo de execução (na ordem de minutos, horas) e acessa uma grande quantidade de dados do banco com operações realizadas em lotes.

Transações podem, também, ser classificadas conforme sua estrutura, como as transações planas e as transações alinhadas (OZSU e VALDURIEZ, 1999). Para realizar a organização em estrutura, as transações são divididas em subtransações, as quais são executadas conforme sua classificação:

- transação plana: é aquela que é executada de forma linear, onde realiza suas operações do início ao fim de forma serial, ou seja, todos os recursos estão bloqueados para outras transações enquanto a transação corrente não encerrar suas operações;

- transação aninhada: é um modelo alternativo, onde uma transação é dividida em subtransações internas, e cada subtransação possui o seu próprio ponto de início e fim, determinando estados em que outras subtransações podem iniciar. Uma composição utilizando as subtransações determina uma ordem de execução conveniente para a transação. Os aninhamentos de subtransações em um mesmo nível podem ser executados simultaneamente conforme a Figura 2.2. A organização é realizada, basicamente, de forma hierárquica representada através de uma árvore, onde a transação é a raiz e as diversas subárvores e as folhas são subtransações internas. 
Figura 2.2 - Exemplo de transação aninhada

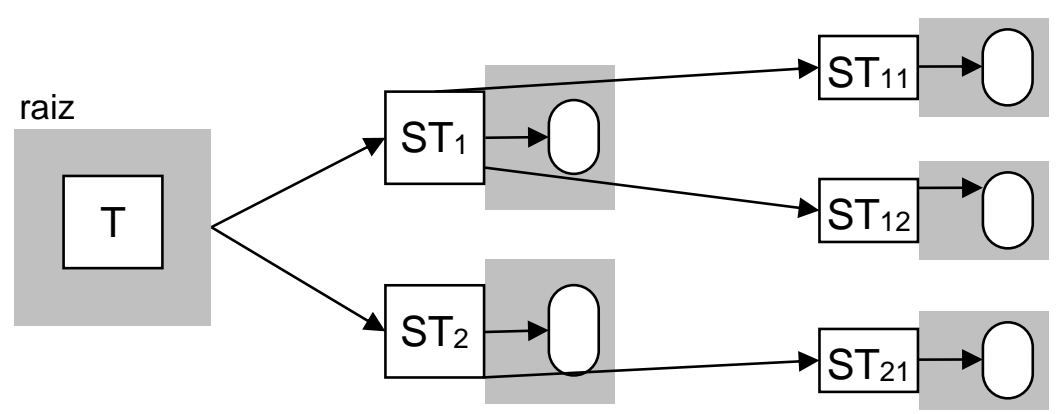

Fonte: O Autor (2015)

A transação aninhada é classificada em duas classes:

- fechada: realiza a consolidação de baixo para cima até a raiz, onde a subtransação filha não pode ser executada antes da subtransação pai, e o pai não pode encerrar sua execução antes de seus filhos impondo uma restrição de Atomicidade aos níveis superiores;

- aberta: a restrição de Atomicidade e Isolamento dos níveis inferiores é relaxada, permitindo que os resultados parciais sejam observados fora da transação.

Uma categoria interessante de transação aninhada é apresentada por GarciaMolina em Sagas (GARCIA-MOLINA e SALEM, 1987). Este tipo de transação atribui flexibilidade, uma vez que através da disponibilidade de resultados parciais, durante a execução, estes valores são utilizados para a troca de mensagens entre subtransações que são realizadas paralelamente.

\subsection{WORKFLOW}

A noção de workflow parte da analogia em modelar o trabalho realizado na manufatura, onde através de diversas etapas de atividades distintas e estruturada consegue-se fabricar um produto (GEORGAKOPOULOS, HORNICK e SHETH, 1995). O intuito de utilizar workflow está em aumentar a eficiência na execução de tarefas em um processo, determinando quais práticas que devem ser descritas através de atividades específicas e quais os papeis que devem ser desempenhados para tornar efetivas as regras impostas pelo ambiente.

Um workflow pode ser descrito como um conjunto de tarefas e interações organizadas de maneira que atenda as exigências dos requisitos, fornecendo uma 
funcionalidade ao sistema. A organização em workflow facilita a automação de atividades que necessitam de diversas etapas, planejando e direcionando responsabilidades das tarefas de maneira que atenda uma necessidade específica. $O$ arranjo da composição deve contemplar movimentos alternados de sucessão de acesso a dados, interações humanas e determinada quantidade de computação que deve ser realizada entre as tarefas utilizadas.

Do ponto de vista transacional, workflow é uma generalização sobre transações específicas com propósito de automatizar processos complexos em sistemas distribuídos, modelando por decomposição de tarefas em subprocessos que possam ser executados de maneira hierárquica, sequencial ou seguindo uma determinada política (WANG, VONK, et al., 2008). Para atender a necessidade de executar transação em processos complexos, o workflow deve combinar transações aninhadas e abertas, realizando algum tipo de relaxamento nas propriedades ACID (GREFEN e VONK, 2006). De maneira geral, os workflows podem ser caracterizados da seguinte forma:

- workflow orientado para pessoas: tarefas que envolvem pessoas para a sua realização. Para esta execução o sistema fornece uma coordenação para o processo colaborativo onde as próprias pessoas são responsáveis pela coerência das ações;

- workflow orientado para sistemas: realiza tarefas especializadas que fazem uso intenso de computação, onde o sistema deve prover o suporte através de controle de concorrência, recuperação, execução automática de tarefas entre outras;

- workflow transacional: é a combinação entre workflow orientado para pessoas e para sistemas, envolvendo execução coordenada de tarefas que envolvem pessoas e exige acessos a sistemas. Atende as propriedades transacionais na execução de uma tarefa individual e do workflow completo.

\subsection{Web Services}

Web Services é uma tecnologia de sistema distribuído, que oferece uma interface de comunicação entre sistemas computacionais heterogêneos através da Internet, para que possam realizar interações entre processos em máquinas distintas sem a 
necessidade de intervenção humana. Esta característica permite a realização de atividades conjuntas entre organizações distintas, propiciando a integração de sistemas.

Web Services vem despertando atenção devido ao propósito de realizar computação distribuída integrando diversas plataformas que utilizam sistemas operacionais distintos, executando programas desenvolvidos em linguagem de programação distinta, de maneira transparente.

De maneira sucinta, um Web Service é referenciado através de um URI que indica o serviço, e realiza comunicação requisição/resposta através do protocolo HTTP. Parte da comunicação é realizada através de troca de mensagens em XML, um formato texto auto descritivo, o qual auxilia a leitura humana em caso de depuração, e padroniza as mensagens facilitando a interoperabilidade entre sistemas (ERL, 2009).

Diversos aspectos tornam Web Services uma tecnologia atraente, como o baixo acoplamento do sistema para minimizar as dependências entre os serviços. Isso faz com que serviços sejam coesos e executem sua rotina independentemente do estado de outros serviços, o que Ihe confere a autonomia no sistema (SHENG, QIAO, et al., 2014). A utilização de protocolos conhecidos, consolidados e amplamente utilizados possibilitam um padrão de comunicação em um meio heterogêneo onde há diversas formas para comunicação e protocolos para a troca de mensagens. Uma interface de Web Services é composta de um conjunto de operações que podem ser utilizadas por qualquer um conectado à Internet. As operações proveem a manipulação de qualquer recurso computacional, por exemplo, consulta ao banco de dados, referência a objeto, interação com algum programa, etc. Um serviço pode ser constituído de uma composição de serviços, combinando operações e serviços em conjunto, onde este conjunto será encapsulado deixando transparente a composição de serviços.

O uso de serviços estimula novas possibilidades para o desenvolvimento de software, pois cada organização pode desenvolver um serviço customizado para a sua necessidade e pode disponibilizar o uso a este serviço. Aqueles que necessitam deste tipo de serviço, não precisam desenvolver uma rotina que realize esta tarefa, bastando utilizá-la, verificando como é a interface e quais os dados necessários para interagir com o serviço. Agilizar o desenvolvimento de aplicações para a integração entre organizações distintas, é um atrativo que Web Services disponibiliza, encobrindo 
aplicações existentes em um invólucro, oferecendo novas oportunidades (GOTTSCHALK, GRAHAM, et al., 2002).

Atualmente, os Web Services são o paradigma predominante para a programação de sistemas distribuídos (COULOURIS, DOLLIMORE, et al., 2011). A computação em grade (FOSTER e KESSELMAN, 2004) é um ambiente para o uso colaborativo no intuito de compartilhar arquivos, softwares, computadores e outros recursos computacionais entre usuários de diferentes organizações. Para tanto, Web Services vem sendo utilizado como infraestrutura básica para projetos de middleware, oferecendo este tipo de compartilhamento. A arquitetura de serviços de grade, a OGSA - Open Grid Service Architecture (FOSTER, KESSELMAN, et al., 2002), é um padrão para aplicações baseadas em grade, fornecendo estrutura para que os seus requisitos sejam satisfeitos. Existe uma variação de Web Services, especificado pelo W3C (W3C, 2013) denominado de Grid Service, o qual procura customizar os serviços de maneira que atenda melhor as necessidades do ambiente de grade.

Outra área que tem realizado o uso intenso de Web Services é o de computação em nuvem. Este conceito é apresentado como um conjunto de recursos de computação, que atende a maioria das necessidades do usuário, oferecidos através da Internet (ARMBRUST, FOX, et al., 2009). Este conjunto prescinde armazenamento de dados e uso de diversos tipos de softwares promovendo uma visão de que todos estes recursos são serviços, desde a infraestrutura física de hardware até todos os níveis de software. Este paradigma representa um novo modelo de computação comercial, onde o usuário paga somente pela demanda computacional utilizada, que pode ser computada através de chamadas ao serviço.

\subsection{ReLógio Lógico}

Os eventos ocorridos em um computador, do ponto de vista do processo em execução, é a ocorrência de uma ação em relação ao valor do relógio, onde é possível determinar a ordem dos acontecimentos. Em um ambiente distribuído, tal tarefa não é tão trivial assim, pois não há como sincronizar relógios perfeitamente, utilizando o tempo físico para descobrir a ordem dos eventos.

A Figura 2.3 ilustra a situação para três processos diferentes que possuem relógios com velocidade diferente, onde em $\mathrm{P}_{1}$ o relógio avança de um em um, em $\mathrm{P}_{2}$ 
de dois em dois e em $\mathrm{P}_{3}$ de três em três para cada instante do relógio. No instante 0 de $P_{1}$, é enviada uma mensagem $M_{1}$ para $P_{2}$, que levará um período para chegar até o destino, o que pela figura pode-se concluir que levou 2 unidades de tempo. $O$ mesmo processo ocorre com a mensagem $\mathrm{M}_{2}$ enviada por $\mathrm{P}_{2}$ a $\mathrm{P}_{3}$, a qual leva 4 unidades de tempo até o destino. Mas o problema de coerência entre os relógios ocorre para as mensagens $M_{3}$ e $M_{4}$, pois não é possível receber uma mensagem antes de ser enviada. A mensagem $\mathrm{M}_{3}$ é enviada no instante 9 e chega ao destino no instante $8 \mathrm{e}$ a mensagem $\mathrm{M}_{4}$ é enviada no instante 8 e chega no instante 5 .

Figura 2.3 - O relógio lógico em cada nó

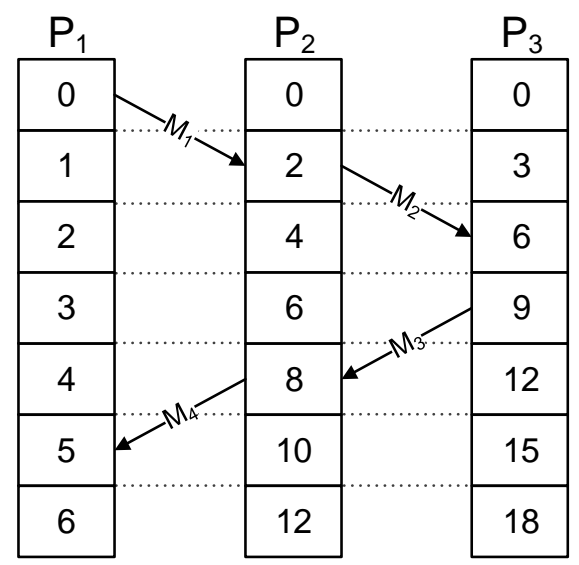

Fonte: (TANENBAUM e STEEN, 2007)

Lamport (LAMPORT, 1978) apresenta o conceito de relógio lógico, onde o tempo não precisa ser absoluto, bastando definir a relação acontece-antes. A seguinte expressão $a \rightarrow b$ pode ser lida como $a$ acontece antes que $b$. A operação aconteceantes é transitiva, podendo afirmar que se $a \rightarrow b$ e $b \rightarrow c$, então $a \rightarrow c$. Lamport determina um mecanismo simples, o qual captura numericamente um contador inteiro que não precisa ter relação com qualquer relógio físico. Desta forma, basta cada processo possuir um valor de relógio lógico, denominado carimbo de tempo de Lamport, para ordenar os eventos.

Seguindo o raciocínio de que $a \rightarrow b$, isso significa que a ocorreu antes de $b$. Lamport utiliza a marcação de tempo junto ao processo, que será alterada conforme a troca de mensagens entre os processos. Na Figura 2.4, o processo $\mathrm{P}_{2}$ ao receber a mensagem $\mathrm{M}_{3}$ com marca de tempo maior que seu relógio local, atualiza o valor para o mesmo da mensagem recebida e incrementa de um, registrando o valor de 10. A mesma ação é aplicada para $\mathrm{P}_{1}$ que recebe $\mathrm{M}_{4}$ com marca de tempo maior, o qual 
será utilizado para atualizar o valor do relógio local e incrementá-lo passando para 11. Com o uso deste algoritmo, o sistema tem uma marca de tempo o qual possibilita a ordenação dos eventos criando critérios para determinar prioridades.

Figura 2.4 - O algoritmo de Lamport corrige os relógios

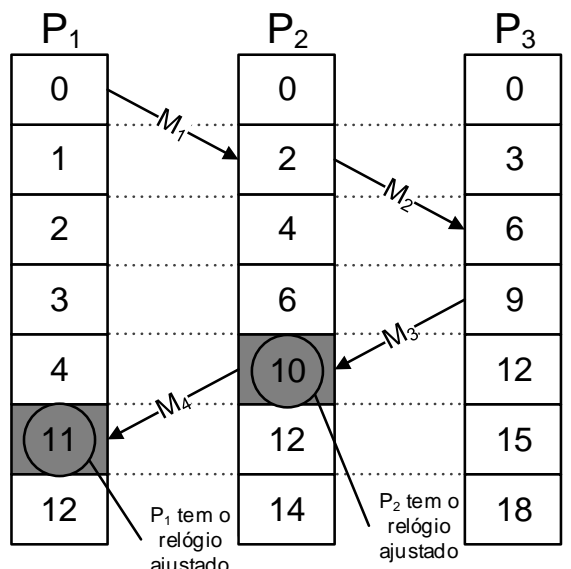

Fonte: (TANENBAUM e STEEN, 2007) 


\section{TRABALHOS RELACIONADOS}

O conceito de Web Services surge com o propósito de permitir que sistemas computacionais possam interoperar entre diversos sistemas com arquiteturas distintas, oferecendo um conjunto de operações que podem ser utilizadas por um cliente através da Internet (COULOURIS, DOLLIMORE, et al., 2011). Diversos provedores disponibilizam serviços, que oferecem facilidades para o desenvolvimento de aplicações, provendo as necessidades básicas e delegando o atendimento das necessidades específicas a serviços oferecidos por terceiros.

Oferecer autonomia entre os serviços é algo não só primordial, mas natural, permitindo que os serviços sejam oferecidos sem dependência e comunicação entre eles. Desse modo, Web Services são projetados de maneira independente e normalmente são livres de restrições externas para executar de maneira autônoma as requisições solicitadas sobre os seus recursos, oferecendo baixo acoplamento ao sistema e minimizando as dependências entre os serviços (SHENG, QIAO, et al., 2014). Entretanto, um serviço pode ser uma composição de vários serviços, necessitando de alguma coordenação para gerenciar o fluxo de execução dos serviços e a interação entre os participantes.

Com a popularização no uso dos serviços, começa a haver uma maior demanda no seu uso, aumentando a concorrência e a complexidade em sua execução através da criação de serviços que realizam a composição entre os serviços existentes. Para contornar esta situação, esforços são empregados para aprimorar o controle de concorrência e o gerenciamento de transação aos serviços. A seguir são apresentados alguns trabalhos que propõem soluções para o problema.

\subsection{OASIS}

Organizações como o OASIS - Organization for the Advanced of Structured Information Standarts (OASIS, 2013) e o W3C - World Wide Web Consortium (W3C, 2013) realizam estudos para criar padrões e convergência visando promover a interoperabilidade entre sistemas. Devido ao esforço destas organizações existem hoje, na computação baseada em Internet, especificações e boas práticas para 
diminuir os obstáculos na integração de sistemas e uma convergência para que os aprimoramentos dos padrões sigam para uma direção comum.

Com o uso de serviços compostos percebeu-se que transações tradicionais não poderiam atender aos novos requisitos para manter a consistência de dados. Web Services possuem a característica, regularmente, de execução através de longo período de tempo, necessidade de ação de desfecho em tempo de execução e o relaxamento dos níveis de isolamento (FREUND e STOREY, 2002).

Observando necessidades como as apresentadas no parágrafo anterior foram definidas novas especificações para aprimorar os padrões para Web Services. Especificações como a Web Service Coordination (OASIS, 2009e), define o papel do coordenador para gerenciar a execução transacional de uma composição de serviços. A Web Service Atomic Transaction (OASIS, 2009c) e a Web Service Business Activity (OASIS, 2009d) são especificados para transpor os obstáculos das transações de curta e de longa duração respectivamente. A seguir essas três especificações são apresentadas.

\subsubsection{Web Service Coordination}

WS-Coordination é um framework que oferece protocolos para coordenar ações de aplicações distribuídas. Estes protocolos podem ser utilizados para atender inúmeras de aplicações.

Permite a criação de um contexto, que pode ser utilizado para propagar uma atividade para outros serviços realizando registros no coordenador. Após esta etapa, o coordenador indica quais os serviços envolvidos na atividade, e quem e quando os serviços podem ser utilizados de maneira que a execução seja coordenada e transacional (OASIS, 2009e).

\subsubsection{Web Service Atomic Transaction}

WS-AtomicTransaction é uma especificação que define transações atômicas, utilizando o papel do coordenador, pois está baseada no WS-Coordination. De maneira geral, o uso do WS-AtomicTransaction é para transações em atividades distribuídas denominadas de curta duração, que possuem o comportamento de tudo ou nada na utilização do serviço para realizar as operações. 
Nesta especificação, todas as operações realizadas sem a confirmação de que a operação deve ser realmente realizada, são consideradas como mera tentativa, pois na maioria dos casos, a persistência não é realizada ou o resultado da operação não é visível fora da transação. Este tipo de comportamento é obtido através de protocolos que implementam algum tipo de técnica de 2PC (Two Phase Commit), os quais efetuam o gerenciamento para recursos em cache, denominado 2PC volátil, e o gerenciamento de recursos que necessitem persistir valores, como um banco de dados, denominado 2PC durável (OASIS, 2009c).

Ao executar as operações de uma transação, o coordenador fica aguardando o resultado de cada participante, e ao receber a resposta que cada participante realizou sua tarefa com sucesso, o coordenador envia uma mensagem para que todos os participantes efetivem suas operações. Caso haja falha, com no mínimo um participante, o coordenador aborta a transação e as tarefas realizadas pelos participantes não são persistidas (OASIS, 2009c).

\subsubsection{Web SerVICE BUSINESS ACtIVITY}

WS-BusinessActivity é uma especificação baseada em coordenação, a qual define o comportamento de negócios para a transação e foi projetada para fornecer suporte para transações de longa duração em um ambiente distribuído. Uma atividade WSBusinessActivity pode levar muito mais tempo que uma WS-AtomicTransaction, onde o bloqueio de um recurso ao longo de um tempo pode inviabilizar uma aplicação (LIMTHANMAPHON e ZHANG, 2004). Deste modo, esta especificação prevê a divulgação de resultados intermediários antes que a atividade global seja concluída no intuito de diminuir a latência, permitindo que outros usuários possam utilizar o recurso sem inviabilizar suas execuções.

A especificação WS-BusinessActivities foi definida para atender certos requisitos, denominados de atividades de negócios, considerando os seguintes aspectos:

- atividades de negócio utilizam diversos recursos através de um longo período de tempo;

- pode envolver transações atômica; 
- resultados e tarefas individuais contidas em uma transação podem ser visualizados antes da execução completa da transação. Estes resultados podem ter impacto externo ao sistema computacional;

- uma resposta pode levar um longo período de tempo, caso necessitem de uma ação fora do sistema computacional, como uma decisão humana, a fabricação de um produto, entre outros, e estas ações devem ocorrer antes que uma resposta possa ser enviada;

- caso ocorra um problema, à atividade de negócio não é desfeita simplesmente através de uma operação de compensação para retroceder a operação que resultou em problema, deve haver uma tarefa de compensação para reverter as tarefas concluídas;

- os participantes de uma atividade de negócio podem possuir diversos níveis de confiança, mas a relação de confiança deve ser estabelecida de maneira explícita entre os envolvidos.

A relação entre coordenador e participante é realizada através de dois protocolos. O Atomic Outcome estabelece que a relação com todos os participantes é realizada como no WS-AtomicTransaction, através de tudo ou nada com uma mensagem comum a todos participantes (confirma ou aborta). O Mixed Outcome determina que o coordenador gerencie cada participante de maneira individual para que aborte ou compense a operação realizada (OASIS, 2009d).

\subsection{Transação em Ambiente de Grade Computacional com Controle de CONCORRÊNCIA DESCENTRALIZADO}

Turker (TURKER, HALLER, et al., 2005) realizou uma pesquisa no intuito de prover suporte para transações em ambiente de computação em grade, enfatizando outros autores (FOSTER e KESSELMAN, 2004) (COULOURIS, DOLLIMORE, et al., 2011) (W3C, 2013), que existe uma fusão entre Web Services e as tecnologias de computação em grade no intuito de proporcionar uma infraestrutura aberta para a integração e atender a demanda por recurso computacional entre os participantes do ambiente compartilhado. Para utilizar os recursos disponíveis, cada participante organiza suas aplicações na forma de composição de serviços, o qual será executado 
através de um processo de workflow, garantindo para que seja realizado de maneira transacional, encerrando em um estado final bem definido.

A proposta visa oferecer um ambiente descentralizado para o controle de concorrência, em ambiente de grade computacional, para execução transacional do workflow. Enfatiza a necessidade de garantir execuções globalmente corretas sem a necessidade de um coordenador global, porque adotar esta abordagem em ambiente de grade pode inviabilizar o sistema, uma vez que com milhares de peers acessando um ponto centralizado fatalmente tornar-se-ia um gargalo. Outro aspecto contemplado pela proposta, está em como detectar e lidar com os conflitos de maneira que possa, também, ser realizada de forma descentralizada.

Para contemplar estes requisitos, não é permitido a um workflow confirmar sua execução se ele depende da execução de outro workflow. Para conseguir esta informação, sobre a dependência entre workflows, é necessário que cada workflow possua informação de outros workflows, de maneira que possa decidir se tem ou não a permissão de confirmar suas operações. Esta decisão, para que seja executada, necessita de informação global sobre todo o fluxo de execução do workflow e os eventuais conflitos envolvidos nesta execução, a qual deve ser transmitida de forma colaborativa, entre os peers envolvidos no conflito.

Cada peer de serviço mantém uma matriz de conflito, onde cada requisição para o serviço, indica quais os outros serviços que são invocados na execução do workflow que efetuou esta requisição. Os conflitos serão detectados pelos peers, que analisam a sua matriz local de maneira autônoma, podendo interromper parcialmente a execução de um workflow através de comunicação P2P (Peer-To-Peer) entre os serviços que possuem o conflito. Isto ocorre da seguinte maneira:

- o peer ao detectar que o workflow $\mathrm{W}_{1}$ aguarda por um recurso alocado para $\mathrm{W}_{2}$ que não o libera;

- o peer verifica a matriz de conflito, constatando que há dependência entre os serviços solicitados por $\mathrm{W}_{1}$ e os serviços solicitados por $\mathrm{W}_{2}$;

- o peer então comunica com o outro peer, onde foi detectado o conflito entre os workflows, e toma uma decisão entre abortar a operação no peer atual, ou solicitar para que aborte a operação no outro peer. O critério de seleção para esta decisão é mencionado como trabalho futuro no artigo (TURKER, 
HALLER, et al., 2005). Contudo, na busca em trabalhos posteriores dos autores não foram encontradas novas publicações referentes a este assunto. A operação para abortar a execução em um determinado peer, não envolve somente parar de executar, mas a utilização de alguma compensação para as ações que já foram realizadas em outros serviços;

- a partir deste passo, o conflito é desfeito e os workflows podem prosseguir em suas execuções, sem a necessidade de abortar por completo as operações até então realizadas, necessitando somente desfazer as operações nos peers onde houveram os conflitos.

Esta abordagem deixa transparente, para o workflow, qualquer conflito que o impeça de prosseguir em sua execução, de maneira transacional, processando todos os serviços previstos em sua composição, evitando também situações de deadlock entre os workflows, sem a necessidade de um coordenador global. Outro aspecto relevante está nos mecanismos que impedem de reexecutar um workflow a partir do seu início, bastando executar novamente a partir do ponto onde houve o conflito.

\subsection{Protocolo Baseado em Timestamp e two Phase Commit para Web SERVICES}

Maciel (MACIEL e HIRATA, 2010) apresenta uma proposta voltada para fornecer um protocolo, baseado na arquitetura REST (Representational State Transfer), e uma extensão que prevê suporte para comportamento de regras de negócios através de novas interações entre cliente e Web Service, com o intuito de oferecer controle transacional autônomo e distribuído entre Web Services utilizando o conceito de relógio lógico e o protocolo $2 \mathrm{PC}$.

A pesquisa desenvolvida cria uma abordagem otimista evitando operações de compensação em caso de falhas e livre de deadlock na execução das requisições. A arquitetura está baseada na especificação WS-Coordination, onde uma requisição deve ser gerenciada por um coordenador que irá anexar um valor de relógio lógico para as requisições.

O conceito de execução livre de deadlock está presente no uso do relógio lógico, onde as requisições não entram em impasse devido às requisições serem ordenadas conforme o valor do relógio lógico recebido. Caso o valor de relógio da 
requisição seja maior que o valor de relógio do site que disponibiliza o serviço, 0 relógio do site é atualizado e esta requisição é aceita para utilizar o serviço. Em caso de valores iguais de relógio para requisições diferentes, o critério de desempate é o identificador de quem está realizando a solicitação. Caso o valor de relógio da requisição seja menor ou igual ao valor do relógio do site, a requisição é recusada e é solicitado ao cliente que reenvie a solicitação com um valor de relógio lógico maior do que o do relógio do serviço. Este tipo de abordagem pode gerar uma situação de starvation, onde uma requisição pode ficar indefinidamente sem atendimento, uma vez que durante o período anterior ao reenvio, pode ocorrer de outra requisição ser atendida, atualizando o relógio lógico do serviço, deixando a requisição que está realizando o reenvio necessitar novamente realizar outro reenvio, visto que estará com o relógio lógico defasado.

Baseado no conceito de 2PC, toda operação realizada é armazenada, em um primeiro instante, em uma lista denominada LPW (List of Prewrite) para que desta forma, caso haja a desistência de alguma requisição ou falha nas outras requisições de serviços, não há a necessidade de executar uma atividade compensatória em relação à operação realizada, bastando retirá-la da LPW.

Outro aspecto interessante nesta pesquisa está na extensão para contemplar regras de negócio. Uma requisição que não foi atendida, caso existam operações na LPW para realizar, e se essas operações não forem confirmadas existe a possibilidade da disponibilidade do recurso para a requisição atual. Esta requisição pode ficar aguardando até que sejam confirmadas ou canceladas as operações em LPW, assim obtendo privilégio em caso de cancelamento sem a necessidade de reenvio.

\subsection{Considerações Sobre o Capítulo}

Algumas pesquisas que propõem diversas maneiras para lidar com a questão sobre a execução transacional em composição de serviços foram apresentadas neste capítulo.

O framework, WS-Coordination, através das especificações WSAtomicTransaction WS-BusinessActivity, oferece controle transacional baseado em derivações do protocolo 2PC. O controle de coordenação fica a cargo de um serviço específico, criando um possível gargalo no sistema que fica dependente deste ponto 
de gerenciamento. Outro aspecto, para que haja o controle de transação, é que os serviços envolvidos devem ser declarados no escopo do coordenador, o qual gerencia as instancias de processo iniciadas no serviço coordenador. Outras composições que executam alguns destes serviços, os quais não estão registrados no coordenador, podem sofrer alguma restrição na execução, criando situação que não seja justa.

O suporte a execução transacional de workflows distintos proposto por Turker (TURKER, HALLER, et al., 2005), em ambientes de grade computacional provê a autonomia para as execuções sem a necessidade de um nó central coordenando os workflows. Para tanto, cada solicitação de serviço carrega consigo informações sobre a dependência de serviços envolvida na composição do workflow. Cada peer de serviço, para que tenha a capacidade de detectar um conflito entre os workflows, constrói uma matriz de conflito a partir das informações de dependência. Esta matriz é utilizada para realizar a comunicação, através da arquitetura P2P, de modo que as entidades envolvidas na comunicação, resolvam o conflito entre as requisições dos workflows distintos. Devido ao foco da pesquisa ser voltado a um ambiente de grade computacional, onde existe um controle maior entre os participantes se comparados aos usuários de Web Services na Internet, utilizou-se a abordagem P2P para solucionar os problemas de conflito. Este tipo de solução viola o princípio da autonomia dos Web Services, pois necessita que um peer de serviço se comunique com outro peer de serviço. Outro aspecto que não foi apresentado de maneira clara no trabalho publicado é a respeito das políticas adotadas para que, em uma situação de conflito entre workflows, quais os critérios para determinar qual workflow irá realizar uma operação de rollback em sua execução, cedendo o recurso obtido. Este aspecto é relevante, pois dependendo da política adotada poderá gerar uma situação injusta de execução.

O trabalho realizado por Maciel (MACIEL e HIRATA, 2010) apresenta uma solução para a execução de composição de serviços através de clientes distintos, utilizando critérios baseados nos valores de relógios lógicos dos servidores do sistema para decisões que garantam a não ocorrência de deadlock. Definir que a execução deve ser realizada através de estágios, utilizando o protocolo 2PC, faz com que não haja a necessidade de utilizar ações compensatórias em caso de falha na execução da transação, ou pela desistência do recurso adquirido. No entanto, esta solução pode gerar situações de starvation de requisições, uma vez que, caso a requisição tenha 
um valor de relógio lógico menor que o serviço, esta requisição necessita realizar reenvio, o qual pode persistir de maneira infinita.

Pretende-se, na proposta aqui apresentada, realizar o gerenciamento da execução entre workflows originados de servidores distintos, de forma transacional e autônoma, sem violar o princípio da autonomia entre Web Services, realizando a execução das requisições de maneira justa, oferecendo ao site de serviço subsídios para realizar o atendimento das requisições de maneira justa, impedindo o conflito entre workflows de domínios distintos, evitando deadlock e starvation. 


\section{ATENDIMENTO DE REQUISIÇÕES ORIUNDAS DE MÚLTIPLOS DOMÍNIOS EXECUTANDO COMPOSIÇÕES DE SERVIÇOS PROVIDOS POR SERVIDORES DISTINTOS}

Este capítulo apresenta uma proposta para garantir operações transacionais em workflows de domínios distintos realizados de forma simultânea que executam operações referentes ao consumo de recursos. Tais recursos são oferecidos e gerenciados por serviços específicos em nós remotos, onde no atendimento das requisições, busca-se garantir justiça na atribuição dos recursos, não ocorrência de deadlock como também de starvation.

Existem trabalhos que oferecem algum tipo de gerenciamento para a execução de serviços compostos, como alguns apresentados no capítulo 3. Contudo, o gerenciamento fica restrito à execução de workflows provenientes do mesmo domínio, isto é, workflows oriundos de domínio distinto podem produzir resultados que não reflitam a realidade uma vez que disputam os serviços de maneira aleatória. Todavia é oportuno ressaltar que, na coordenação de serviços, as políticas para controle de execução do workflow são aplicadas somente entre processos criados em um mesmo domínio.

\subsection{ReQuisições de Múltiplos DomínIOS PARA EXeCUTAR COMPOSIÇÕES DE Serviços Providos Por Servidores Distintos}

O cenário, aqui considerado, apresenta requisições provenientes de múltiplos domínios de requisições. Cada requisição é composta de requisições de serviços providos por servidores distintos. A Figura 4.1 apresenta um exemplo deste cenário.

Cada cliente, em sua requisição, solicita a execução de uma composição de serviços que pode ser descrita através de um workflow.

O Servidor Requisição (RQT) é o local físico onde um serviço Requisição disponibiliza a execução de um workflow composto pela chamada de serviços providos por múltiplos Servidores Recurso (RSC). Durante a execução do workflow são geradas requisições individuais as quais são encaminhadas para o Servidor Recurso específico.

Os serviços disponibilizados pelos Servidores Recurso gerenciam recursos de quantidade finita que são consumidos quando atribuídos para uma requisição. 
Durante a execução de um workflow os recursos solicitados a um Servidor Recurso, permanecem no estado de reserva até que todos os recursos solicitados, em uma composição de serviços, tenham sido reservados. Neste momento, todas as reservas são confirmadas para consumo. Caso não exista quantidade suficiente de recursos, em um Servidor Recurso, mesmo contando com os recursos no estado de reserva, a requisição é negada, abortando a execução do workflow e cancelando as reservas já efetuadas. Caso exista quantidade suficiente de recursos em um Servidor Recurso para atender a requisição do serviço solicitado, mas considerando a quantidade de recurso em reserva para outras requisições, o atendimento fica pendente até que tais requisições confirmem ou cancelem as reservas.

A Figura 4.1 ilustra clientes utilizando as aplicações App1, App2 e App3, que estão realizando requisições para, respectivamente, $R Q T_{1}, R Q T_{2}$ e $R Q T_{3}$, os quais estão em domínios distintos e foram concebidos de maneira independente. As requisições de App1, App2 e App3 contém, respectivamente, composições de serviços providas por $\mathrm{RSC}_{1}$ e $\mathrm{RSC}_{2}$; $\mathrm{RSC}_{1}$ e $\mathrm{RSC}_{3}$; e $\mathrm{RSC}_{1}, \mathrm{RSC}_{2}$ e $\mathrm{RSC}_{3}$.

Figura 4.1 - Exemplo de cenário

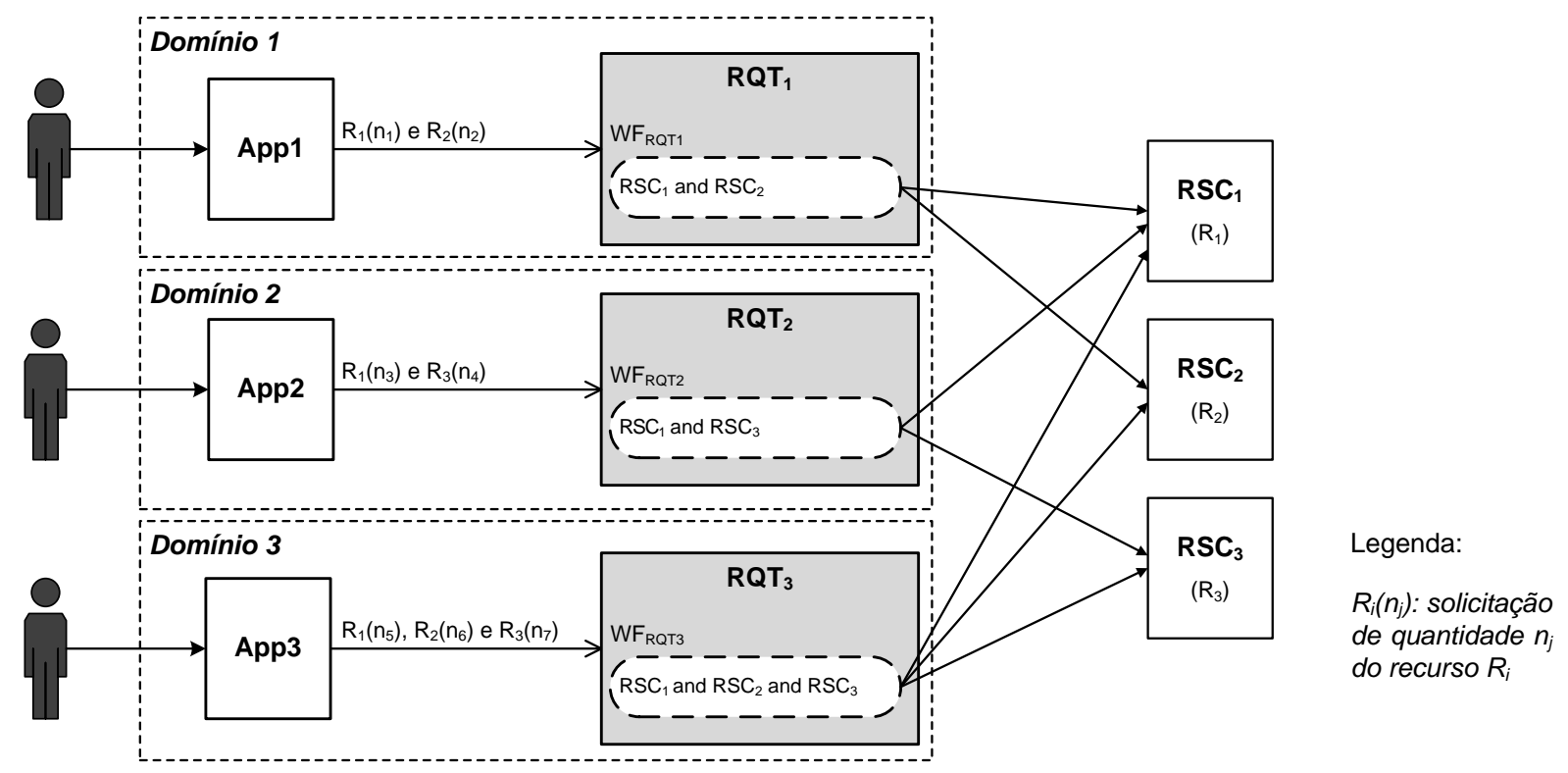

Fonte: O Autor (2015)

A execução de múltiplas composições, simultaneamente, envolvendo a solicitação de múltiplos recursos, conforme o cenário considerado neste trabalho, pode levar a situação de deadlock. A Figura 4.2 ilustra este cenário, onde RQT 1 executa o workflow WF $\mathrm{RQT}_{1}$ o qual requisita 10 unidades de $\mathrm{RSC}_{1}$ e 5 de $\mathrm{RSC}_{2}$, e RQT2 executa $\mathrm{WF}_{\mathrm{RQT} 2}$ solicitando 9 unidades de $\mathrm{RSC}_{1}$ e 6 de $\mathrm{RSC}_{2}$. Ambos os Servidores 
Requisição executaram seus workflows no mesmo instante, porém RQT ${ }_{1}$ consegue o recurso em $R_{S C} C_{1}$ ficando este sem unidades, e $R Q T_{2}$ consegue o recurso em $R_{S C}$, permanecendo este com 2 unidades. $\mathrm{RSC}_{1}$ possui 10 unidades e $\mathrm{RSC}_{2}$ possui 8 unidades. Ambos não conseguem completar sua execução de maneira transacional pois $R Q T_{1}$ fica aguardando a confirmação de consumo ou cancelamento de reserva por RQT2, e vice-versa. Cada execução de workflow fica aguardando a liberação do recurso que está de posse do outro gerando uma espera circular.

Figura 4.2 - Disputa por recurso gerando deadlock

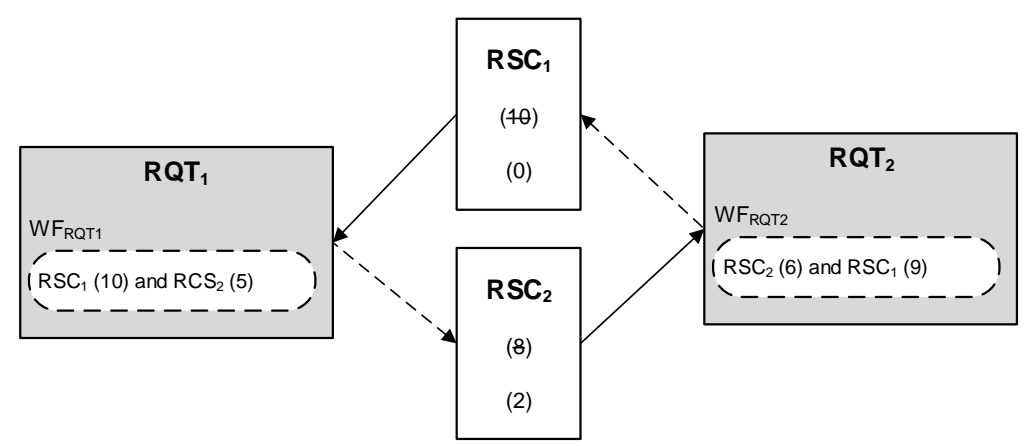

Fonte: O Autor (2015)

Mecanismos para evitar deadlock são necessários em sistemas que possuem concorrência, mas uma política inadequada pode gerar uma situação de starvation na execução de um workflow.

O objetivo da proposta é prover mecanismos que impeçam a ocorrência de deadlock nas execuções de composições originadas em domínios diferentes, de forma que os Servidores Recurso que disponibilizam os recursos tenham uma gerência autônoma. É importante ressaltar que tais mecanismos devem promover um atendimento justo, sem a possibilidade de ocorrer starvation para alguma requisição, sendo considerada a ordem do momento em que foi realizada a requisição.

\subsection{Descrição do Sistema e dos Mecanismos para CoORdenação das REQUISIÇÕES E dO GERENCIAMENTO dOS RECURSOS}

A proposta, apresentada neste trabalho, busca prover o gerenciamento autônomo da execução de workflows de domínios distintos requisitando múltiplos serviços de servidores distintos, sem a perda da autonomia dos serviços. Os mecanismos aplicados promovem um atendimento justo e livre de deadlock e starvation. 
Para prover uma atribuição de recursos justa e sem ocorrência de deadlock ou starvation aplica-se um critério de prioridade baseado no momento em que é realizada a requisição. Para tanto, é necessário que se tenha um relógio global, em que será utilizado o mecanismo de relógio lógico apresentado por Lamport (LAMPORT, 1978), o qual oferece subsídios para determinar a ordem dos eventos e assim estabelecer a prioridade de uma requisição. A abordagem oferecida no conceito de relógio lógico auxilia na aplicação da política de orquestração para o atendimento das requisições impedindo situações de deadlock e starvation.

\subsubsection{O USO dE RELÓGIO LÓGICO}

O relógio lógico funciona de maneira que indique a relação acontece-antes definido por (LAMPORT, 1978), onde cada local possui um contador crescente, o qual é adicionado à mensagem de comunicação indicando uma marca temporal dentro do sistema.

De posse desta marca temporal (TS - timestamp) recebida na mensagem de cada requisição/resposta, a marca temporal referente ao relógio lógico local é ajustada à marca recebida, mantendo o sistema sincronizado. Ao receber uma solicitação do Servidor de Requisição (RQT), o Servidor de Recurso (RSC) atualiza o seu relógio local e, ao receber a resposta do Servidor Recurso, o Servidor Requisição atualiza o seu relógio local.

O valor de relógio local é atualizado somente quando há interações entre os servidores, no qual não há mecanismo de contagem local para cada servidor, incrementando o relógio somente com a comunicação no sistema.

A atualização do TS, ilustrado na Figura 4.3, ocorre da seguinte maneira:

1. Caso o TS recebido seja menor que o TS local, incrementa o TS local.

2. Caso o TS recebido seja maior ou igual ao TS local, atualiza o TS local com o valor do TS recebido e incrementa. 
Figura 4.3 - Atualização de relógio lógico

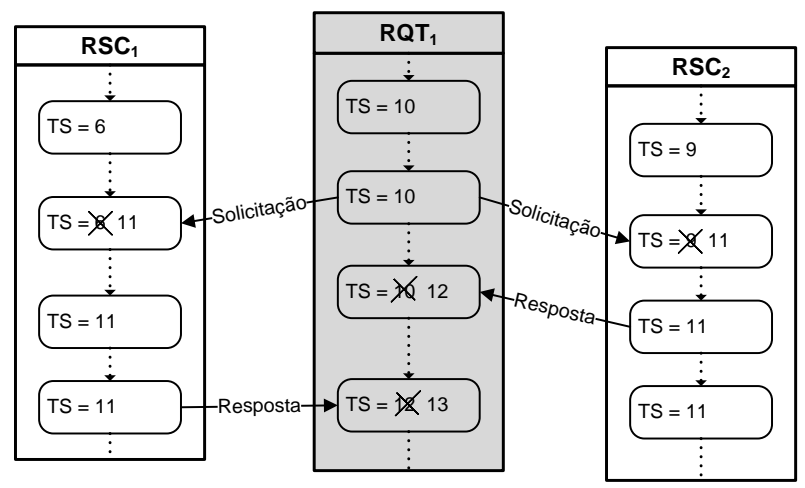

Fonte: O Autor (2015)

Após esta primeira etapa para a execução do workflow, realizada a sincronização, o Servidor Requisição adiciona a mesma marca de tempo em cada uma das requisições individuais, as quais são encaminhadas para os respectivos Servidores Recurso, onde esta marca de tempo será utilizada para definir a prioridade no atendimento.

\subsubsection{CRITÉRIO DE PRIORIDADE}

Para promover o atendimento justo, as requisições obedecem ao critério de prioridade, o qual determina a ordem entre as requisições para utilizar o recurso.

O critério de prioridade leva em conta o instante em que uma requisição é realizada pelo Servidor Requisição e não o instante em que a requisição é recebida pelo Servidor Recurso. Para tanto, o Servidor Requisição ao executar o workflow, na primeira etapa, tem seu relógio lógico sincronizado e o TS deste instante será inserido em todas as requisições que compõem o workflow. O Servidor Recurso ao receber a requisição, verifica o TS, determinando a ordem para a utilização do recurso, onde requisição com TS menor terá prioridade no atendimento. A maior prioridade dada a TS's menores provê a justiça no atendimento às requisições, ou seja, uma requisição solicitada em um momento anterior a outra será atendida com prioridade em relação a esta.

\subsubsection{ARQUITETURA}

Apresenta-se, nesta seção, uma arquitetura, onde uma das preocupações é manter características fundamentais de serviço, que compreende desde a autonomia entre eles, o baixo acoplamento, a interoperabilidade de sistemas e a transparência de como o serviço é implementado ou disponibilizado. A arquitetura está estruturada para 
oferecer dois serviços, serviço Requisição e serviço Recurso, ilustrados na Figura 4.4, os quais em conjunto promoverão o comportamento transacional para a execução de workflows evitando deadlock e starvation na execução de requisições de serviços concorrentes.

Figura 4.4 - Organização dos serviços

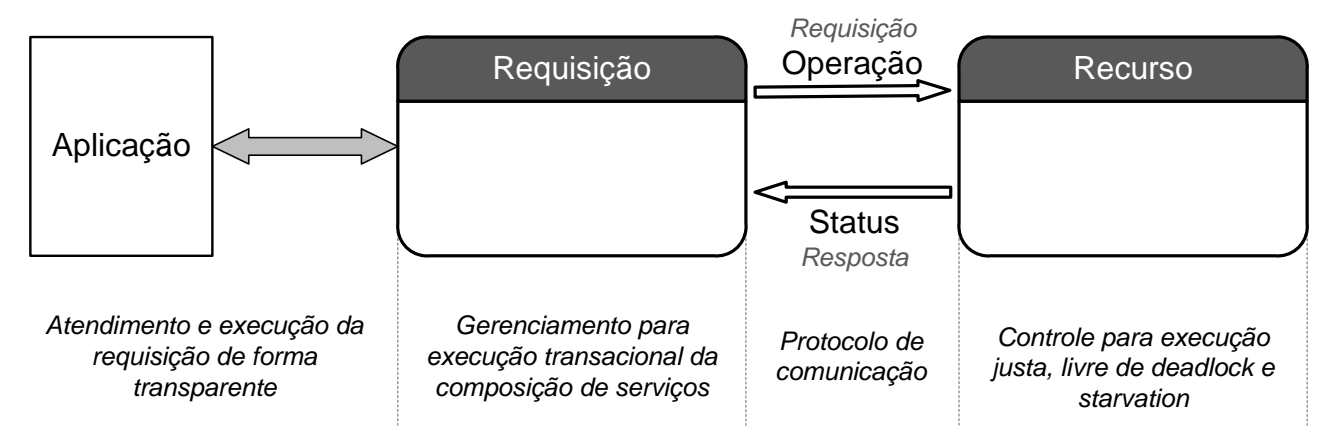

Fonte: O Autor (2015)

O serviço Requisição é disponibilizado nos Servidores Requisição. É encarregado de receber a solicitação do cliente, montar uma lista de recursos e as respectivas quantidades que compõem a requisição, executar 0 workflow correspondente a esta composição e enviar o retorno ao cliente. Para tal, cria requisições individuais para cada um dos serviços chamados na composição, que são encaminhadas para os respectivos Servidores Recurso. Um Servidor Recurso realiza as operações sobre os recursos por ele gerenciados.

Para proporcionar um procedimento transacional, o Servidor Requisição deve encaminhar informações para os respectivos Servidores Recurso das requisições presentes na composição e receber destes, informações referentes aos resultados. É necessário um protocolo em que interagem o Servidor Requisição e os respectivos Servidores Recurso das requisições individuais da composição através da chamada de operações, referentes aos serviços solicitados, pelo Servidor Requisição e execução pelos respectivos Servidores Recurso.

Nas seções seguintes serão apresentados o protocolo e os detalhamentos do serviço de Requisição e do serviço Recurso.

\subsubsection{Descrição do MECANISMO PARA EXECUÇão de REQUisições de Múltiplos DOMÍNIOS COM COMPOSIÇÃO DE SERVIÇOS DE SERVIDORES DISTINTOS}

Uma requisição solicitada pelo cliente a um Servidor Requisição envolve pedidos de múltiplos recursos os quais são gerenciados por Servidores Recurso distintos. Para o 
seu atendimento é executada uma composição de serviços que gerenciam as requisições dos recursos solicitados. Esta execução segue um protocolo que garante o procedimento transacional da composição, a concessão justa de cada recurso, priorizada pelo momento da solicitação da sua requisição, e o impedimento de situações de deadlock e starvation.

Nesta seção são apresentadas as operações realizadas pelo Servidor Requisição para a execução da requisição do cliente, as operações executadas pelo Servidores Recurso e chamadas pelo Servidor de Requisição, como também os protocolos seguidos na execução das operações.

\subsubsection{Operacões no Servidor de Requisicão para execucão das requisicões}

O Servidor de Requisição recebe uma requisição do cliente solicitando múltiplos recursos para o atendimento da requisição. É executada uma composição de serviços providos pelos Servidores Recurso que gerenciam os recursos solicitados.

Para garantir o procedimento transacional desta composição, são executadas operações, seguindo-se um protocolo que impõe a ordem necessária, representada pelo workflow da Figura 4.5.

Os recursos solicitados são primeiramente reservados e alocados apenas quando todos os recursos solicitados pela requisição do cliente foram reservados. Se não foi obtida a reserva de algum dos recursos, aqueles que já foram reservados são liberados e atribuídos para requisições que aguardam em uma lista de espera.

Seguem as operações executadas no Servidor de Requisição:

- Query_Resources(lista_recursos):

lista_recursos: lista dos recursos sobre os quais se deseja fazer a consulta.

Realiza a consulta dos recursos presentes na lista_recursos nos respectivos Servidores Recurso retornando uma lista com a quantidade disponível para cada um dos recursos. 
Figura 4.5 - Workflow para execução das requisições

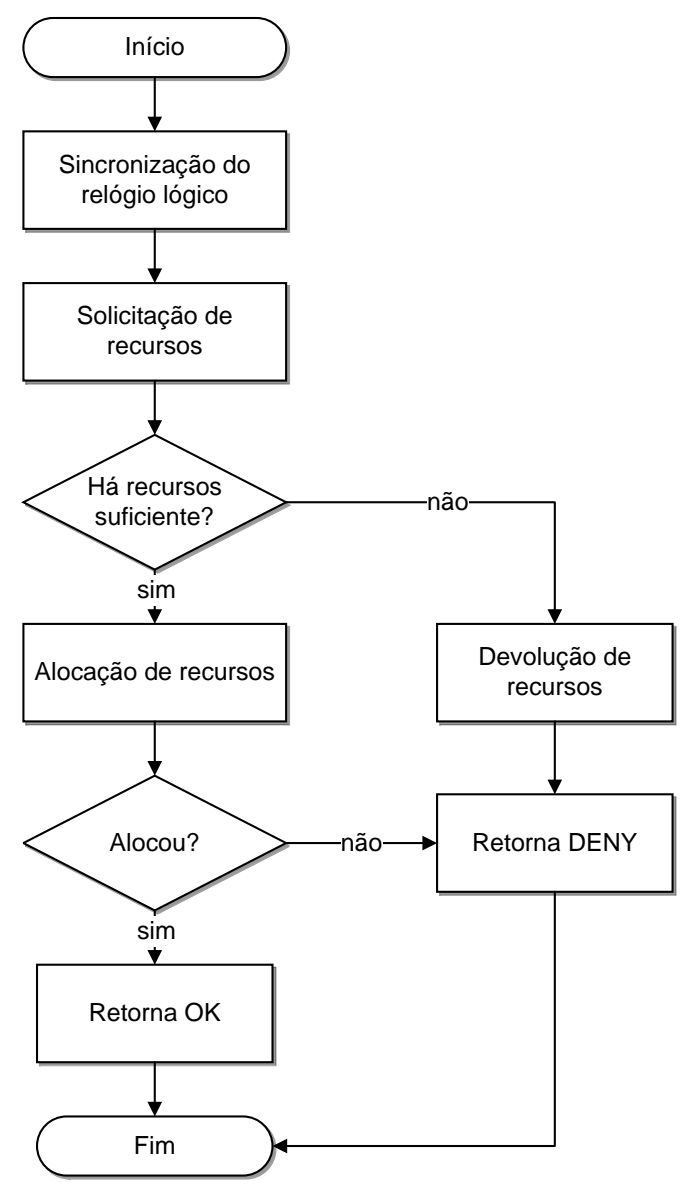

Fonte: O Autor (2016)

- Request_Resources(lista_recurso_qtd):

lista_recurso_qtd: lista dos recursos solicitados. Cada registro contém dois campos: recurso e quantidade.

Reserva cada um dos recursos, na quantidade solicitada, solicitandoo ao respectivo Servidor Recurso. Retorna a confirmação de sucesso (OK/DENY) e a lista dos recursos obtidos com sucesso (lista_recursos_res). Caso todos os recursos presentes na lista_recurso_qtd foram reservados retorna OK. Caso contrário retorna DENY.

- Commit_Resources(lista_recursos_res):

lista_recursos_res: lista dos recursos obtidos com sucesso.

Realiza a alocação dos recursos que foram reservados para a requisição do cliente. Retorna a confirmação sobre a operação 
(OK/DENY). Caso todos os recursos reservados sejam alocados retorna OK. Caso contrário, se algum recurso reservado não foi alocado ou algum recurso reservado foi alocado para outra requisição com prioridade, retorna DENY.

- Rollback_Resources(lista_recursos_res):

lista_recursos_res: lista dos recursos obtidos com sucesso.

Devolve os recursos que foram reservados. Retorna a confirmação de sucesso (OK/DENY).

Conforme apresentado na Figura 4.5, o fluxo de execução inicia com a execução de uma operação Query_Resources em todos os recursos informados na lista de recursos. Após a consulta realizada, verifica-se as quantidades disponíveis em cada recurso para então solicitar a quantidade de cada recurso através da operação Request_Resources retornando um status de operação e uma lista dos recursos que obtiveram sucesso no procedimento de sua reserva. Caso o status da operação Request_Resources seja OK, a operação Commit_Resources confirma todas as reservas que foram realizadas e, caso seja DENY, a operação Rollback_Resources devolve todos os recursos que haviam sido reservados. A operação Commit_Resources retorna um status da operação indicando OK caso todas as reservas foram alocadas, e caso contrário retorna DENY indicando que uma ou mais reservas não foram efetivadas.

\subsubsection{Operacões no Servidor Recurso}

O Servidor Recurso provê operações para gerenciar a alocação de quantidades disponíveis do recurso.

As seguintes listas são utilizadas na gerencia de alocação do recurso:

- A lista de chegada (AL - Arrival List) é utilizada para armazenar as requisições recebidas, atuando como uma listagem de pedidos que chegaram e ainda não foram atendidos.

- A lista de reserva ( $R \mathrm{~L}$ - Reservation List) é utilizada para armazenar as requisições que obtiveram a reserva do recurso, porém a alocação do recurso ainda não foi efetivada. 
- A lista de espera (WL - Wait List) é utilizada para armazenar requisições que não conseguiram a reserva e aguardam a liberação de reservas de outras requisições. Esta lista é reorganizada quando deve ser incluída uma nova requisição com maior prioridade do que algumas requisições presentes na lista.

- Na lista Committing List (CL) são armazenadas as requisições que confirmaram a reserva do recurso e se encontram no processo de confirmação de suas demais reservas. Na ocorrência de uma nova requisição ao recurso e não disponibilidade de unidades em quantidade suficiente, mesmo considerando as quantidades em reserva, é verificado se a consideração da quantidade total de unidades que se encontram nesta lista permite atingir a quantidade solicitada. Em caso positivo, a requisição é mantida na lista WL. Caso contrário, ela tem a sua solicitação negada.

A estratégia adotada na gerência do uso do recurso busca garantir o atendimento justo das requisições impedindo a ocorrência de situações de deadlock e starvation. É baseada em relógio lógico global, definido pela marca de tempo (TS timestamp), e um mecanismo de alocação que considera o momento em que a requisição do recurso é solicitada.

Os recursos não são alocados imediatamente, mas reservados. Os recursos são alocados, quando todos os recursos solicitados em uma requisição do cliente foram reservados. Caso algumas das reservas não foram obtidas, os recursos reservados são liberados.

O gerenciamento para o uso do recurso está organizado em duas etapas. A primeira etapa envolve o tratamento realizado ao receber uma nova requisição, ilustrado pela Figura 4.6. Ao receber uma nova requisição, o Servidor Recurso verifica o TS da requisição:

- Caso o TS da requisição seja maior que o TS do Servidor Recurso, a requisição é inserida na lista de chegada (AL);

- Caso contrário, verifica se há requisições na lista de reserva $(R L)$ maiores que a requisição recebida;

- Caso afirmativo:

- Remove as requisições com TS maior da lista RL; 
- Atualiza o BUFFER com os elementos removidos;

- Insere a requisição recebida na lista de espera (WL);

- Insere as requisições removidas da lista $R L$ na lista $W L$ a nova requisição é inserida na lista de espera (WL), aplicando o critério de prioridade sobre as requisições da lista de reserva $(R L)$ transferindo as requisições com TS maior para a lista WL;

- Caso negativo:

- Insere a requisição recebida na lista WL.

Figura 4.6 - Fluxo de execução ao receber requisição

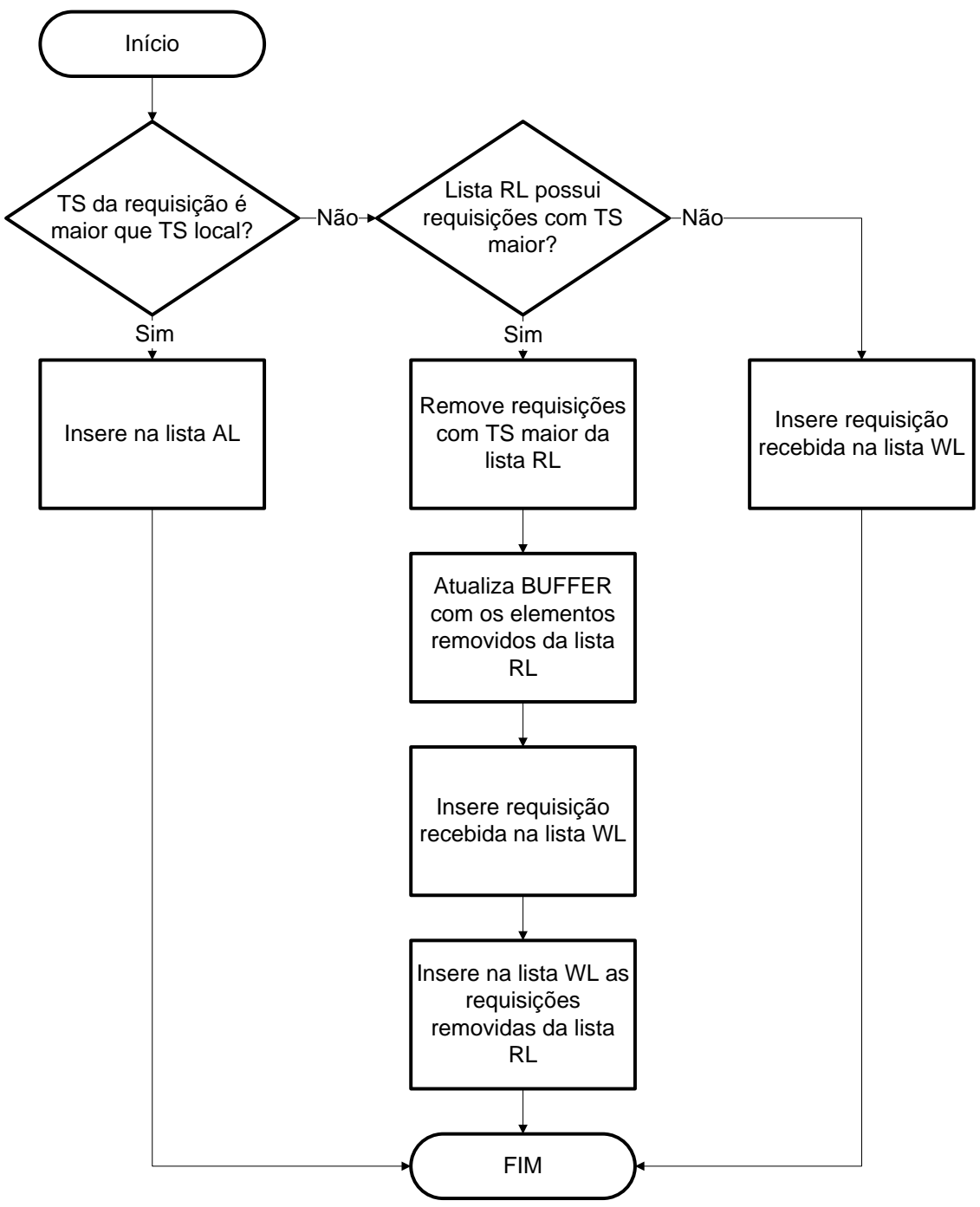

Fonte: O Autor (2016)

O critério de prioridade, baseando no valor do TS, define uma ordem para o atendimento as requisições, que será a mesma entre os Servidores Recurso, tornando a execução de workflow livre de deadlock. 
A segunda etapa envolve o tratamento para verificar a possibilidade da requisição em obter a reserva do recurso, ilustrado pela Figura 4.7. O Servidor Recurso ao retirar a primeira requisição, seja da lista $W L$ ou da lista $A L$, verifica se há quantidades de recurso disponíveis:

- Caso haja quantidades disponíveis suficiente para atender a requisição, incrementa o BUFFER com as quantidades solicitadas, retira a requisição da lista e insere na lista $R L$, indicando que a reserva foi efetuada.

- Caso contrário, verifica se a quantidade em reserva é suficiente para atender a requisição:

- Então existe a possibilidade em obter o recuso, desse modo a requisição é mantida na lista;

- Senão, verifica se a lista CL não está vazia e considera se as quantidades das requisições que estão em processo de committing é suficiente;

- Caso afirmativo, existe a possibilidade de obter o recurso, então a requisição é mantida na lista;

- Caso negativo, não existe a possibilidade de obter o recurso, então a requisição é retirada da lista e o recurso é negado.

As requisições presentes na lista WL têm prioridade em relação às requisições da lista $A L$ para efetuar a reserva do recurso. As listas WL e AL seguem uma ordem crescente de TS na inserção de uma requisição, sendo o primeiro elemento é a requisição de maior prioridade, ou seja, de menor TS, e a próxima a ser atendida.

A estratégia de mover as requisições da lista $R L$ para a lista $W L$, para prover 0 atendimento com prioridade, revoga temporariamente uma reserva obtida antes por uma requisição, porém não perde a prioridade em relação as novas requisições, bastando aguardar a disponibilidade do recurso sem a necessidade de realizar reenvio. Esta abordagem contribui para a alocação justa do recurso e impede a ocorrência de starvation. 
Figura 4.7 - Fluxo de execução para verificar disponibilidade

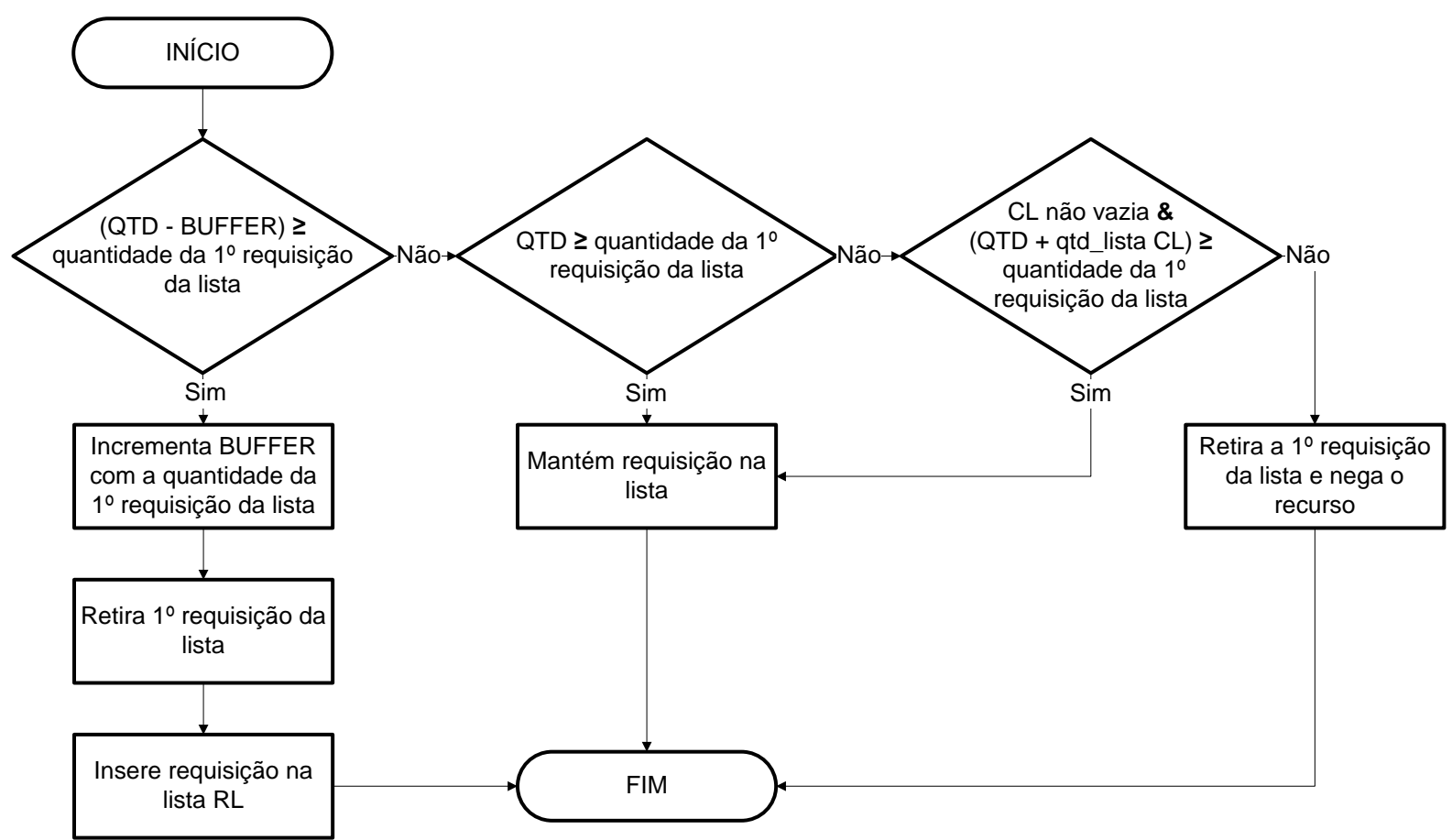

Fonte: O Autor (2016)

Para confirmar reserva, a requisição é inserida na lista $C L$ indicando que esta requisição está aguardando a finalização do processo de committing de suas demais reservas. A estratégia em aguardar que requisições sejam retiradas da lista $C L$ foi adotada no intuito de que caso uma requisição tenha que abortar a alocação de recurso, os recursos liberados sejam atribuídos a requisições, obedecendo o critério de prioridade, evitando uma alocação injusta. Ao concluir o processo de alocação em todos os recursos, a requisição é retirada da lista CL.

As seguintes operações são disponibilizadas pelo serviço Recurso:

\section{- QUERY}

Realiza a leitura sobre o recurso informando a quantidade disponível no momento. Retorna a quantidade disponível.

- REQUEST(id, rqt, ts, qtd)

id: identificador local da requisição.

rqt: identificador do Servidor Requisição de origem.

ts: valor do relógio lógico do servidor de origem.

qtd: quantidade solicitada do recurso. 
Esta operação é a primeira etapa para requisitar o recurso. Caso o TS da requisição seja maior que o TS local, insere a requisição na lista $A L$, senão insere na lista WL conforme o critério de prioridade para execução justa. Retorna:

- OK: caso a requisição foi inserida em uma das listas

- DENY: caso a quantidade disponível é menor que a quantidade solicitada.

\section{- REQUEST_STEP2(id, rqt)}

id: identificador local da requisição.

rqt: identificador do Servidor Requisição de origem.

É o segundo estágio da operação REQUEST. Verifica se a requisição que está na lista $A L$ ou na lista $W L$ foram movidas para a lista $R L$, indicando que a reserva foi realizada. Retorna:

- OK: caso a reserva foi concluída com sucesso;

- WAIT: caso a requisição ainda esteja na lista AL ou WL, indicando que a requisição está aguardando a disponibilidade do recurso, necessitando aguardar alguns instantes e realizar a operação novamente;

- DENY: caso não haja possibilidade de obter o recurso, uma vez que a quantidade disponível é menor que a quantidade solicitada.

- $\quad$ COMMIT(id, rqt)

id: identificador local da requisição.

rqt: identificador do Servidor Requisição de origem

Realiza a alocação de um recurso solicitado pela requisição identificada por (id, rqt). Aloca a quantidade do recurso referente a reserva especificada na lista $R L$, retirando-a da lista $R L$ e decrementando esta quantidade da disponível do recurso. Retorna:

- OK: caso a alocação seja concluída com sucesso; 
- WAIT: caso a alocação ainda não pôde ser concluída, indicando que a requisição foi movida para a lista $W L$;

- CANCEL: caso a requisição não pode ser atendida. Esta situação ocorre quando o recurso foi alocado para outra requisição com prioridade maior. Não há quantidade suficiente e nem possibilidade de liberação de recurso em reserva;

- DENY: caso a requisição especificada não exista.

- ROLLBACK(id, rqt)

id: identificador local da requisição.

rqt: identificador do Servidor Requisição de origem

Desfaz uma reserva realizada no recurso retirando-a da lista $R L$. Retorna:

- OK: caso a reserva foi desfeita;

- DENY: caso não haja reserva para ser desfeita.

- REVOKE(id, rqt, qtd)

id: identificador local da requisição.

rqt: identificador do Servidor Requisição de origem.

qtd: quantidade que será compensada no recurso.

Devolve um recurso alocado, incrementando a quantidade disponível do recurso. Retorna:

- OK: indicando que a quantidade foi devolvida.

- FINALIZE_COMMIT(id, rqt)

id: identificador local da requisição.

rqt: identificador do Servidor Requisição de origem

Encerra o processo de committing para alocação de recurso iniciada pela operação COMMIT, retirando a requisição da lista CL. Retorna:

- OK: indicando que a requisição foi retirada da lista CL.

Um detalhamento sobre essas operações é apresentado na subseção 4.2.6.4. 


\subsubsection{Protocolo de execucão de cada operacão no Servidor Requisicão}

Apresenta-se aqui o protocolo de execução de cada uma das operações no Servidor Requisição que são chamadas na execução do atendimento da requisição do cliente, apresentadas na seção 4.2.4.1.

- Request_Resources(lista_recurso_qtd)

Para cada recurso solicitado, presente em lista_recurso_qtd, é chamada a função req_resource que fará o encaminhamento individual do pedido de recurso para cada serviço Recurso. Caso o pedido tenha sido atendido com sucesso, o recurso é colocado em uma lista de recursos reservados.

Se todos os recursos solicitados foram reservados retorna uma confirmação de sucesso (OK) e a lista dos recursos reservados. Caso contrário retorna à confirmação de insucesso (DENY) e a lista dos recursos reservados. A Figura 4.8 apresenta o fluxo de execução da operação.

Figura 4.8 - Fluxo da operação Request_Resources

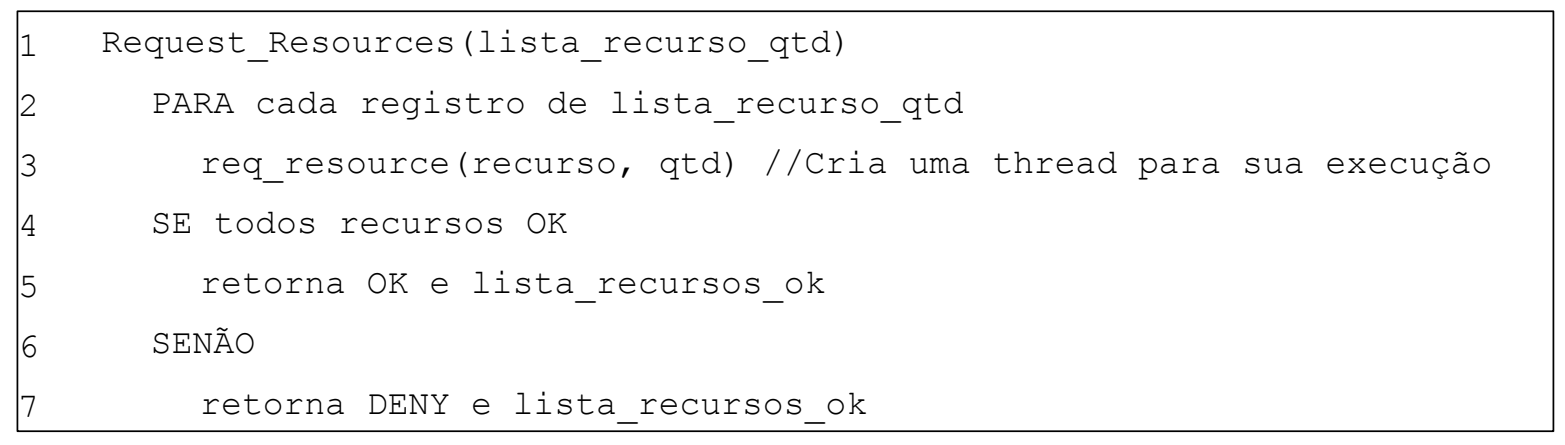

Fonte: O Autor (2015)

req_resource(recurso, qtd)

recurso: recurso solicitado.

qtd: quantidade solicitada do recurso.

A função req_resource providencia a reserva da quantidade especificada do recurso solicitado. A Figura 4.9 apresenta o diagrama de sequência de mensagens durante a execução da função. 
Figura 4.9 - Diagrama de sequência de mensagens da função req_resource

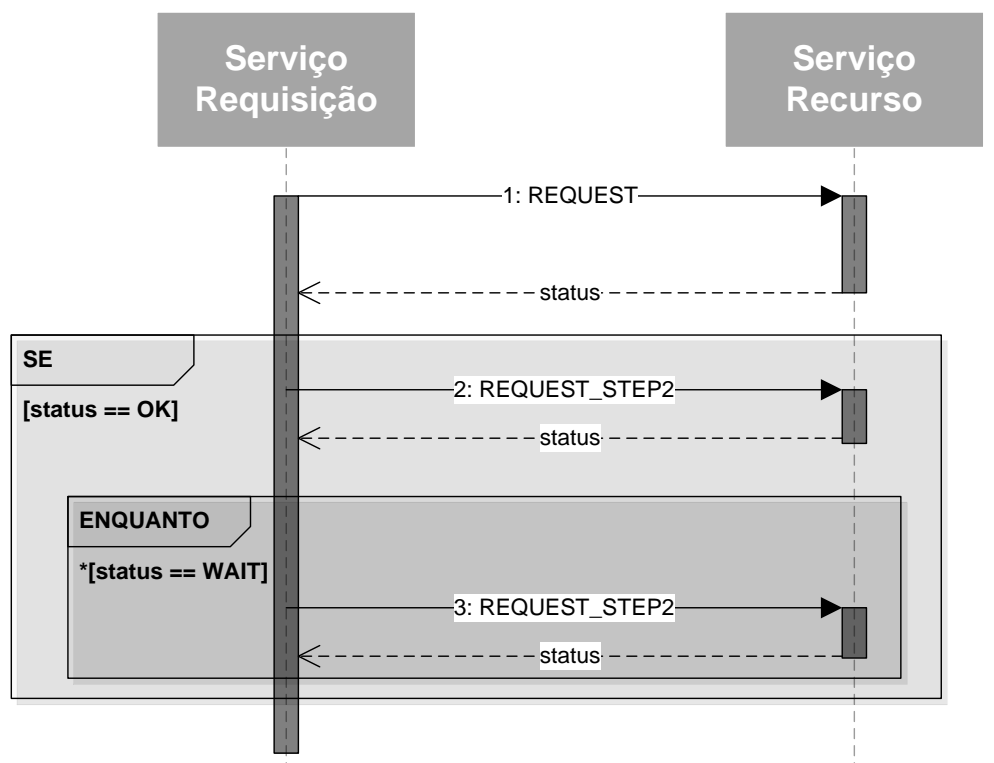

Fonte: O Autor (2015)

A função req_resource é realizada solicitando a execução de duas operações distintas no serviço Recurso: a operação REQUEST e REQUEST_STEP2. A abordagem, em realizar a reserva em duas etapas, foi aplicada no intuito de liberar o serviço Recurso para receber novas requisições.

Faz uma chamada do serviço Recurso correspondente ao recurso solicitado, especificando a execução da operação REQUEST, a quantidade, o timestamp (TS) e a identificação da requisição (ID), que é gerada localmente.

Se a operação REQUEST retornar:

- OK: será dado o prosseguimento do processo de reserva solicitando a execução da operação REQUEST_STEP2 no serviço Recurso.

Se a operação REQUEST_STEP2 retornar:

- OK: a requisição obteve a pré alocação, realizando a reserva do recurso.

- WAIT: não foi obtida a reserva, mas há possibilidade de consegui-la, se alguma requisição liberar sua reserva. Neste caso, a função req_resource prossegue em sua execução 
realizando uma nova chamada do serviço Recurso solicitando a operação REQUEST_STEP2.

- DENY: a reserva não foi efetuada, como também não há possibilidade de liberação de quantidade reservada, e neste caso a função req_resource retorna DENY.

- Query_Resources(lista_recursos):

Para cada recurso, presente em lista_recursos, é chamada a função que_resource que fará o encaminhamento individual de consulta de recurso para cada serviço Recurso. Caso a consulta seja negada, a quantidade do recurso negado recebe zero. Retorna lista_valores com os valores dos recursos da lista_recursos. A Figura 4.10 apresenta o fluxo de execução da operação.

Figura 4.10 - Fluxo da operação Query_Resources

Query_Resources(lista_recursos)

PARA cada registro de lista_recursos

lista_valores = que_resource (recurso) //Cria uma thread para sua execução retorna lista_valores

Fonte: O Autor (2015)

que_resource(recurso)

recurso: recurso solicitado.

A função que_resource realiza um procedimento de consulta sobre o recurso solicitado através da operação QUERY. Retorna uma lista_valores com a quantidade de cada recurso. A Figura 4.11 ilustra o diagrama de sequência de mensagens durante a execução da função.

Figura 4.11 - Diagrama de sequência de mensagens da função que_resource

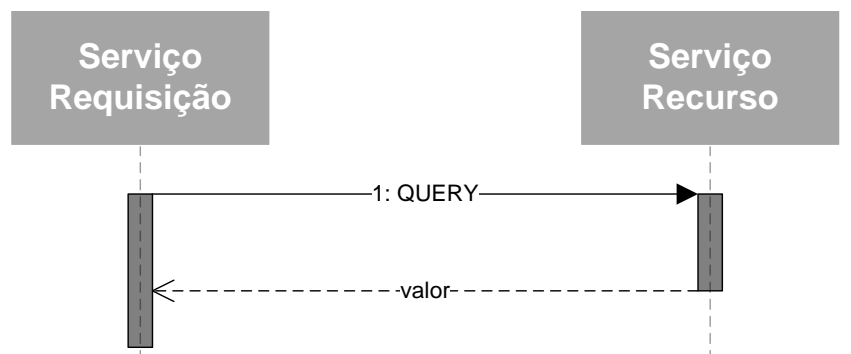

Fonte: O Autor (2015) 
- Rollback_Resources(lista_recursos_res):

Para cada recurso, presente na lista_recursos_res, será desfeita a reserva, através da função rol_resource, das requisições que obtiveram sucesso utilizando a operação Request_Resources. Caso desfaça as reservas em todos os recursos retorna sucesso na operação (OK). Caso contrário retorna insucesso (DENY) indicando que havia recursos que não necessitavam desfazer a operação. A Figura 4.12 apresenta o fluxo de execução da operação.

Figura 4.12 - Fluxo da operação Rollback_Resources

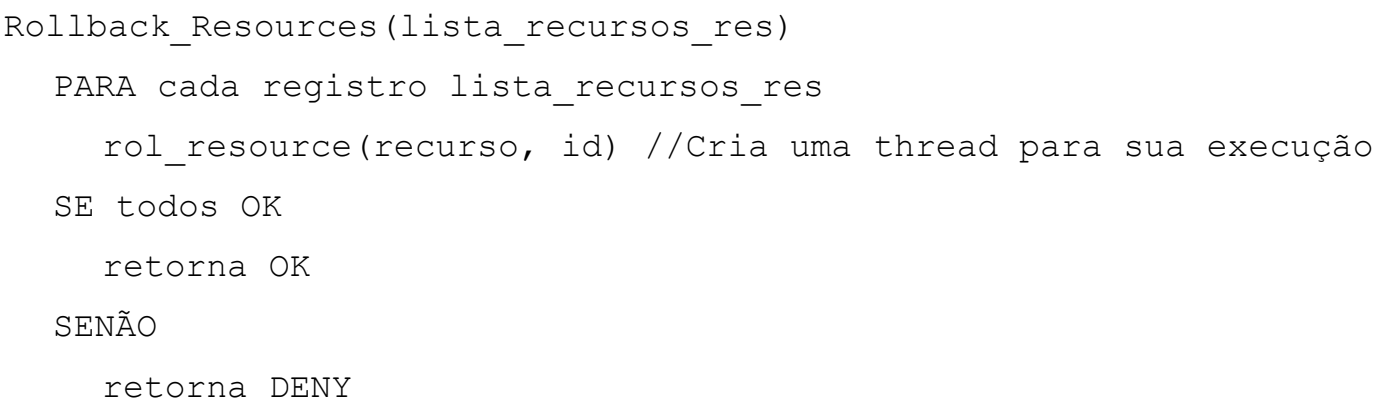

Fonte: O Autor (2015)

rol_resource(recurso, id)

recurso: recurso solicitado

id: identificação da requisição

A função rol_resource desfaz a reserva de uma requisição em um recurso. Para tanto, faz uma chamada ao serviço Recurso, solicitando a execução da operação ROLLBACK.

Se a operação ROLLBACK retornar:

- OK: retorna OK, indicando sucesso para desfazer a reserva;

- DENY: retorna DENY indicando que não existe reserva para desfazer.

A Figura 4.13 apresenta o diagrama de sequência de mensagens durante a execução da função. 
Figura 4.13 - Diagrama de sequência de mensagens da função rol_resource

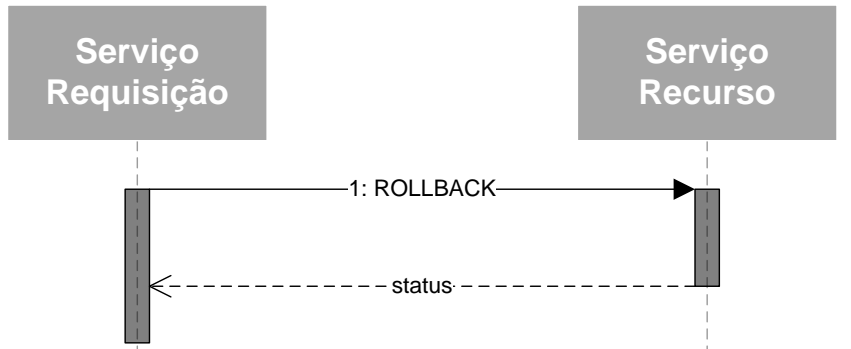

Fonte: O Autor (2015)

- Commit_Resources(lista_recursos_res):

Para cada recurso, presente na lista_recurso_res, é chamada a função com_resource que fará a confirmação da reserva obtida, através da chamada ao serviço Recurso, solicitando a execução da operação COMMIT que fará a alocação do recurso.

Figura 4.14 - Fluxo da operação Commit_Resources

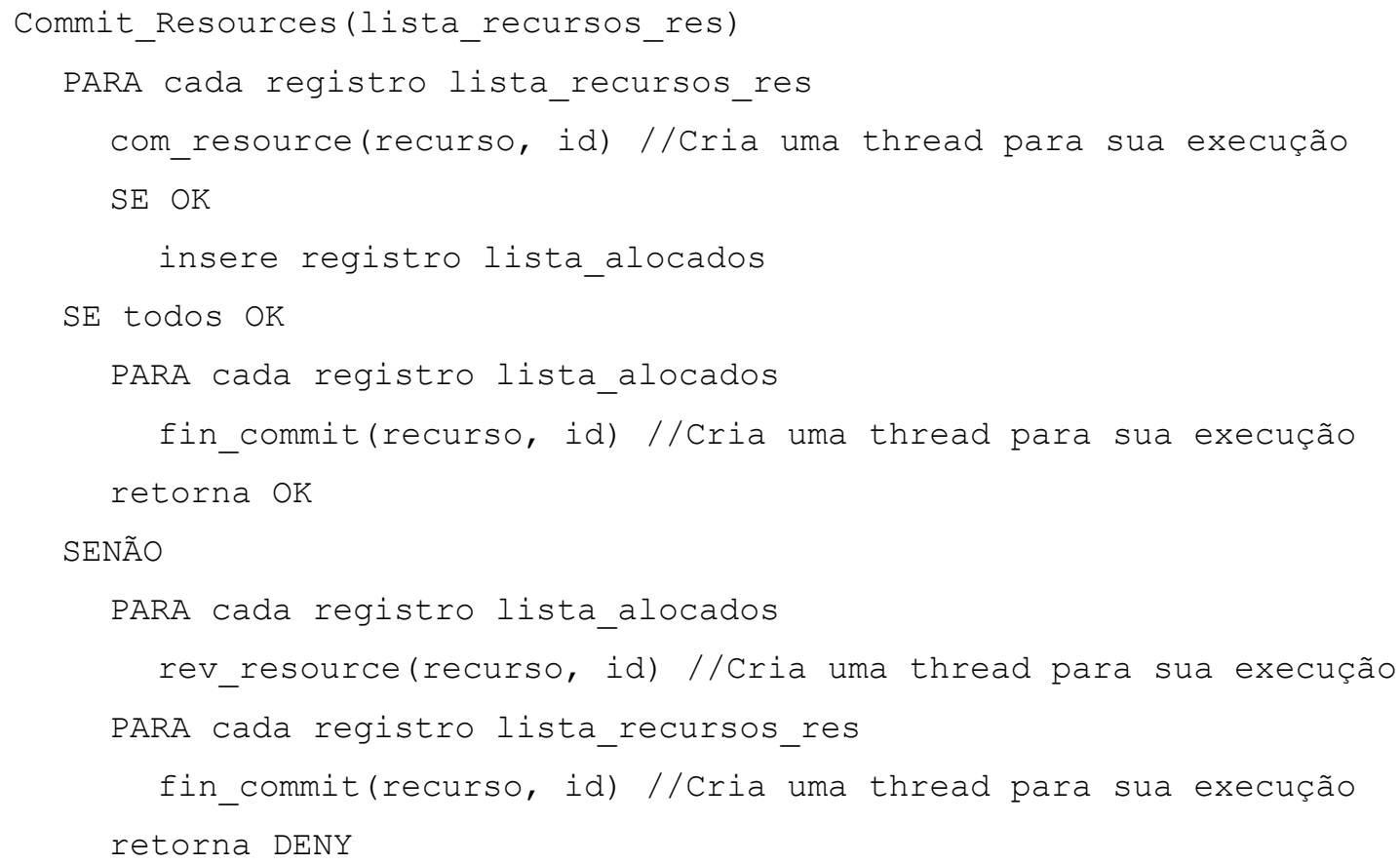

Fonte: O Autor (2015)

Se todos os recursos foram alocados, encerra o processo de committing através da função fin_commit, retornando OK. Se alguns dos recursos não foram alocados, devolve as quantidades alocadas aos demais recursos, através da chamada da função rev_resource, e em seguida a função fin_commit para encerrar o processo de committing. Neste caso 
retorna DENY. A Figura 4.14 apresenta o fluxo de execução da operação.

com_resource(recurso, id)

recurso: recurso solicitado

id: identificação da requisição

A função com_resource confirma uma reserva, efetuando uma chamada ao serviço Recurso, solicitando a execução da operação COMMIT que providenciará a alocação da quantidade em reserva do recurso. A Figura 4.15 ilustra o diagrama de sequência durante a execução da função.

Figura 4.15 - Diagrama de sequência de mensagens da função com_resource

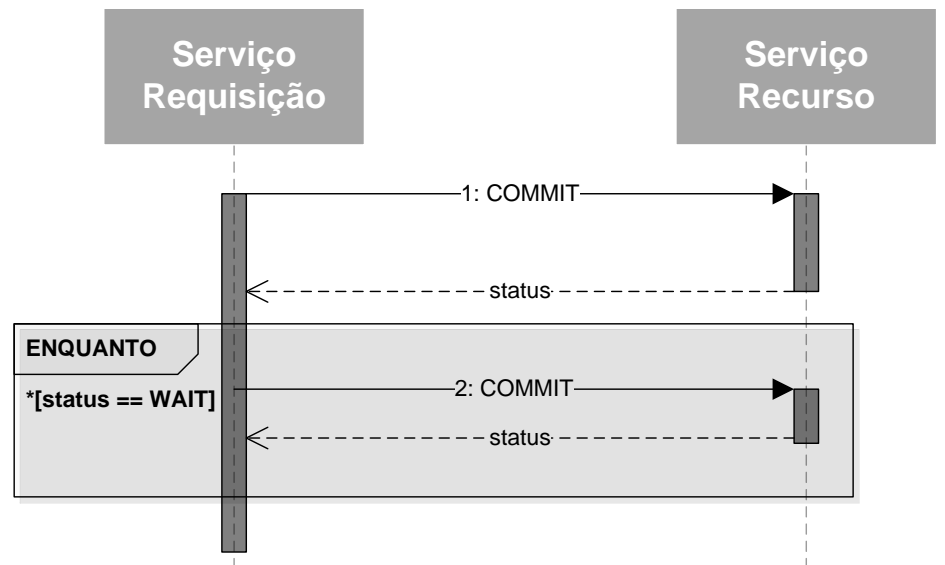

Fonte: O Autor (2015)

Se a operação COMMIT retornar:

- OK: retorna OK, indicando o sucesso da alocação do recurso;

- WAIT: solicita uma nova execução da operação COMMIT;

- DENY/CANCEL: retorna DENY, indicando que a alocação não foi efetuada.

rev_resource(recurso, quantidade).

recurso: recurso alocado

qtd: quantidade devolvida ao recurso 
A função rev_resource libera os recursos que foram alocados, solicitando a operação REVOKE. Retorna OK indicando que os recursos foram liberados. A Figura 4.16 apresenta o diagrama de sequência de mensagens durante a execução da função.

Figura 4.16 - Diagrama de sequência de mensagens da função rev_resource

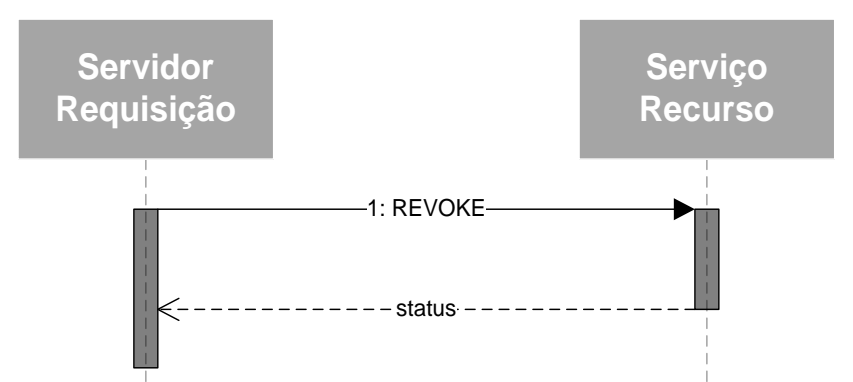

Fonte: O Autor (2015)

fin_commit(recurso, id)

recurso: recurso solicitado

id: identificação da requisição

A função fin_commit conclui a etapa para confirmar reserva, indicando que a requisição encerrou o processo de committing. Efetua uma chamada ao serviço Recurso, solicitando a execução da operação FINALIZE_COMMIT que irá remover a requisição da lista CL. A Figura 4.17 ilustra o diagrama de sequência durante a execução da função.

Figura 4.17 - Diagrama de sequência de mensagens da função fin_commit

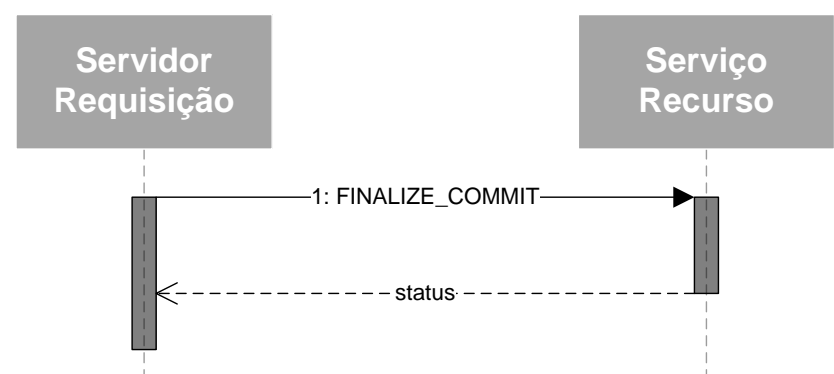

Fonte: O Autor (2015)

A operação FINALIZE_COMMIT retorna:

- OK: indicando que a requisição foi retirada da lista CL. 


\subsubsection{SERVIÇO REQUISIÇÃo}

O serviço Requisição é disponibilizado no Servidor Requisição (RQT). Recebe uma requisição do cliente, que solicita múltiplos recursos, efetua a alocação dos recursos e retorna uma confirmação do sucesso ou não da requisição.

Após o recebimento da requisição, cria uma lista contendo os recursos solicitados e as respectivas quantidades. Em seguida, executa um workflow que processa as operações descritas na subseção 4.2.4.1, decompondo a requisição em requisições individuais para que sejam executadas no Servidor de Recurso utilizando as operações descritas na subseção 4.2.4.2.

Estas execuções são realizadas obedecendo o protocolo descrito na subseção 4.2.4.3, proporcionando o comportamento transacional para a execução do workflow de maneira justa, livre de deadlock e starvation.

A Figura 4.18 ilustra a arquitetura do serviço Requisição, composta por três componentes.

Figura 4.18 - Serviço Requisição

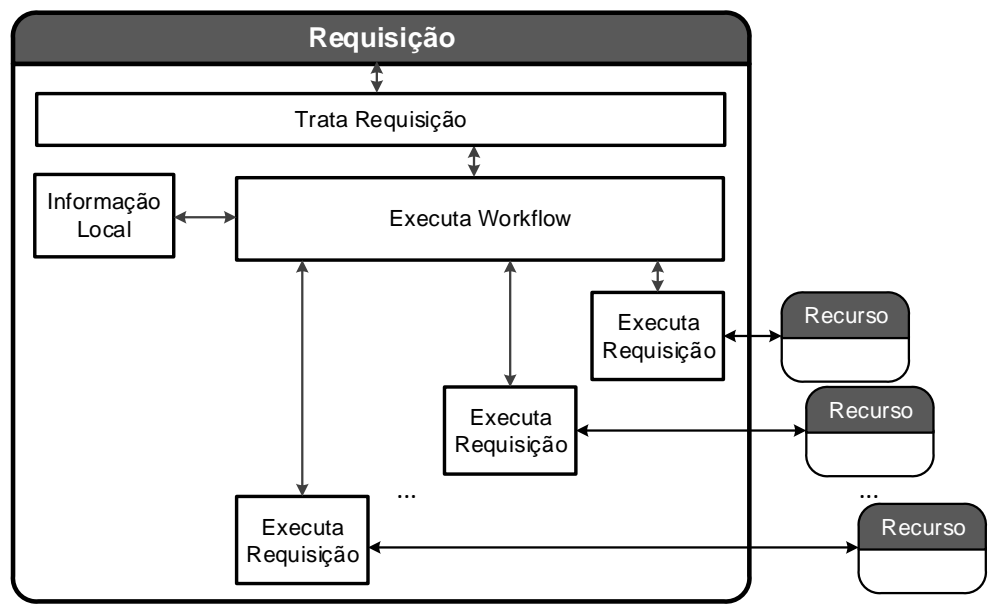

Fonte: O Autor (2015)

\subsubsection{Trata Requisição}

O componente Trata Requisição irá receber do cliente uma lista com a quantidade de cada recurso que deseja solicitar. De posse destas informações é montada uma lista de elementos contento dois campos: a quantidade solicitada em cada recurso e a informação dos recursos envolvidos na execução. Esta lista é a informação necessária para que o componente Executa Workflow possa iniciar sua tarefa. 


\subsubsection{Executa Workflow}

Este componente, ilustrado na Figura 4.18, recebe a lista dos recursos solicitados e inicia a execução do workflow, organizado conforme a descrição da Figura 4.19, a qual detalha o workflow apresentado na Figura 4.5. Na execução do workflow serão processadas as funções Query_Resources, Request_Resources, Commit_Resources e Rollback_Resources, apresentadas na subseção 4.2.4.1.

Figura 4.19 - Fluxo de execução do workflow

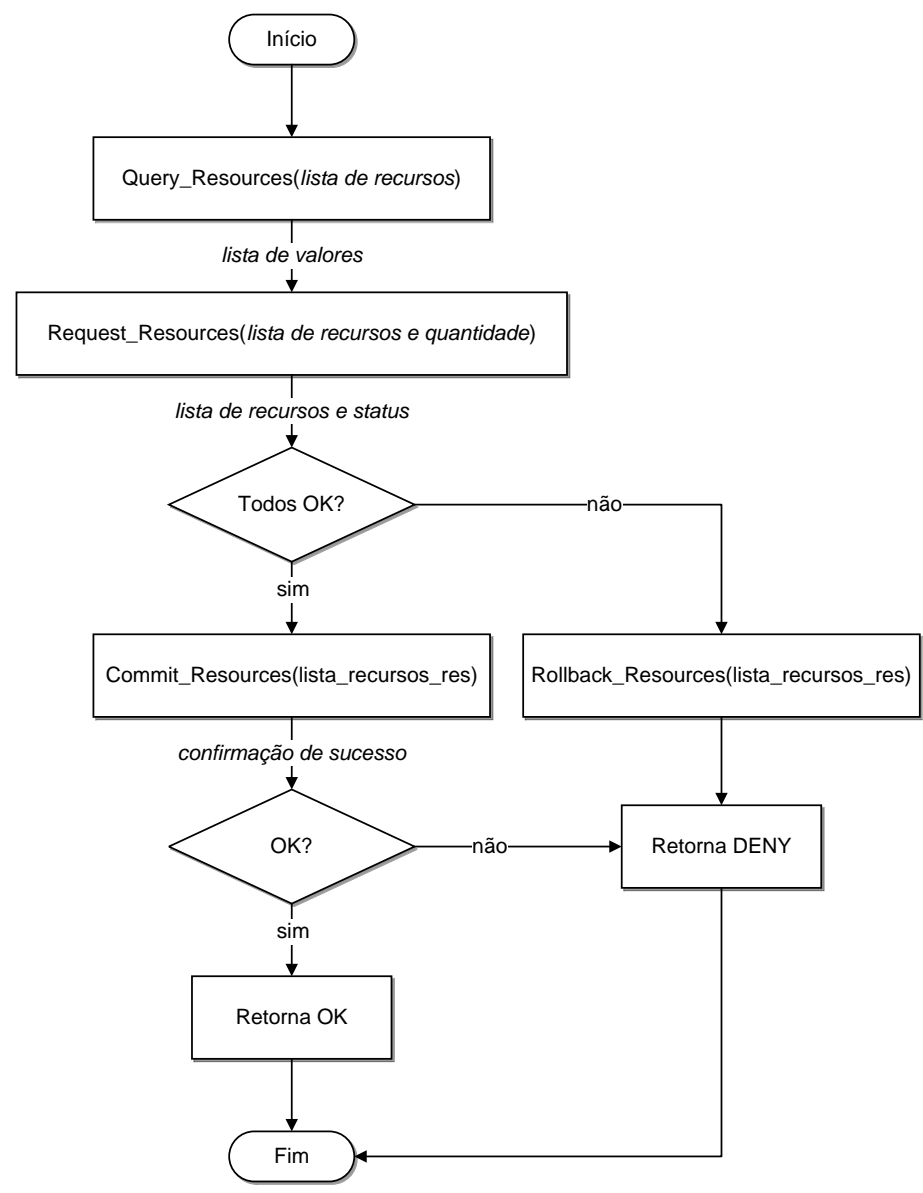

Fonte: O Autor (2015)

Cada uma destas funções, visando atender a lista de recursos solicitados, realiza uma decomposição, criando uma thread para cada recurso solicitado, representada na Figura 4.18 como Executa Requisição. Esta thread, conforme a solicitação da função, executa uma função específica. Cada função específica realiza uma chamada ao serviço Recurso, solicitando a execução de uma operação. Por exemplo, conforme a Figura 4.19, a função Request_Resources(lista_recursos_qtd) cria uma thread, correspondendo a cada recurso solicitado, e que executa a função 
req_resource, a qual solicita para o serviço Recurso do respectivo Servidor Recurso a execução das operações REQUEST e REQUEST_STEP2.

\subsubsection{Informacão Local}

Auxilia o componente Executa Workflow gerenciando e fornecendo as seguintes informações sobre o Servidor Requisição:

- identificação do servidor: fornece o número IP do servidor;

- o valor do seu relógio local através de uma marca de tempo (TS): gerencia o relógio lógico provendo mecanismo para atualizar o seu valor, conforme apresentado na subseção 4.2.1;

- identificação de requisições: gera automaticamente uma numeração sequencial.

\subsubsection{SERVIÇO RECURSO}

O serviço Recurso, ilustrado na Figura 4.20, é disponibilizado nos Servidores Recurso (RSC) recebendo as requisições individuais dos Servidores Requisição.

Figura 4.20 - Serviço Recurso

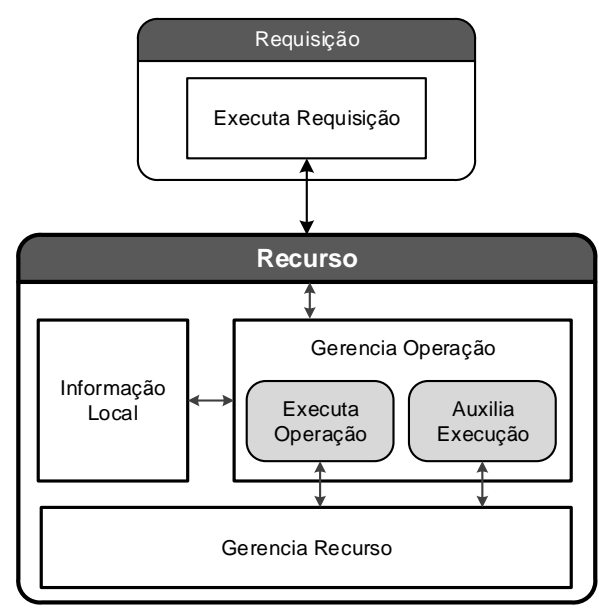

Fonte: O Autor (2015)

Controla e organiza o acesso e a manipulação do recurso para que sejam realizados de maneira justa, através do critério de prioridade apresentado na seção 4.2.24.2.4.2, o qual considera o instante de envio da requisição pelo Servidor Requisição e não o instante que o Servidor Recurso recebe a requisição. Esta política foi adotada, pois requisições enviadas, a partir de uma mesma origem, para diversas localidades podem atingir seus destinos em instantes de tempo diferentes. Isto pode ocorrer devido a distribuição geográfica dos computadores e também ao tráfego na 
rede. Desta forma, pode-se considerar que a ordem de chegada, no recurso solicitado, não é um critério tão justo para determinar o atendimento as requisições.

A seção 4.2.4.2 apresenta os procedimentos propostos neste trabalho para promover uma política justa na utilização do recurso.

O serviço Recurso possui três componentes para o gerenciamento e a organização das requisições para utilizar as operações sobre o recurso.

\subsubsection{Executa Requisicão}

Executa Requisição é uma thread executada no serviço Requisição que realiza chamada ao serviço Recurso, solicitando a execução de uma operação para ser realizada pelo componente Gerencia Operação.

\subsubsection{Informação Local}

Este componente é o mesmo utilizado pelo serviço Requisição, apresentado na seção 4.2.5.3.

Entre as funcionalidades oferecidas pelo componente Informação Local, o serviço Recurso utiliza somente o mecanismo de gerenciamento de relógio lógico, o qual atualiza e informa o valor de marca de tempo para definir a prioridade no atendimento as requisições.

\subsubsection{Gerencia Recurso}

O componente coordena o acesso ao recurso. Gerencia a quantidade do recurso em reserva, armazenando-a em BUFFER. No momento em que a reserva de uma quantidade do recurso, solicitada por uma requisição, é realizada, incrementa BUFFER desta quantidade.

Caso a quantidade do recurso, solicitada por uma requisição, seja alocada, o BUFFER é decrementado desta quantidade e a quantidade corrente do recurso (QTD) é decrementada do mesmo valor, indicando o consumo do recurso. Caso a reserva seja desfeita, basta decrementar a quantidade reservada de BUFFER. Caso a alocação seja desfeita, a quantidade alocada é incrementada em QTD.

\subsubsection{Gerencia Operação}

O componente Gerencia Operação promove a execução de seis operações, descritas na seção 4.2.4.2, que são realizadas sobre o recurso: QUERY, REQUEST, REQUEST_STEP2, COMMIT, ROLLBACK, REVOKE e FINALIZE_COMMIT. 
O componente está organizado, conforme apresentado na Figura 4.20, através de duas atividades que serão processadas simultaneamente pelas threads Executa Operação e a Auxilia Execução.

A thread Executa Operação recebe as requisições do Servidor Requisição, faz a chamada da operação solicitada em cada requisição e retorna uma resposta ao Servidor Requisição. A Figura 4.21 apresenta o algoritmo executado por esta thread.

Figura 4.21 - Algoritmo thread Executa Operação

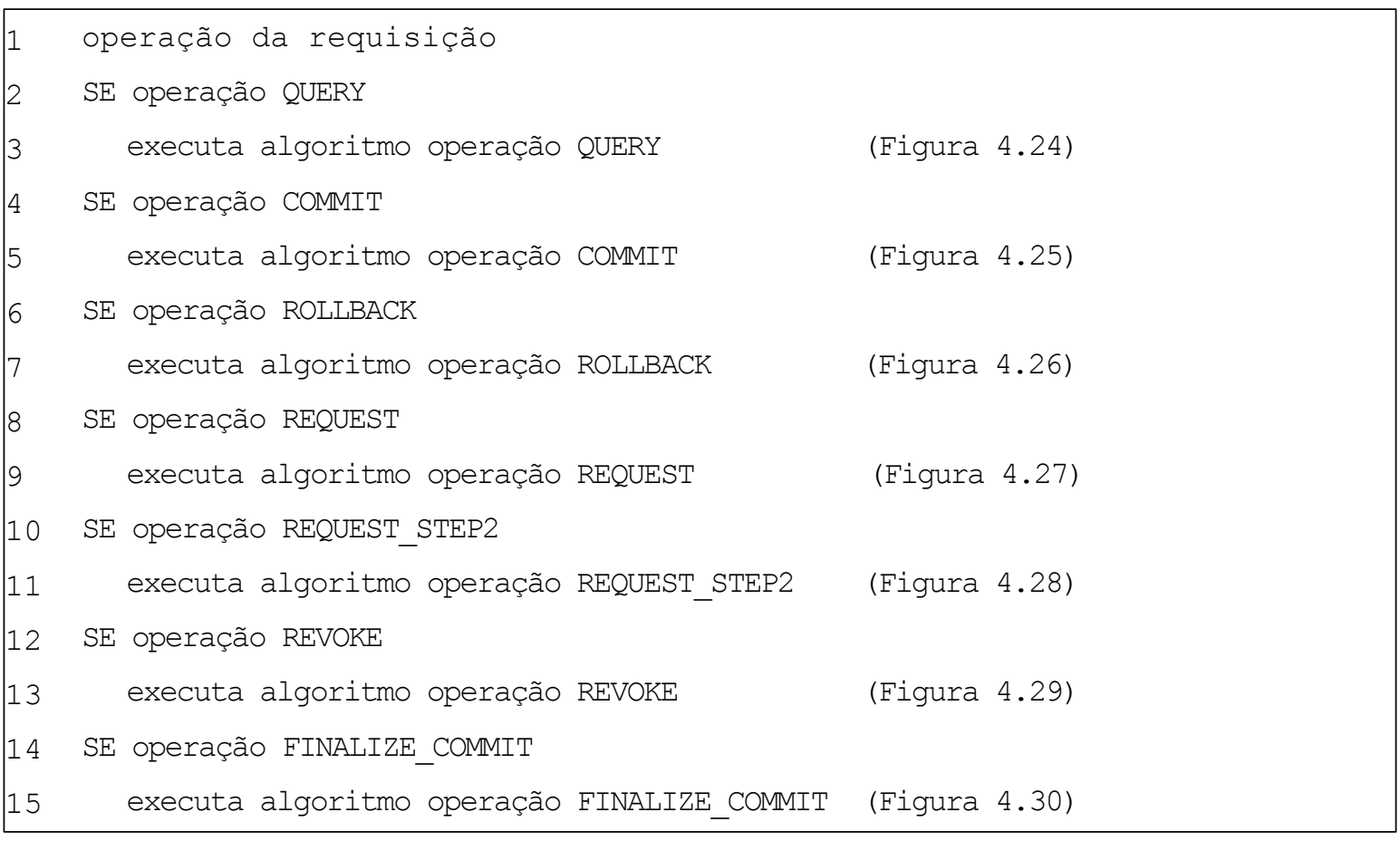

Fonte: O Autor (2015)

O propósito da thread Auxilia Execução, cujo algoritmo é apresentado pela Figura 4.22, é liberar a thread Executa Operação para receber novas requisições, sem ficar ocupada até a finalização do tratamento de uma requisição. A thread Auxilia Execução fica suspensa aguardando a thread Executa Operação realizar uma ação sobre qualquer uma das listas. Caso a thread Executa Operação efetue uma ação sobre as listas $A L$ e WL, ativa a thread Auxilia Execução que verifica a disponibilidade para utilizar o recurso.

Esta estratégia foi adotada pois a thread Executa Operação é responsável pelo recebimento e tratamento de todas as requisições no Servidor Recurso, cujo processamento é exclusivo para garantir a consistência do recurso, uma vez que existem diversas requisições que estão sendo atendidas. Com esta estratégia a thread 
Executa Operações é liberada para o recebimento de uma nova requisição, sem que haja a espera pela conclusão sobre a disponibilidade do recurso.

Figura 4.22 - Algoritmo thread Auxilia Execução

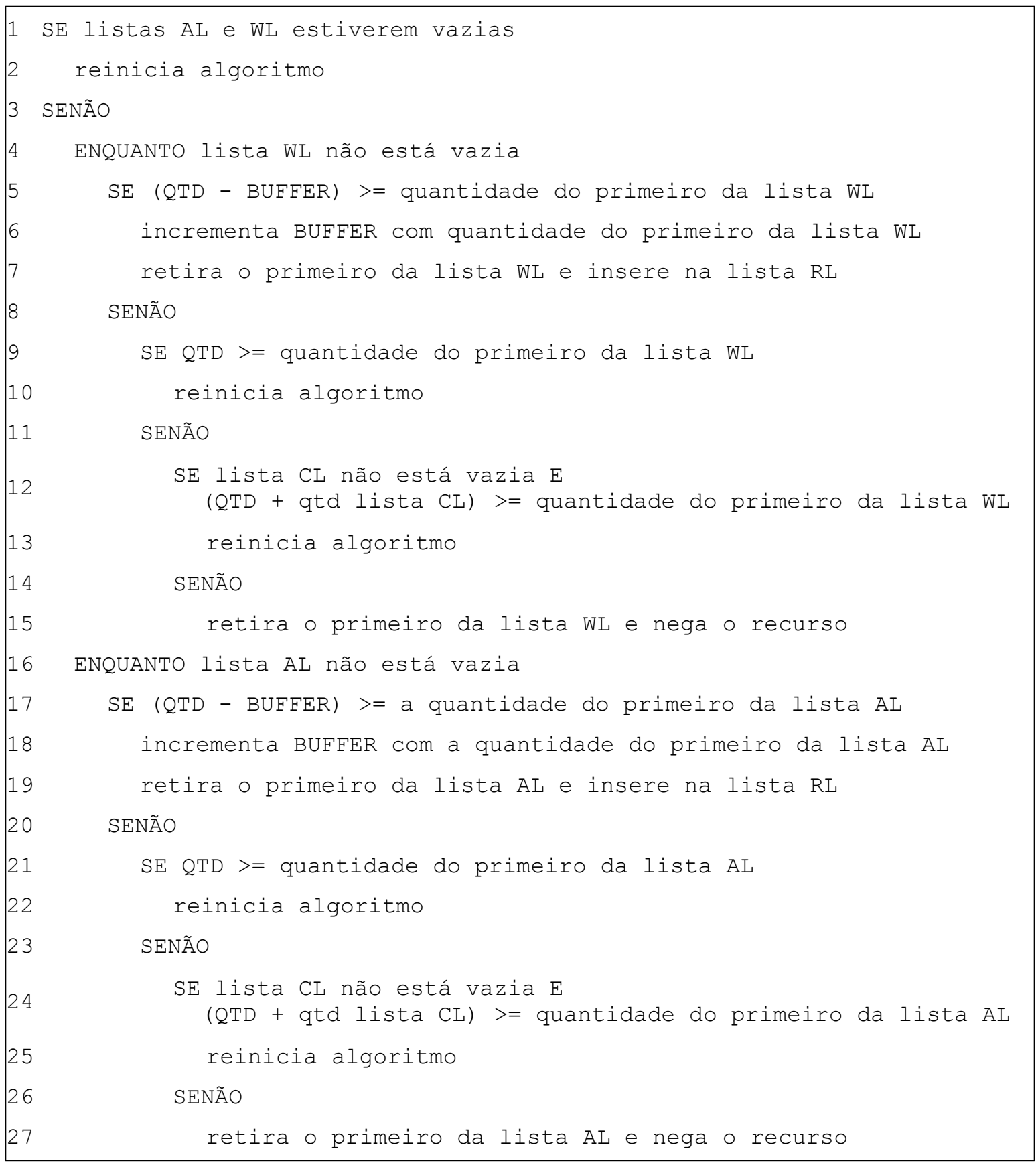

Fonte: O Autor (2015)

Caso não haja requisições inseridas nas listas $A L$ e WL a thread Auxilia Execução reinicia o processo aguardando que haja solicitações inseridas nestas listas (linhas 1 e 2 da Figura 4.22). Caso contrário a thread irá verificar se é possível realizar a reserva da requisição, verificando para as requisições que estão na lista WL e, caso 
não haja requisição na lista $W L$, verifica para as requisições que estão na lista $A L$ (linha 4 e linha 16 da Figura 4.22).

O tratamento realizado para as requisições da lista WL é o mesmo tratamento para as requisições da lista $A L$, os quais podem ser verificados entre as linhas 5 e 15 para as requisições da lista WL e entre as linhas 17 e 27 para as requisições da lista $\mathrm{AL}$ apresentados na Figura 4.22, porém as requisições presentes na lista WL serão atendidas antes das requisições da lista $\mathrm{AL}$.

Verifica se há quantidade disponível (QTD - BUFFER), ilustrados na linha 5 para a lista WL e linha 17 para a lista $A L$ da Figura 4.22. Caso haja quantidade disponível incrementa BUFFER com a quantidade da requisição retirando-a da lista que está armazenada e inserindo na lista $R L$ realizando a reserva (linhas 6 e 7 para a lista WL e linhas 18 e 19 para a lista AL da Figura 4.22). Caso contrário, verifica se a quantidade total do recurso, desconsiderando as reservas, é suficiente para atender a requisição, uma vez que haja desistência de reservas esta requisição terá prioridade em obter a reserva. Caso a quantidade total seja suficiente, a requisição aguarda na lista com prioridade em relação a novas requisições com TS maior (linhas 9 e 10 para a lista WL e 21 e 22 para a lista AL da Figura 4.22). Caso contrário, verifica se há requisições em processo de committing, confirmando suas reservas, indicados pela presença na lista CL, e se o total das quantidades das requisições que estão confirmando suas reservas é suficiente para atender a requisição corrente. Se sim, a requisição é mantida na lista (linhas 12 e 13 para a lista WL e linhas 24 e 25 para a lista $A L$ da Figura 4.22). Senão, não há quantidade suficiente para atender a requisição e o recurso é negado (linhas14 e 15 para a lista WL e linhas 26 e 27 para a lista AL da Figura 4.22).

A seguir são apresentadas as listas de chegada $(A L)$, de espera $(W L)$, de reserva $(R L)$ e Committing List $(C L)$ :

- Lista de chegada ( $A L)$ : Armazena as requisições que foram recebidas, porém ainda não foram completamente atendidas.

- Lista de reserva $(R L)$ : Armazena as requisições que obtiveram sucesso para realizar a reserva do recurso.

- Lista de espera (WL): Armazena as requisições que tiveram a reserva suspensa e aguarda a liberação de reserva de outras requisições, ou requisições que tiveram a prioridade reparada. 
- Lista Committing List (CL): Armazena as requisições que estão em processo de committing, aguardando que todas as requisições do workflow aloquem efetivamente o recurso.

As listas armazenam a estrutura de dados apresentada na Figura 4.23, contendo os seguintes campos:

- ID requisição: Identificador da requisição no Servidor Requisição.

- ID Servidor Requisição: Identificador do Servidor Requisição que realizou a solicitação.

- Timestamp: Valor do relógio lógico (TS) do Servidor de Requisição que está realizando a requisição.

- QTD: quantidade de recurso solicitada.

Figura 4.23 - Estrutura de dados das listas

\begin{tabular}{|l|l|l|l|}
\hline ID requisição & $\begin{array}{l}\text { ID Servidor } \\
\text { Requisição }\end{array}$ & Timestamp & QTD \\
\hline
\end{tabular}

Fonte: O Autor (2015)

As operações processadas pelo componente Gerencia Operações são apresentadas a seguir.

\section{Operação QUERY}

A operação QUERY realiza uma consulta ao recurso, verificando a quantidade disponível, ilustrado pela Figura 4.24. Nesta operação não há necessidade de manipular as listas, constituindo-se de uma atualização do relógio lógico local e a leitura da quantidade disponível, a qual é a quantidade oferecida pelo recurso (QTD) menos a quantidade em reservada, a qual está armazenada temporariamente em BUFFER, aguardando uma confirmação ou cancelamento. Ao final retorna OK indicando que a operação foi executada com sucesso.

Figura 4.24 - Algoritmo para operação QUERY

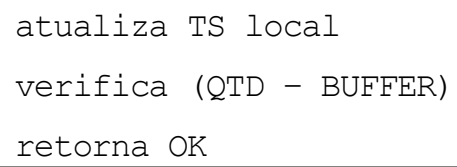

Fonte: O Autor (2015) 


\section{Operação COMMIT}

A operação COMMIT, ilustrado na Figura 4.25, verifica em qual lista a requisição está, de maneira que possa confirmar reserva, alocando o recurso. Os seguintes procedimentos são realizados pela operação:

- Caso a requisição esteja na lista $R L$, ela é inserida na lista $C L$, indicando que a requisição está em processo de committing, aguardando a confirmação de suas demais reservas. $O$ valor solicitado é decrementado de BUFFER e de QTD, alocando o recurso para a requisição. Este procedimento retorna OK indicando que a operação foi concluída com sucesso;

- Caso a requisição esteja na lista WL retorna WAIT, indicando que uma nova operação COMMIT deve ser solicitada. Esta situação indica que houve a perda da reserva no recurso, ocorrendo o reparo no atendimento, uma vez que uma requisição com maior prioridade solicitou e obteve o recurso. Neste caso, caso haja possibilidade de futura reserva, a requisição é incluída na lista WL.

- Caso a requisição não esteja nas listas $R L$ ou WL, o recurso será negado retornando CANCEL, indicando que a reserva obtida, foi cedida para outra requisição com maior prioridade e não há a possibilidade de futura reserva;

- Caso a requisição não tenha sido solicitada será retornado DENY, indicando que não há requisição para confirmar reserva.

Figura 4.25 - Algoritmo para operação COMMIT

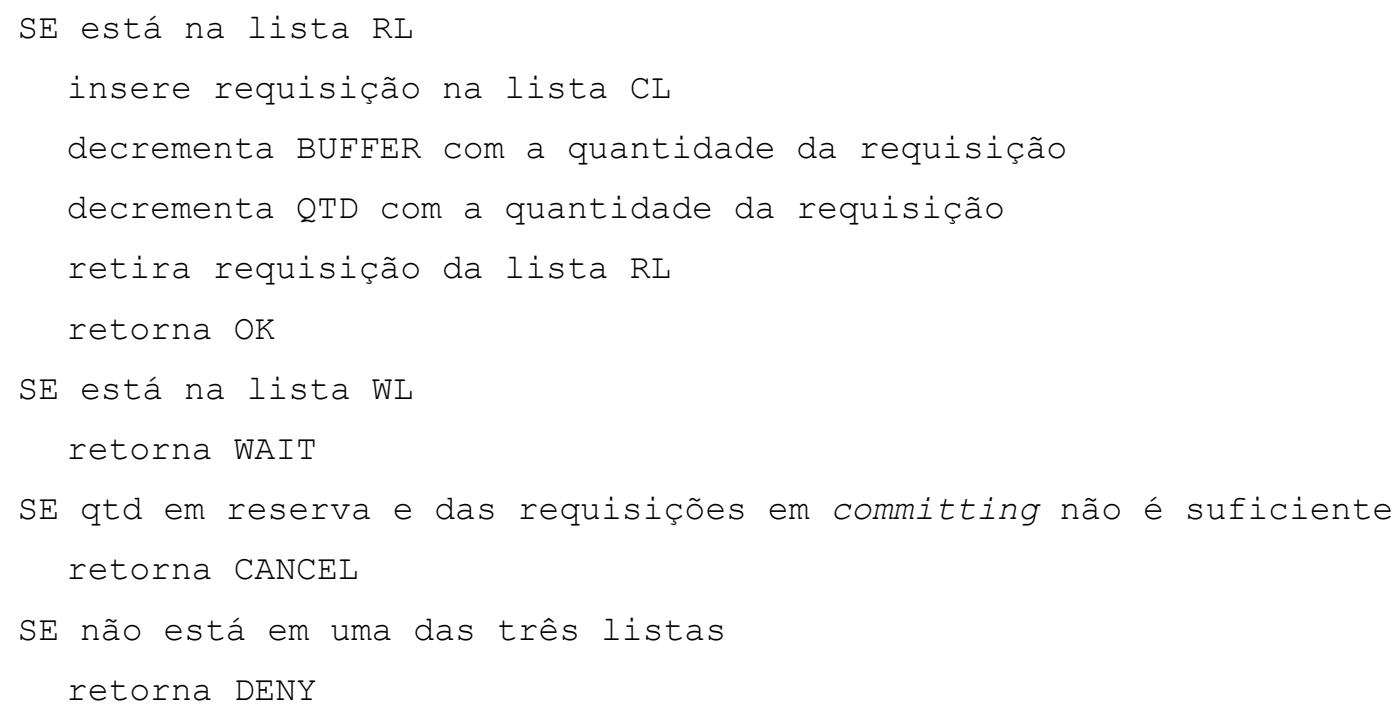




\section{Operação ROLLBACK}

A operação Rollback consiste em desfazer uma reserva que foi realizada. Caso a requisição esteja na lista $R L$, o valor da requisição é retirado do BUFFER, a requisição é retirada da lista $R L$ retornando $O K$ para indicar que a operação foi concluída com sucesso. Caso a requisição esteja na lista WL, retira-se a requisição da lista WL e retorna OK indicando que a operação foi concluída com sucesso. Caso a requisição não esteja nestas duas listas, não há requisição para ser desfeita retornando DENY indicando que o cancelamento solicitado não foi realizado. A Figura 4.26 ilustra o algoritmo para a operação ROLLBACK.

Figura 4.26 - Algoritmo para operação ROLLBACK

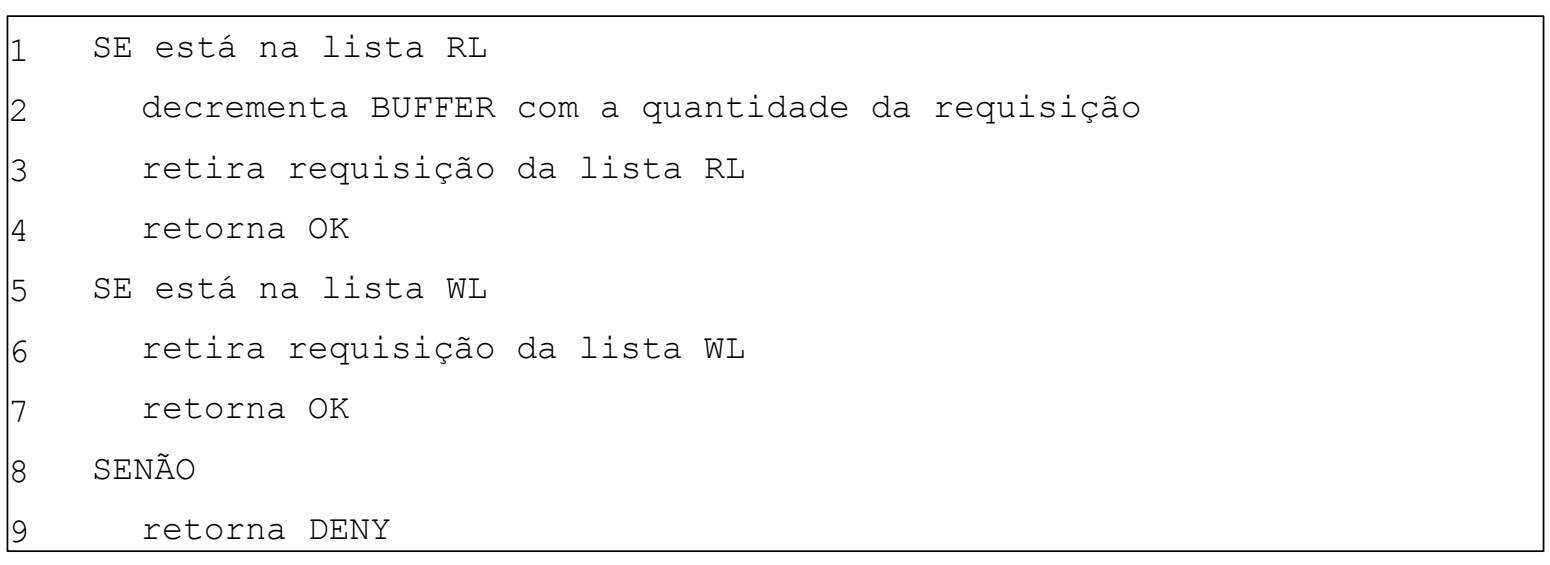

Fonte: O Autor (2015)

\section{Operação REQUEST}

A operação REQUEST consiste em realizar a primeira etapa para realizar a reserva de uma requisição considerando o critério de prioridade apresentado na seção 4.2.2.

A Figura 4.27 ilustra o algoritmo para a operação REQUEST. Caso o TS da requisição recebida seja maior que o valor do TS local, esta requisição é inserida na lista $\mathrm{AL}$ e retorna $\mathrm{OK}$.

Senão, verifica se na lista $R L$ existem requisições com TS maior em relação ao TS da requisição recebida. Caso haja requisições com TS maior, retira-as da lista $R L$, atualiza o valor do BUFFER decrementando as respectivas quantidades, insere a requisição recebida na lista $W L$ e em seguida insere as requisições que foram retiradas da lista $R L$ na lista $W L$. Caso contrário, a requisição recebida é inserida na lista WL. Desta forma, a requisição recebida será a primeira da lista WL, devendo ser 
transferida para a lista $R L$ pela thread Auxilia Execução. Em todas essas situações retorna $\mathrm{OK}$, indicando que a requisição recebida foi inserida na lista $A L$ ou WL.

Figura 4.27 - Algoritmo para operação REQUEST

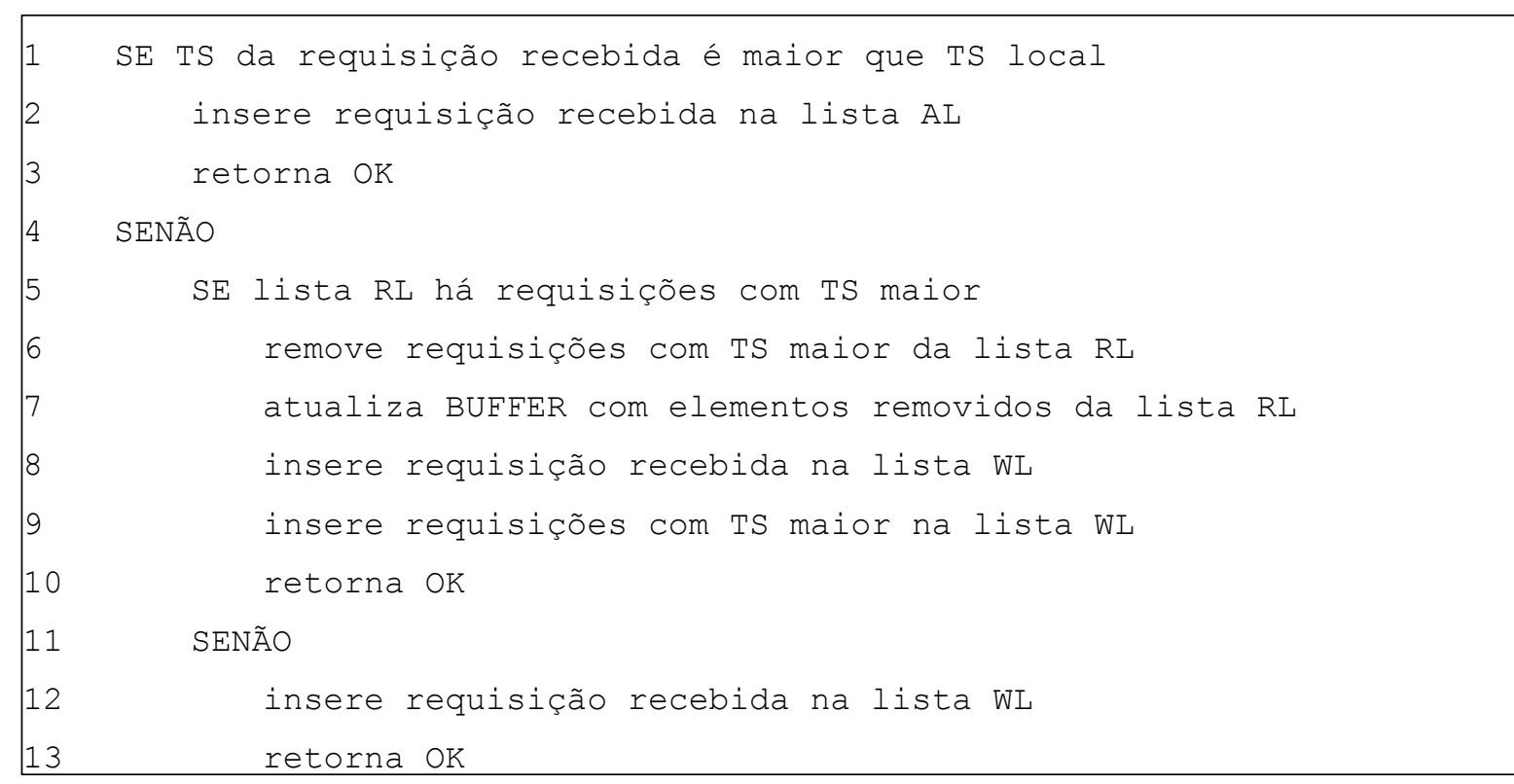

Fonte: O Autor (2015)

\section{Operação REQUEST_STEP2}

A operação REQUEST_STEP2 é a segunda etapa do processo para realizar a reserva do recurso. Enquanto a operação REQUEST consiste em inserir uma requisição na lista $A L$ ou WL, a operação REQUEST_STEP2 verifica em qual das listas a requisição se encontra, uma vez que através da thread Auxilia Execução é verificado a disponibilidade do recurso e a transferência entre as listas.

A Figura 4.28 ilustra o funcionamento da operação REQUEST_STEP2. Caso a requisição esteja na lista $R L$, a reserva foi efetuada retornando $O K$. Caso a requisição esteja na lista $A L$, a reserva ainda não foi efetuada retornando WAIT. Caso a requisição esteja na lista $\mathrm{WL}$, a reserva ainda não foi efetuada retornando WAIT. $E$ caso a requisição não esteja em nenhuma das três listas, a reserva não foi efetuada retornando DENY. 
Figura 4.28 - Algoritmo para operação REQUEST_STEP2

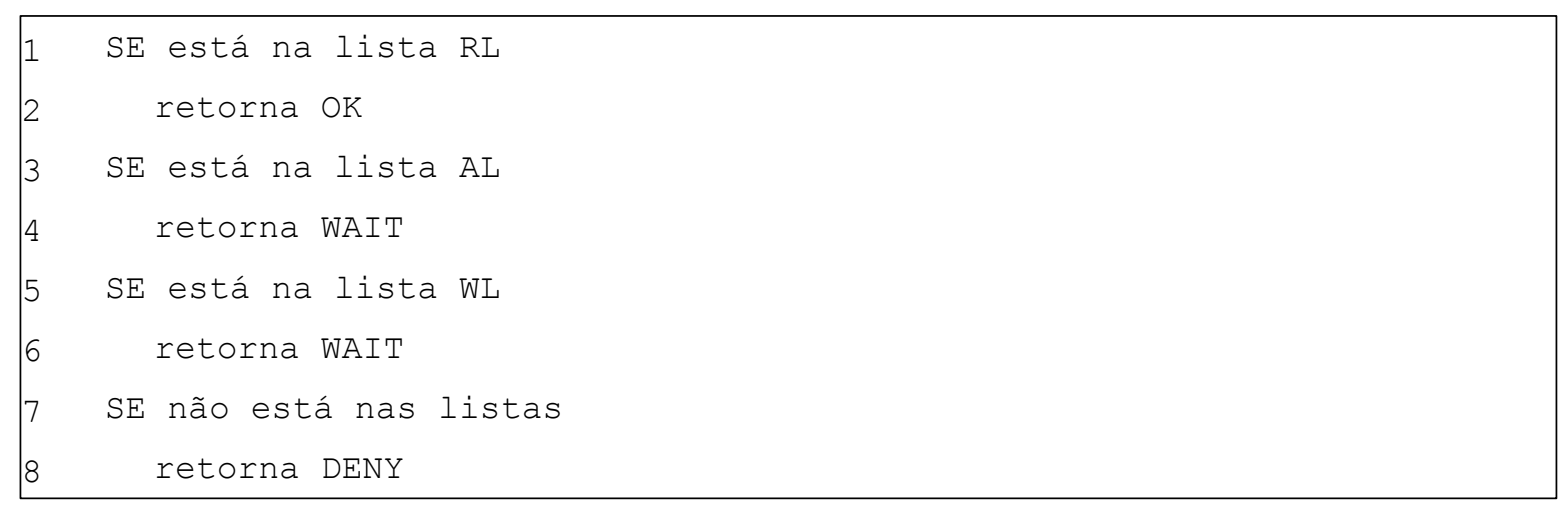

Fonte: O Autor (2015)

\section{Operação REVOKE}

A operação REVOKE é utilizada caso a operação Commit_Resources não consiga alocar todos os recursos, necessitando desfazer os recursos que foram alocados até então. A operação consiste em devolver o recurso alocado, incrementando QTD com a quantidade que havia retirado e remover a requisição da lista $\mathrm{CL}$, indicando que o processo de committing foi encerrado. Após concluir a operação retorna OK. A Figura 4.29 ilustra o funcionamento da operação REVOKE.

Figura 4.29 - Algoritmo para operação REVOKE

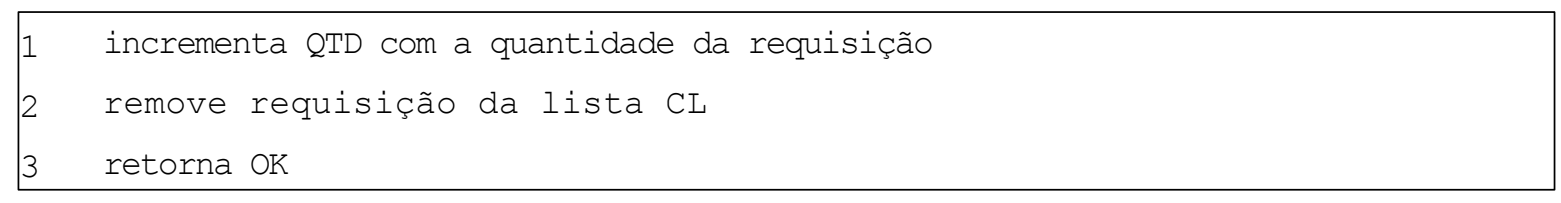

Fonte: O Autor (2015)

\section{Operação FINALIZE_COMMIT}

A operação FINALIZE_COMMIT é utilizada para concluir a operação COMMIT, indicando que a requisição encerrou o processo de committing sobre os recursos. Esta operação consiste em retirar a requisição da lista CL.

Figura 4.30 - Algoritmo para operação FINALIZE_COMMIT

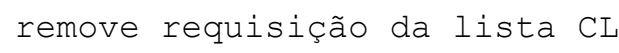




\subsubsection{EXEMPLO ILUSTRANDO O FUNCIONAMENTO DA SOLUÇÃO}

É apresentada aqui, uma aplicação da solução proposta em um cenário, com o objetivo de ilustrar o seu funcionamento. A Figura 4.31 apresenta uma ilustração com os elementos que serão utilizados. Cada servidor deve possuir um relógio lógico, e seu valor representado por uma marca de tempo (TS), a qual será atualizada a cada requisição ou resposta de maneira que os relógios sejam atualizados quando houver interações entre eles.

Figura 4.31 - Descrição dos elementos da proposta

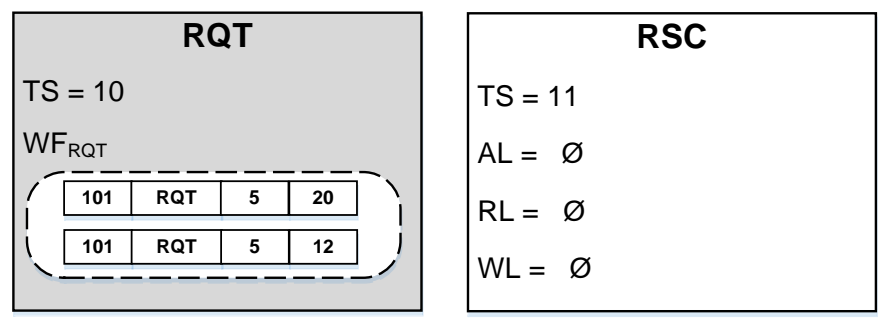

Fonte: O Autor (2015)

O Servidor Requisição (RQT), através do serviço Requisição recebe requisições de clientes, solicitando múltiplos recursos. O serviço Requisição executa um workflow (WFRQT) que processa composições de serviços para conceder os múltiplos recursos solicitados. Durante a execução do workflow são geradas requisições individuais as quais são encaminhadas para os respectivos serviços Recurso, contendo uma mensagem anexada, conforme a Figura 4.32, com quatro campos, contendo os seguintes dados:

1. Identificador da requisição local.

2. Identificador do Servidor Requisição de origem (IP do servidor).

3. Valor do TS da requisição.

4. Quantidade de recursos solicitados.

Figura 4.32 - Descrição das informações contidas na mensagem

\begin{tabular}{|c|c|c|c|}
\hline 1 & 2 & 3 & 4 \\
\hline 101 & RQT $_{1}$ & 5 & 20 \\
\hline
\end{tabular}

Fonte: O Autor (2015)

No cenário, as requisições de múltiplos recursos, são realizadas em dois Servidores Requisição e os recursos estão disponibilizados em dois Servidores 
Recurso.

Para apresentar o funcionamento da solução, a Figura 4.33 ilustra a configuração que será utilizada como exemplo. O Servidor Requisição (RQT1) possui seu relógio lógico (TS) com valor de 5, um workflow (WFRQT1) com uma composição de serviços para adquirir passagem aérea e quarto em hotel. O Servidor Recurso $\mathrm{RSC}_{1}$ disponibiliza um serviço de passagem aérea, possui TS com 3 e 30 passagens disponíveis. O Servidor Recurso $\mathrm{RSC}_{2}$ disponibiliza um serviço para adquirir quarto em hotel, possui TS com 2 e 20 quartos disponíveis.

Figura 4.33 - Configuração exemplo

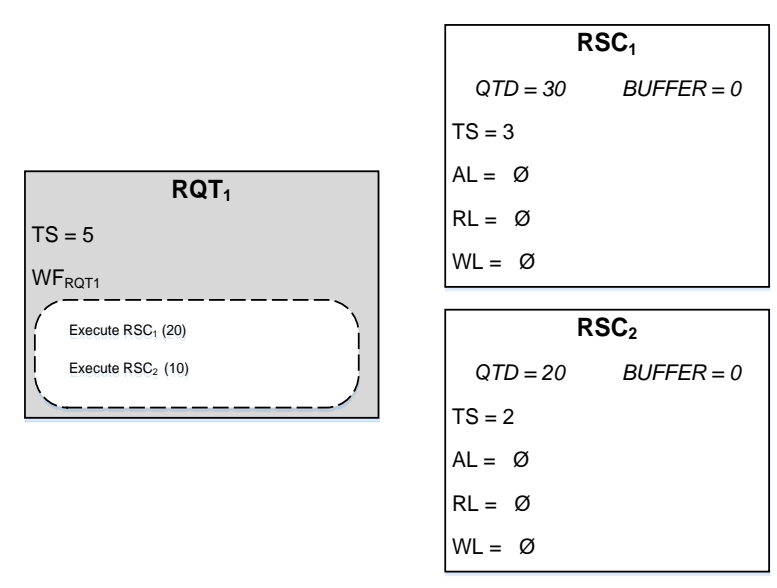

Fonte: O Autor (2015)

Para que pedidos de passagem aérea e quarto de hotel possam ser realizados, uma requisição deverá ser feita no $R Q T_{1}$, informando as quantidades desejadas, para a execução do WFRQT1. Ao executar WFRQ1, são geradas duas requisições. Uma será enviada ao $\mathrm{RSC}_{1}$ solicitando 20 unidades, e a outra será enviada ao $\mathrm{RSC}_{2}$ solicitando 10 unidades, conforme ilustrado na Figura 4.34. A mensagem que RQT 1 envia contém respectivamente as seguintes informações; identificador da requisição, identificador do Servidor Requisição de origem, valor do relógio lógico local e a quantidade que está solicitando.

O exemplo apresentado na Figura 4.34, uma requisição solicitando 20 passagens e 10 quartos foi realizada para executar WFRQT1, a qual será executada de forma transacional. O WFRQT1 é executado enviando o pedido de REQUEST individual para cada Servidor de Recurso. Ao receber a mensagem de REQUEST, RSC ${ }_{1}$ coloca a requisição na lista $A L$ e atualiza seu TS para 6 . O mesmo procedimento ocorre em $\mathrm{RSC}_{2}$, colocando a requisição na lista $\mathrm{AL}$ e atualizando o TS local para 6. 
Figura 4.34 - Solicitação de reserva com operação REQUEST

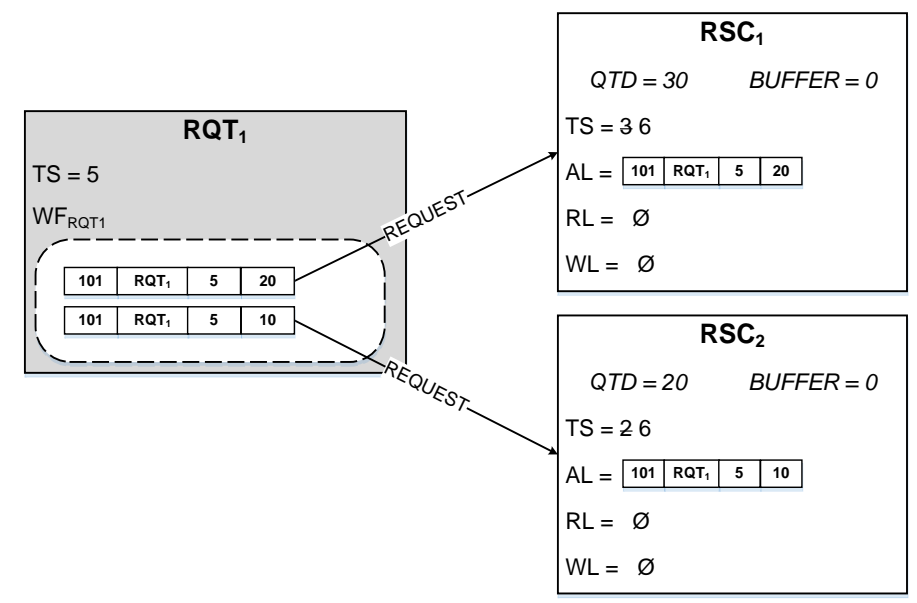

Fonte: O Autor (2015)

Os RSC's ao retirarem as requisições das listas $A L$, conforme ilustrado na Figura 4.35, verificam se há a disponibilidade do recurso. A requisição em $\mathrm{RSC}_{1}$ solicita 20 passagens e há 30 passagens disponíveis (QTD - BUFFER), e a requisição em $\mathrm{RSC}_{2}$ solicita 10 quartos e há 20 quartos disponíveis (QTD - BUFFER). Como há a disponibilidade dos recursos, as requisições são movidas para a lista $R L$, onde em $\mathrm{RSC}_{1}$ o BUFFER irá indicar que há 20 passagens reservadas para $R \mathrm{RT}_{1}$, e em $\mathrm{RSC}_{2}$ o BUFFER registra que há 10 quartos reservados para $\mathrm{RQT}_{1}$, gerando respostas para a execução de $W F_{R Q T 1}$ em $R Q T_{1}$ de êxito para cada requisição individual. No interior das mensagens enviadas como resposta para $\mathrm{RQT}_{1}$ é enviado também o valor do TS de cada RSC no intuito de atualizar o TS local e manter o sistema em compasso.

Figura 4.35 - Confirmação da operação REQUEST

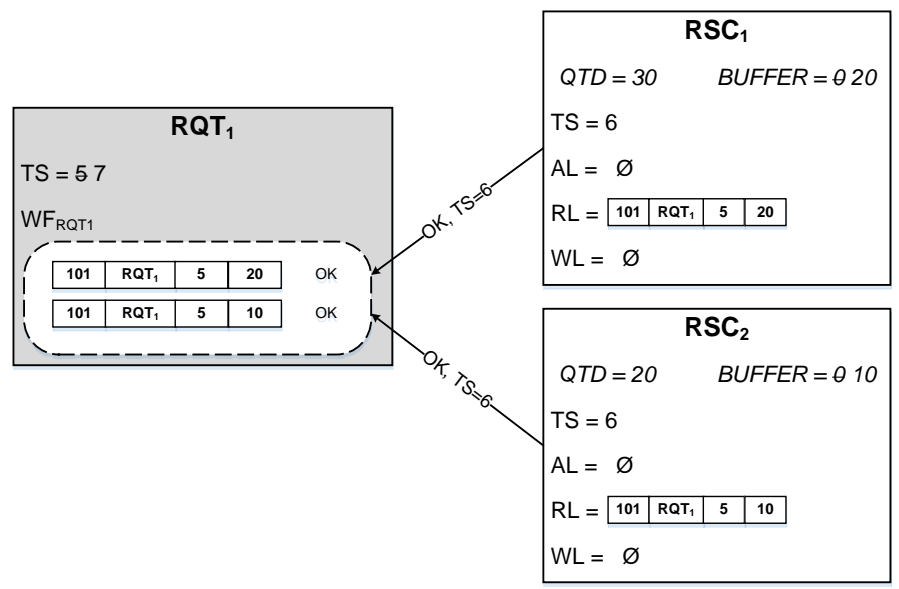

Fonte: O Autor (2015)

Como os requisitos até o instante foram atendidos, WFRQT1 confirma as requisições enviando requisições para a operação COMMIT, ilustrado na Figura 4.36. 
Ao receberem a requisição, $\mathrm{RSC}_{1}$ e $\mathrm{RSC}_{2}$, executam a operação COMMIT, inserindo as requisições na lista $C L$, e em seguida, alocando os recursos. Em $R C_{1}$ havia a quantidade total (QTD) de 30 passagens, foi consumido 20 passagens restando 10 passagens. Em $\mathrm{RSC}_{2}$ havia a quantidade total de 20 quartos e foram alocados 10, restando 10 quartos. Ambos os Servidores Recurso devem atualizar o valor do BUFFER, removendo os valores da reserva confirmada, e em seguida, retirando as requisições da lista $R L$.

Figura 4.36 - Confirmação de reserva com a operação COMMIT

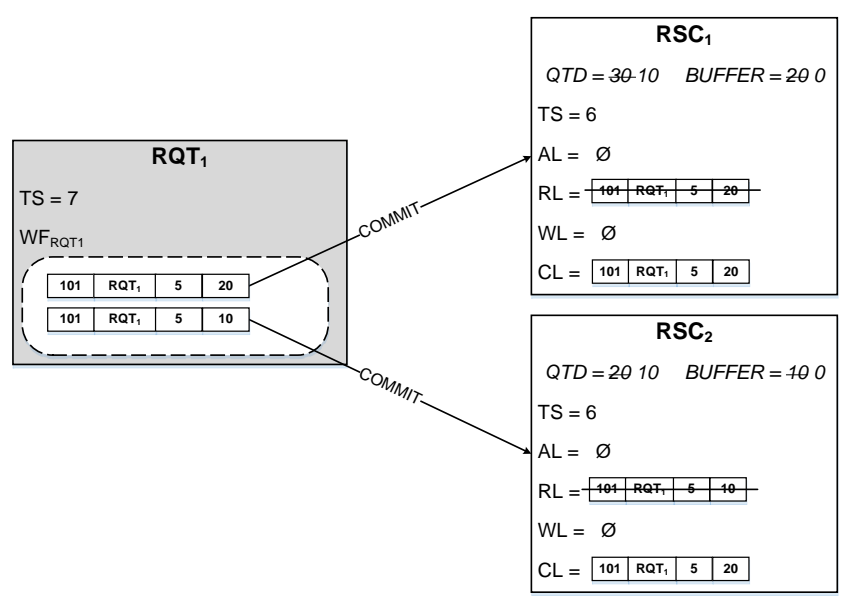

Fonte: O Autor (2015)

Após concluir a operação COMMIT, $\mathrm{RSC}_{1}$ e $\mathrm{RSC}_{2}$ enviam mensagens de resposta, conforme a Figura 4.37, indicando que a operação foi concluída com sucesso. Após alocar os recursos, RQT 1 solicita a operação de FINALIZE_COMMIT, que remove as requisições da lista $C L$, indicando que o processo de committing foi concluído, para que $W_{\mathrm{RQT} 1}$ encerre sua execução com êxito.

Figura 4.37 - Confirmação de execução

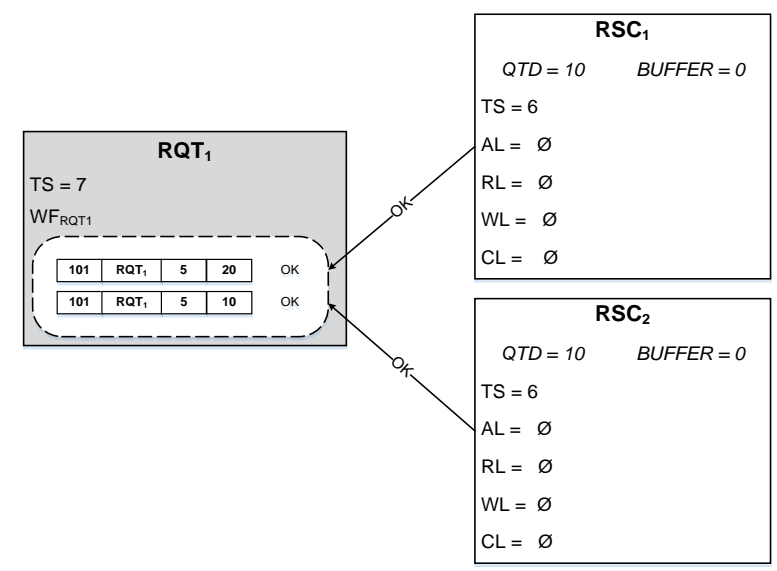

Fonte: O Autor (2015) 


\subsubsection{Exemplo llustrando o Problema de Deadlock e a Solução}

Para configurar a situação de deadlock será utilizado o exemplo da seção anterior (0) a qual apresenta dois serviços distintos: passagem aérea, que é disponibilizado no Servidor Recurso $\mathrm{RSC}_{1}$, e quarto de hotel, que é disponibilizado no Servidor Recurso $\mathrm{RSC}_{2}$. A Figura 4.38 ilustra este cenário, apresentando $\mathrm{RSC}_{1}$ possuindo 8 passagens disponíveis e $\mathrm{RSC}_{2}$ possuindo 4 quartos disponíveis. Haverá dois Servidores Requisição, em domínios diferentes, cada um executa o seu workflow respectivamente, $W F_{R Q T 1}$ e $W F_{R Q T 2}$, e a composição de cada workflow foi realizada conforme a conveniência de cada domínio, porém utilizam-se de serviços comuns, e a execução deve possuir comportamento transacional.

Figura 4.38 - Cenário básico para deadlock

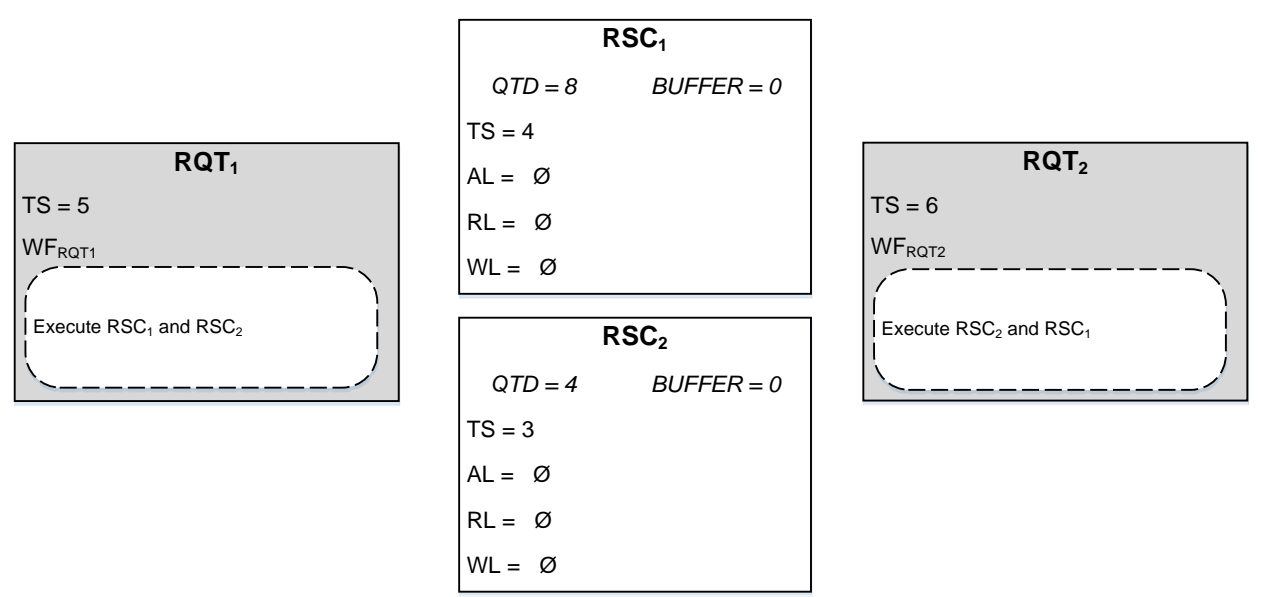

Fonte: O Autor (2015)

Em determinado instante, $\mathrm{RQT}_{1}$ executa seu workflow com uma requisição necessitando de 6 passagens aérea e 3 quartos de hotel e RQT 2 executa seu workflow com uma requisição solicitando 4 passagens e 2 quartos, e por questões como localização geográfica dos servidores ou tráfego na rede, a ordem das requisições chega aos Servidores Recurso conforme enumerado na Figura 4.39, nesta ordem; primeiro a requisição de $R Q T_{1}$ chegue em $R S C_{1}$, a requisição de $R Q T_{2}$ em $R S C_{2}$, a requisição de $R Q T_{1}$ em $R S C_{2}$ e a requisição de $R Q T_{2}$ em $R S C_{1}$. A lista $A L$ de $R S C_{1}$ terá a requisição de $R Q T_{1}$ e em seguida $R Q T_{2}$, a lista $A L$ de $R S C_{2}$ terá a requisição de $R Q T_{2}$ e em seguida $R Q T_{1}$. 
Figura 4.39 - Servidor Requisição disputando Servidor Recurso

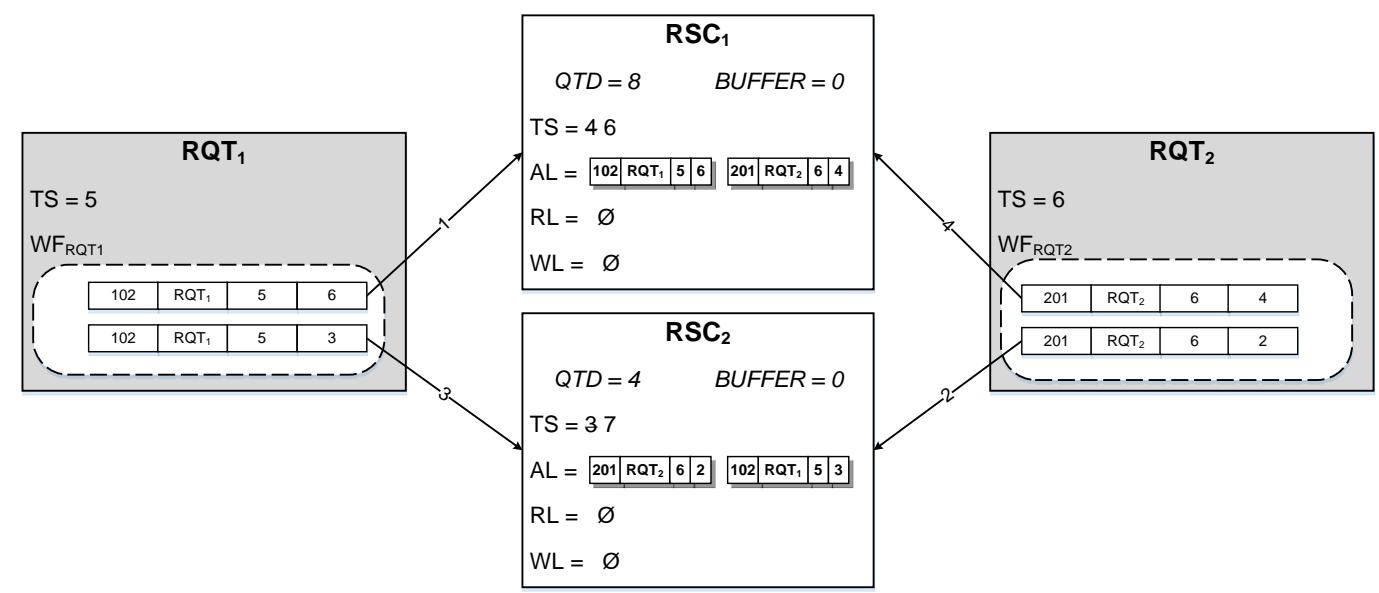

Fonte: O Autor (2015)

A requisição de $R Q T_{1}$ consegue realizar a reserva em $R S_{1}$ e a requisição de $R_{2}$ consegue realizar a reserva em $R_{2} C_{2}$, porém a requisição de $R Q T_{1}$ não consegue a reserva em $R \mathrm{RC}_{2}$ e $R Q T_{2}$ não consegue a reserva em $R Q T_{1}$, ilustrado na Figura 4.40, configurando a situação de deadlock entre a execução dos workflows.

Figura 4.40 - Condição de deadlock

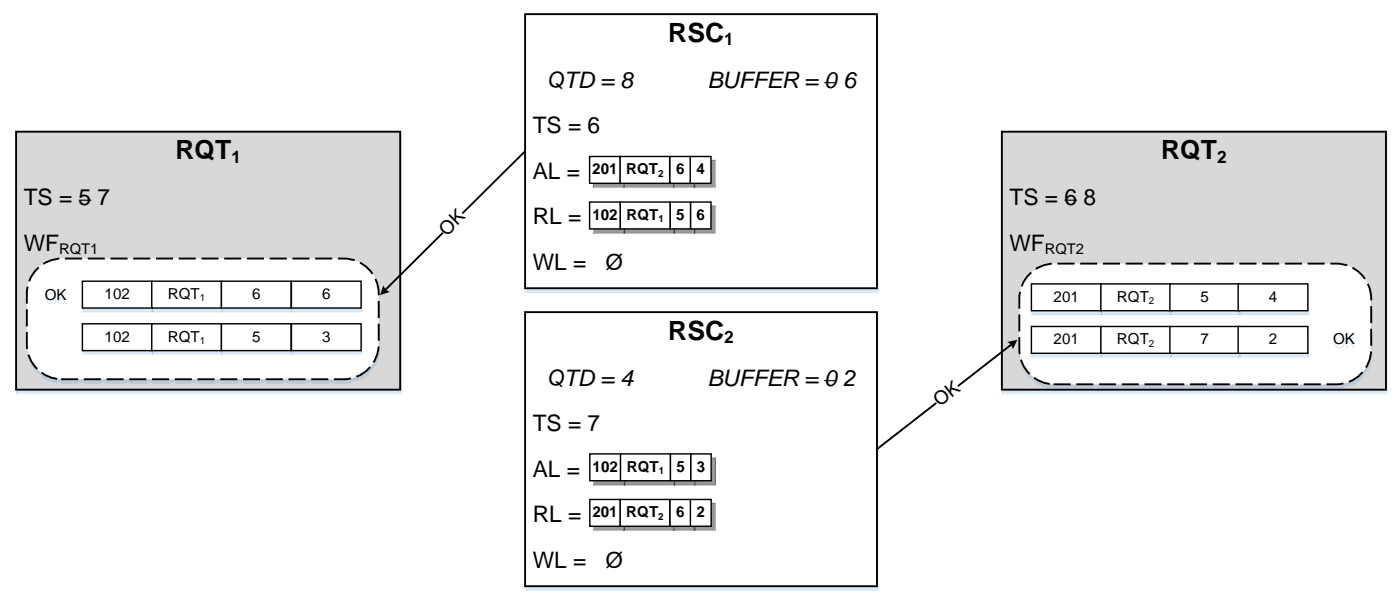

Fonte: O Autor (2015)

O critério de prioridade definido neste trabalho impede a situação de deadlock, privilegiando requisições com TS menor para o uso do recurso. O TS das requisições considera o instante anterior ao envio pelos RQT's, uma vez que considerar a ordem de recebimento das requisições, pelos RSC's, pode gerar distorções devido a dispersão geográfica dos servidores, e ao tráfego na rede interferirem no tempo que as requisições chegam em seus destinos. 
A Figura 4.41 ilustra como, utilizando o critério de prioridade, evita-se a situação de deadlock. $\mathrm{RSC}_{2}$ ao receber a requisição de $\mathrm{RQT}_{1}$ verifica que este possui prioridade maior em relação a requisição de $\mathrm{RQT}_{2}$ pelo valor do $\mathrm{TS}$, suspendendo a requisição de $R Q T_{2}$, colocando as duas requisições na lista WL, ordenadas pelo TS, permitindo que a requisição de $\mathrm{RQT}_{1}$, a primeira da lista WL, obtenha a reserva e seja transferida para a lista $R L$. As requisições de $R Q T_{2}$ não conseguem a reserva, porém aguardam, como primeira na lista $A L$ de $R S C_{1}$ e primeira na lista $W L$ de $R S_{2}$, a confirmação ou o cancelamento das requisições de RQT1. Deste modo, o workflow WFRQT1 pode prosseguir a execução, uma vez que ambas as requisições, a passagem aérea e o quarto de hotel, obtiveram a reserva dos recursos com sucesso.

Figura 4.41 - Eliminando situação de deadlock

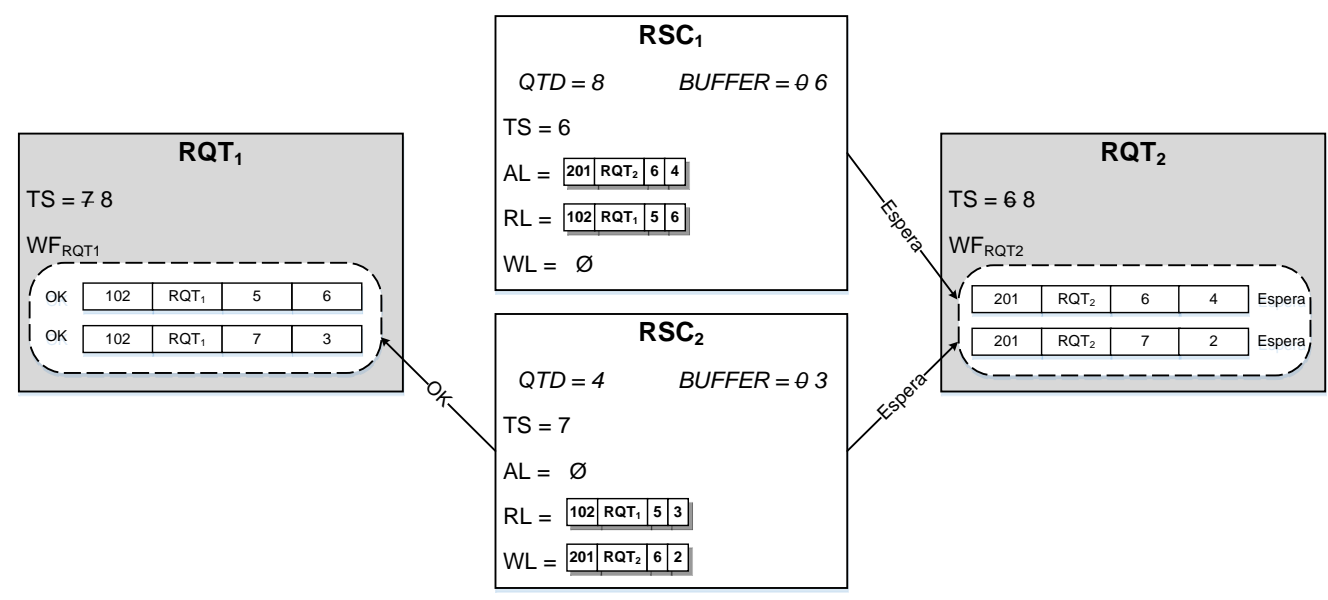

Fonte: O Autor (2015)

A requisição enviada por $\mathrm{RQT}_{2}$ havia obtido o recurso, reservando quarto de hotel, porém esta reserva foi temporariamente suspensa, uma vez que a requisição de $R Q T_{1}$ possui prioridade maior. Mas caso $R Q T_{1}$ desista dos recursos obtidos é $R Q T_{2}$ que possui o privilégio caso haja novas requisições com prioridade maior. A Figura 4.42 ilustra esta possibilidade onde $\mathrm{RQT}_{1}$ desiste das reservas obtidas. Com a operação ROLLBACK, os recursos reservados pelo RQT 1 são desfeitos, liberando os recursos e WFRQ1, encerrando sua execução. 
Figura 4.42 - Desistindo de reserva realizada
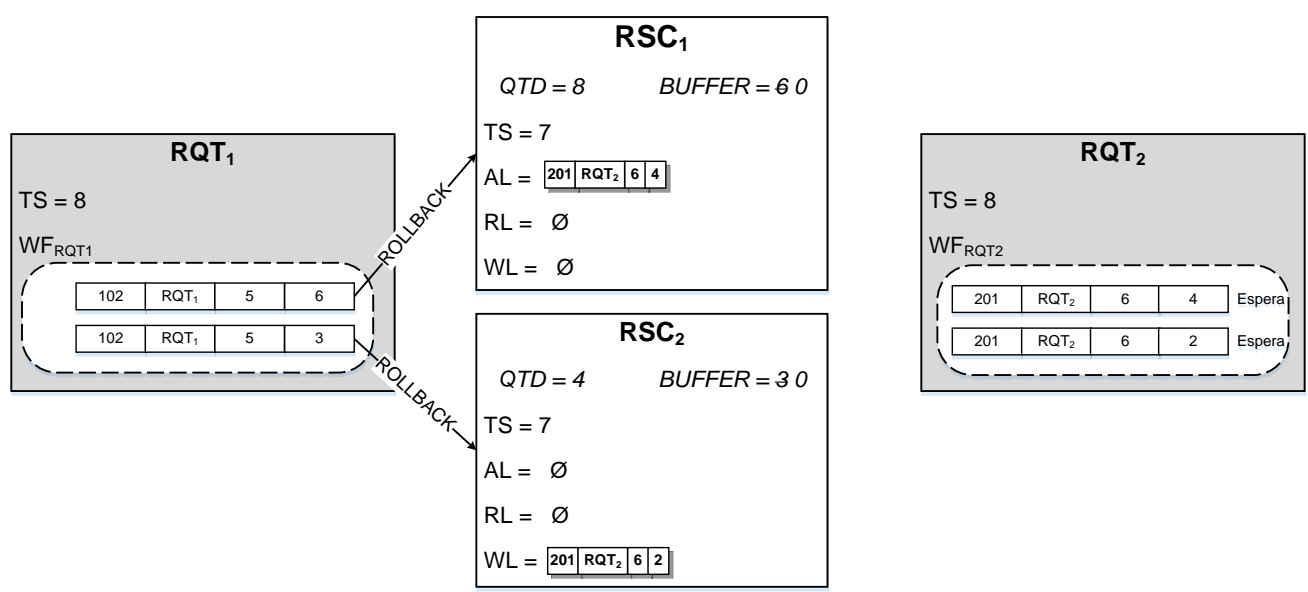

Fonte: O Autor (2015)

Assim sendo, $\mathrm{RQT}_{2}$ possui uma requisição em $\mathrm{RSC}_{2}$ que é o primeiro da lista $\mathrm{WL}$, e a requisição em $\mathrm{RSC}_{1}$ é o primeiro da lista $\mathrm{AL}$, as quais conseguem obter a reserva da passagem aérea e o quarto de hotel, retornando OK para que WFRQT2 prossiga sua execução. Esta situação está ilustrada na Figura 4.43.

Figura 4.43 - Recurso liberado de maneira justa
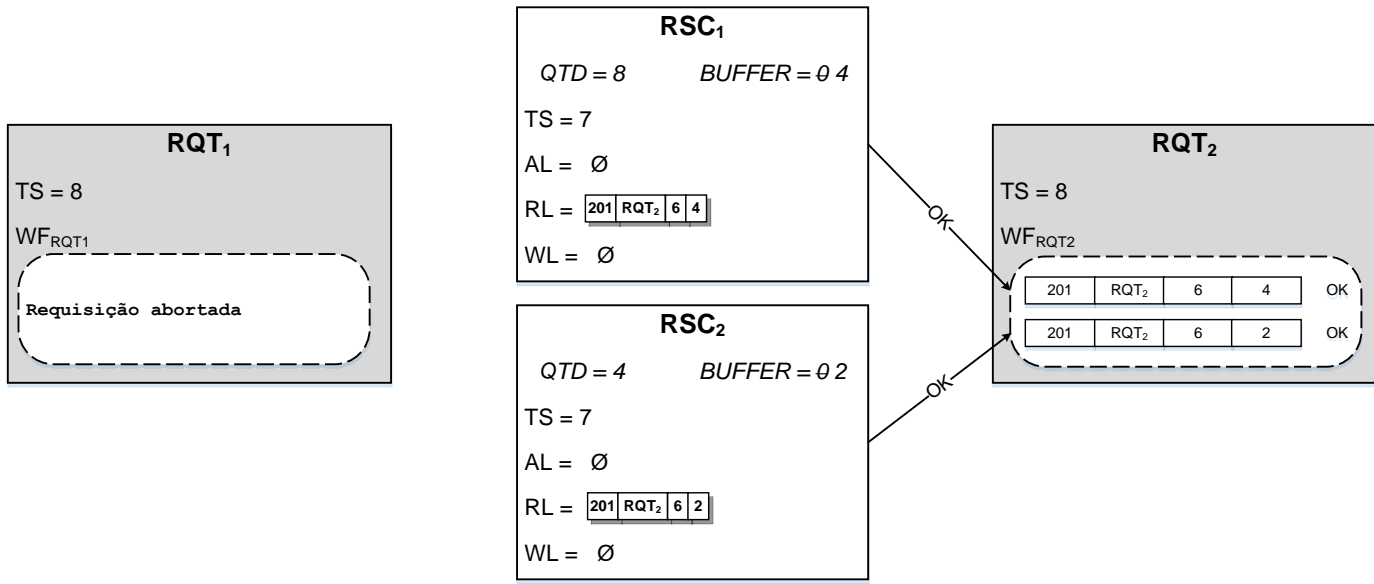

Fonte: O Autor (2015)

A abordagem em manter as requisições aguardando enquanto existe a possibilidade de obter o recurso permite uma execução justa entre os workflows, uma vez que esta estratégia evita com que a requisição tenha que realizar reenvio solicitando novamente o recurso. A política de reenvio pode gerar um atendimento injusto, já que durante o período de reenvio uma nova requisição, com prioridade menor, pode obter o recurso ou o reenvio permanecer infinitamente implicando em starvation. 
A Figura 4.44 ilustra $R Q T_{2}$ prosseguindo a execução de WFRQT2, confirmando as reservas que foram obtidas, onde antes de alocar o recurso a requisição é inserida na lista CL, indicando que WFRQT2 está em processo de committing, confirmando todas as reservas, e em seguida as requisições são retiradas da lista $R L$ onde os valores de QTD e BUFFER são atualizados

Figura 4.44 - Confirmando reserva realizada

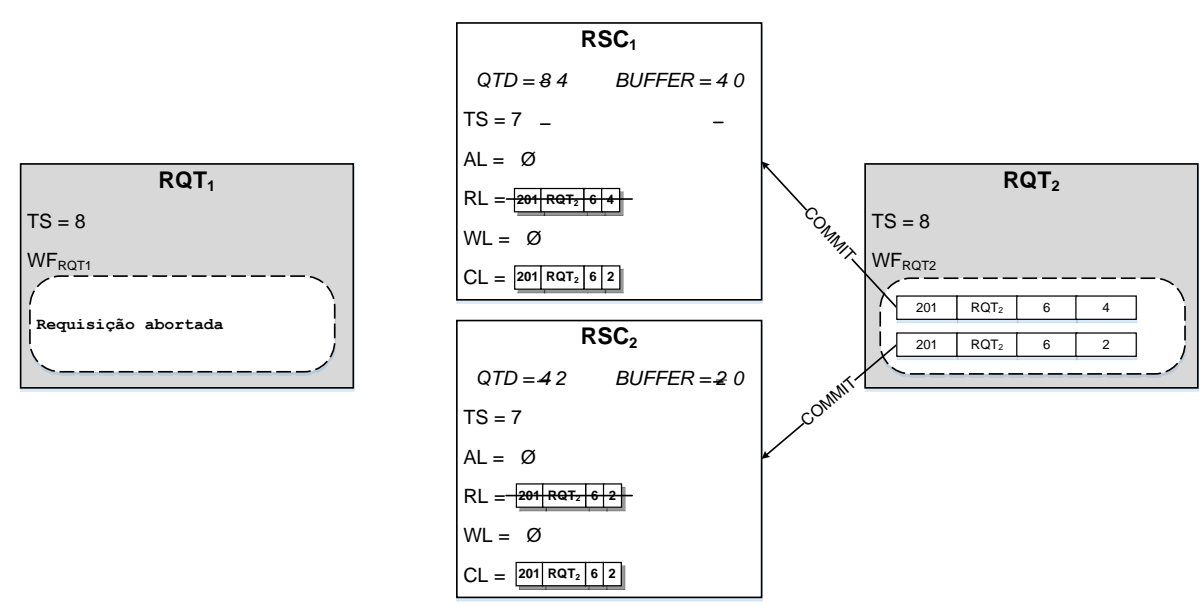

Fonte: O Autor (2015)

Após alocar os recursos, WFRQT2 solicita a operação de FINALIZE_COMMIT, a qual remove as requisições da lista $C L$, indicando que o processo de committing foi concluído sobre os recursos e WFRQT2 encerra sua execução com êxito. A Figura 4.45 ilustra a finalização do processo e WFRQT2, obtendo sucesso para obter todos os recursos.

Figura 4.45 - Encerrando workflow com êxito

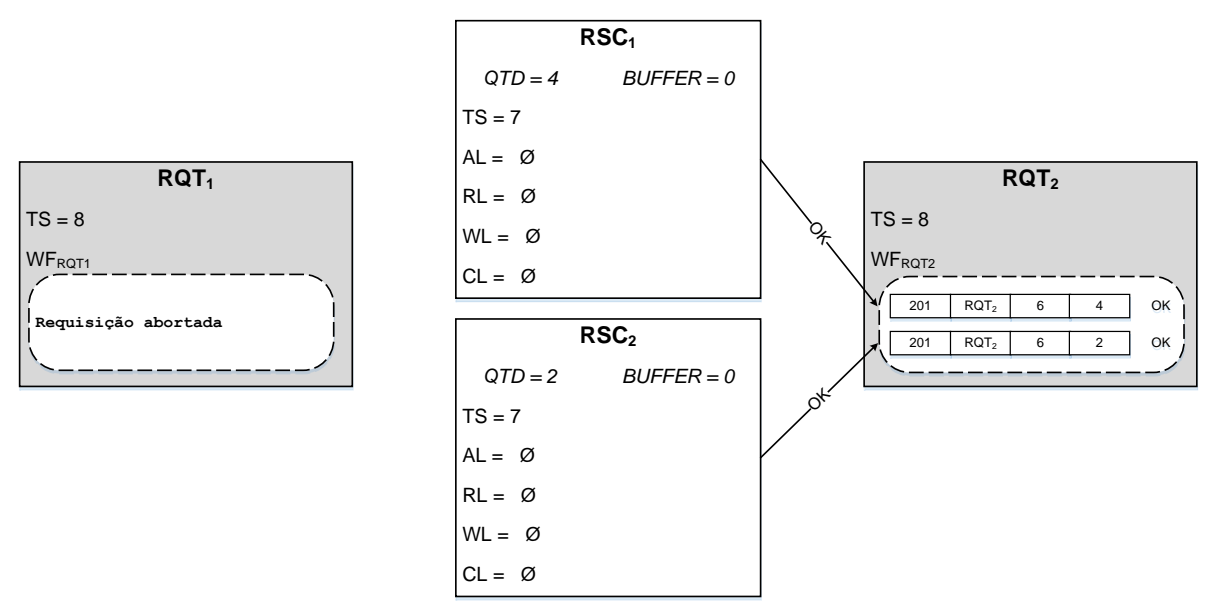

Fonte: O Autor (2015) 


\subsection{Demonstrações}

Nesta seção são apresentadas as demonstrações para o atendimento das requisições oriundas de domínio distinto com justiça, sem a ocorrência de deadlock e starvation.

A Figura 4.46 apresenta o diagrama de estados para o Servidor Requisição, o qual ilustra as situações ao longo da execução do workflow, reproduzindo o comportamento transacional para a composição de serviços. Ao receber nova requisição do cliente para executar o workflow, ilustrado pelo estado Recebe_Req, o Servidor Requisição segue para o estado Sinc_Relogio, realizando uma operação de consulta em todos os Servidores Recurso envolvidos, sincronizando os relógios. Após esta etapa, o Servidor Requisição gera as requisições individuais, com a mesma marca de tempo para cada uma delas.

Figura 4.46 - Diagrama de estados para o Servidor Requisição no atendimento a uma requisição

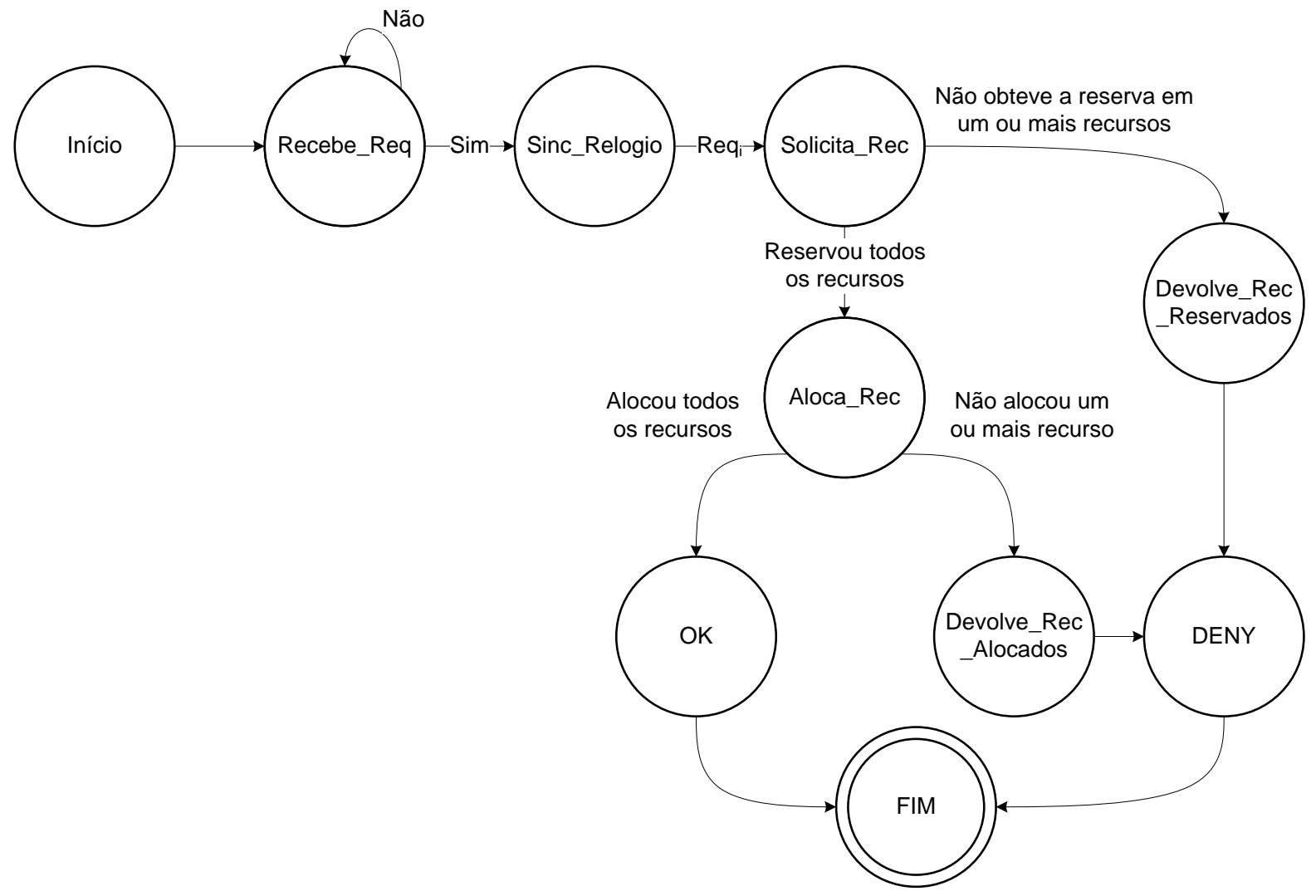

Fonte: O Autor (2016)

Em seguida, o Servidor Requisição vai para o estado Solicita_Rec, realizando o envio, para os respectivos Servidores Recurso, de cada uma das solicitações 
individuais para obter a reserva do recurso, consolidando o resultado de todas as requisições.

Caso o Servidor Requisição, no estado Solicita_Rec, tenha uma ou mais requisições que não obteve a reserva do recurso, o Servidor Requisição assume o estado Devolve_Rec_Reservados, onde as requisições que obtiveram reserva devolvem os recursos, seguindo para o estado $D E N Y$, indicando que a execução do workflow não conseguiu todos os recursos solicitados, e em seguida vai para o estado FIM, encerrando a execução da composição de serviços.

Caso contrário, quando todas as requisições conseguirem êxito na reserva do recurso, o Servidor Requisição vai para o estado Aloca_Rec, solicitando a alocação de cada uma das reservas obtidas. Caso todas solicitações aloquem os recursos, o Servidor Requisição assume o estado $O K$, indicando que a execução do workflow obteve todos os recursos solicitados, e em seguida vai para o estado FIM, encerrando a execução. Caso contrário, quando o Servidor Requisição, no estado Aloca_Rec, possui uma ou mais requisição que não conseguiram alocar o recurso, segue para o estado Devolve_Rec_Alocados, devolvendo os recursos que foram alocados, quando estava no estado Aloca_Rec, e seguindo para o estado DENY para indicar que a execução do workflow não obteve todos os recursos solicitados, para então atingir o estado FIM, encerrando a execução.

O Servidor Requisição, estando no estado Solicita_Rec, não obtendo a reserva a um recurso, caso haja uma quantidade suficiente para o seu atendimento de unidades do recurso que se encontram em reserva ou em processo de alocação, a requisição aguarda que estas sejam alocadas ou devolvidas. Não havendo uma nova solicitação para esta requisição, é mantida a sua prioridade sobre o recurso em relação a novas requisições, garantindo a justiça no atendimento e impedindo que a requisição entre em starvation.

Estando o Servidor Requisição, no estado Aloca_Rec, pode deparar com a situação onde uma requisição $R_{\text {eqi }}$ está alocando os recursos que lhe foram reservados, e em um instante anterior à confirmação da reserva de um dos recursos reservados, esta lhe foi retirada e atribuída a uma requisição $\mathrm{Req}_{\mathrm{j}}$, com prioridade maior. Neste caso, Reqi aguarda para obter novamente a reserva, com prioridade em relação a requisições com prioridade menor, garantindo a justiça de atendimento e impedindo uma situação de starvation. 
A política de aguardar, evita que Reqi necessite realizar reenvio de requisição, o qual poderia ocasionar atendimento injusto, uma vez que outra requisição Reqk, com prioridade menor, poderia obter o recurso no período em que Reqi realiza o reenvio. A abordagem de reenvio pode perdurar de maneira infinita, acarretando em uma situação de starvation.

O Servidor Recurso possui dois diagramas de estados para ilustrar o comportamento justo durante 0 atendimento a requisição. A Figura 4.47 ilustra o primeiro diagrama, apresentando as etapas envolvidas no atendimento do Servidor Recurso ao receber nova requisição, obedecendo o critério de prioridade, descrito na seção 4.2.2. Esta política favorece requisições que possuem o menor valor de TS, criando um critério para privilegiar o uso do recurso, entre todas as requisições, evitando deadlock.

Figura 4.47 - Diagrama de estados para o Servidor Recurso ao receber requisição

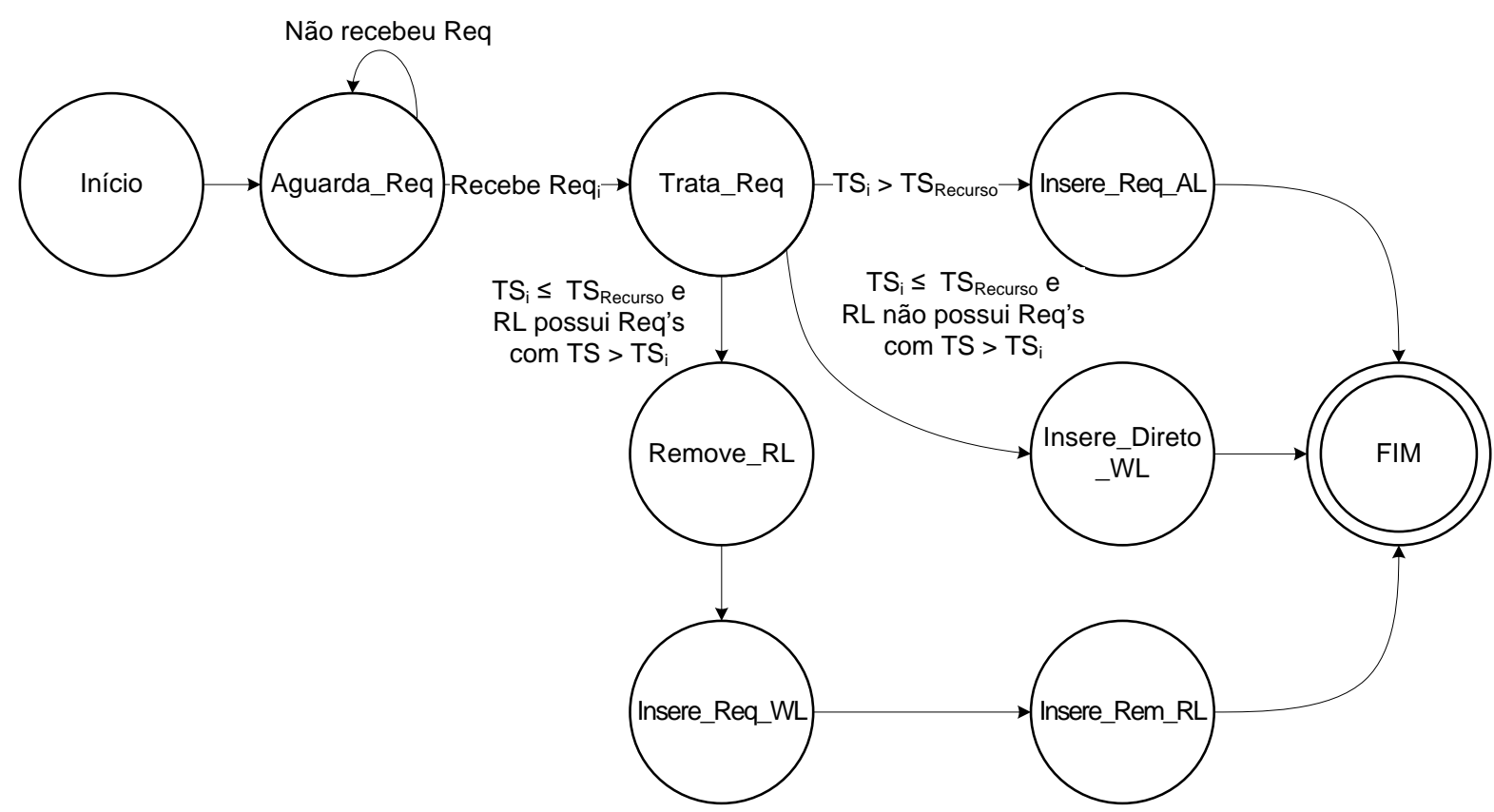

Fonte: O Autor (2016)

No diagrama da Figura 4.47, o Servidor Recurso espera nova requisição, representado pelo estado Aguarda_Req. Ao receber a requisição Reqi, segue para o estado Trata_Req, em que realiza o tratamento necessário para promover 0 atendimento, verificando o valor do TS da requisição. Existem três possibilidades em Trata_Req para o tratamento de Reqi:

1. O TS de Reqi é maior que o valor do relógio do Servidor Recurso. 
No estado Insere_Req_AL, Reqi é inserida na lista $A L$, e em seguida 0 Servidor Recurso vai para o estado FIM, indicando que Reqi foi recebida, e - Servidor Recurso fica liberado para reiniciar o processo para receber outras requisições. Esta possibilidade é empregada quando o valor do TS das requisições segue em ordem crescente e não há necessidade de reparo, realizando o atendimento habitual as requisições.

2. O TS de Reqi é menor/igual ao valor do relógio do Servidor Recurso e a lista $R L$ não possui requisições com TS maior que o TS de Reqi.

Esta situação indica que Reqi possui prioridade no atendimento, porém não há requisições, com menor prioridade, que reservaram o recurso, bastando privilegiar Reqi para utilizar o recurso em relação as requisições que estão na lista AL. Dessa maneira, o Servidor Recurso segue do estado Trata_Req para o estado Insere_Direto_WL, no qual Reqi é inserida imediatamente na lista WL, e em seguida segue para o estado FIM, indicando que a Reqi foi recebida pelo Servidor Recurso, e este fica liberado para reiniciar o processo para receber outras requisições. Esta possibilidade é aplicada para prover a justiça no atendimento, privilegiando a requisição que realizou a solicitação antes. Uma vez aplicada a prioridade, considerandose o TS de Reqi para as requisições de todos os recursos solicitados pela requisição $\mathrm{Req}_{i}$, há uma mesma ordem no atendimento das requisições para o uso do recurso em todos os Servidores Recurso, impedindo a situação de deadlock.

3. O TS de Reqi é menor/igual que o valor do relógio do Servidor Recurso e a lista $R L$ possui requisições com TS maior que o TS de Reqi.

Esta situação indica que houveram requisições com menor prioridade que Reqi que obtiveram a reserva do recurso. Então o Servidor Recurso segue do estado Trata_Req para o estado Remove_RL, reparando o atendimento as requisições, removendo as requisições com menor prioridade que $R q_{i}$ lista $R L$, desfazendo, em um primeiro instante, as reservas obtidas. Em seguida, no estado Insere_Req_WL o Servidor Recurso insere Reqi na lista WL e, na sequência, segue-se para o estado Insere_Rem_RL, inserindo as requisições que foram removidas da lista $R L$ na lista $W L$, considerando a prioridade entre as requisições, deixando as requisições ordenadas pelo 
TS na lista WL. Após este tratamento, o Servidor Recurso vai para o estado FIM, indicando que Reqi foi recebida, e ficando liberado para reiniciar o processo, recebendo outras requisições. Esta possibilidade é utilizada para refazer a ordem das reservas, privilegiando a requisição com maior prioridade, em que é considerado o TS de Reqi para as requisições de todos os recursos solicitados em Reqi, evitando-se a situação de deadlock.

A Figura 4.48 ilustra o segundo diagrama de estados do Servidor Recurso, apresentando as etapas envolvidas para verificar a disponibilidade do recurso para cada requisição.

No diagrama da Figura 4.47, o Servidor Recurso, no estado Trata_Req, ao detectar que há a necessidade de reparo a ordem de prioridade entre as requisições,

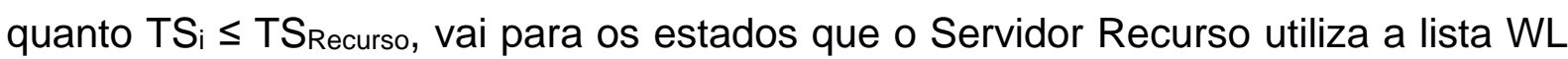
para estabelecer a ordem justa para o atendimento. Avançando no tratamento de prioridade entre requisições, o diagrama da Figura 4.48 ilustra como a abordagem permite corrigir a ordem para uso do recurso, onde as requisições da lista WL possuem prioridade em relação as requisições que estão na lista AL. Após o início do diagrama, o estado Verifica_WL providencia o uso do recurso para as requisições da lista WL, enquanto houver elementos na lista. Caso todas as requisições da lista WL sejam atendidas, deixando-a vazia, o Servidor Recurso, no estado Verifica_WL, vai para o estado Verifica_ $A L$, providenciando o uso do recurso para as requisições da lista $A L$.

O Servidor Recurso, para permitir que as requisições possam utilizar o recurso, manipula as listas $\mathrm{WL}$ e $A L$, considerando os seguintes cenários possíveis:

- a lista WL possuir requisição;

- a lista WL não possuir requisição e a lista $A L$ possuir;

- a lista WL e AL não possuírem requisições. 
Figura 4.48 - Diagrama de estados para o Servidor Recurso ao verificar disponibilidade

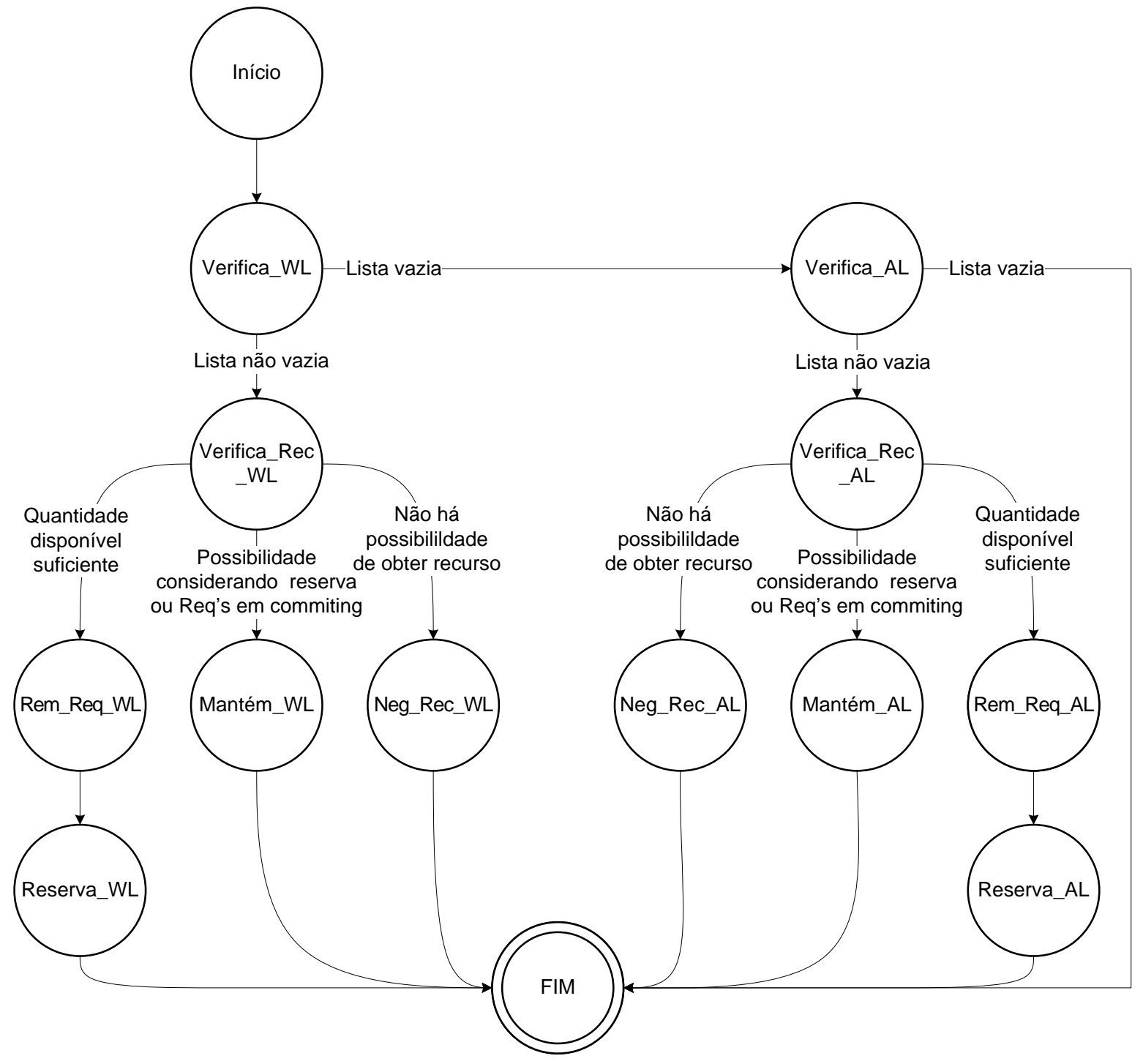

Fonte: O Autor (2016)

No primeiro cenário, quando a lista WL possui requisição, o Servidor Recurso, no estado Verifica_WL, indica que há elemento na lista WL, seguindo para o estado Verifica_Rec_WL, onde a primeira requisição da lista WL é atendida. Então é verificado a disponibilidade do recurso considerando as seguintes possibilidades:

I. Caso haja quantidade de recurso suficiente para atender a requisição.

O Servidor Recurso segue do estado Verifica_Rec_WL para o estado Rem_Req_WL, removendo a primeira requisição da lista WL. Em seguida vai para o estado Reserva_WL, inserindo a requisição removida da lista WL na lista $R L$, indicando que a reserva solicitada pela requisição foi concluída com sucesso. Finalizando o procedimento, o Servidor Recurso vai para o 
estado FIM, indicando que a verificação de disponibilidade foi concluída, ficando liberando para reiniciar o procedimento. Esta abordagem é utilizada para que as requisições da lista WL realizem a reserva do recurso.

II. Caso não haja quantidade de recurso suficiente, mesmo considerando a quantidade reservada e a quantidade alocada pelas requisições que estão em processo de committing.

O Servidor Recurso, no estado Verifica_Rec_WL, prossegue para o estado Neg_Rec_WL, no qual irá remover a primeira requisição da lista WL, negando o recurso. Em seguida vai para o estado FIM, indicando que a verificação de disponibilidade foi concluída, ficando liberando para reiniciar o procedimento. Esta abordagem é aplicada quando não há possibilidades de obter recurso para a primeira requisição da lista WL.

III. Caso não haja quantidade de recurso suficiente, mas existe a possibilidade em obter o recurso, considerando a quantidade reservada e a quantidade alocada pelas requisições que estão em processo de committing.

Para esta circunstância o Servidor Recurso, no estado Verifica_Rec_WL, segue para o estado Mantém_WL, preservando a requisição na primeira posição da lista WL, deixando-a aguardar, com prioridade em relação a novas requisições. A situação de espera perdura enquanto requisições que obtiveram reserva ou as que aguardam a conclusão do workflow para as requisições que não finalizaram a alocação sobre o recurso. Caso estas requisições finalizem suas operações permite que o Servidor Recurso, no estado Verifica_Rec_WL, ofereça, para a primeira requisição da lista WL, a situação I ou II desta lista de possibilidades, seguindo para o estado Rem_Req_WL quando há recurso disponível ou para o estado Neg_Rec_WL quando não há recurso disponível. Esta abordagem é empregada para evitar que as requisições da lista $W L$ necessitem realizar o reenvio de requisição. A política em realizar reenvio de requisição pode configurar em atendimento injusto, uma vez que outra requisição, com menor prioridade, pode obter o recurso durante o período de reenvio, ou o processo de reenvio persistir infinitamente, implicando em starvation. 
No segundo cenário, quando a lista WL não possui requisição e a lista $A L$ possui, o Servidor Recurso, no estado Verifica_WL, constata que não há requisição na lista WL, seguindo para o estado Verifica_ $A L$, verificando que há requisição na lista AL. Desse modo, o Servidor Recurso segue para o estado Verifica_Rec_AL, verificando a disponibilidade do recurso, considerando os mesmos critérios aplicados nas requisições da lista $W L$, para a primeira requisição da lista $A L$. A verificação é realizada considerando as seguintes possibilidades:

A. Caso haja quantidade de recurso suficiente para atender a requisição.

O Servidor Recurso, no estado Verifica_Rec_AL, segue para o estado Rem_Req_AL, removendo a primeira requisição da lista $A L$. Em seguida, realiza a reserva para a requisição removida da lista $A L$, inserindo-a na lista $\mathrm{RL}$, indicando que a reserva foi concluída com sucesso. Na sequência vai para o estado $F I M$, indicando que a verificação de disponibilidade foi concluída liberando o Servidor Recurso para reiniciar o procedimento. Esta abordagem é utilizada para que as requisições da lista $A L$ realizem a reserva do recurso.

B. Caso não haja quantidade suficiente de recurso, mesmo considerando a quantidade reservada e a quantidade alocada pelas requisições que estão em processo de committing.

O Servidor Recurso, no estado Verifica_Rec_AL, segue para o estado Neg_Rec_AL, removendo a primeira requisição da lista $A L$ e negando o recurso. Em seguida, vai para o estado $F I M$, indicando que o procedimento para verificar disponibilidade de recurso foi concluído, liberando o Servidor Recurso para reiniciar o procedimento. Esta abordagem é aplicada quando não há possibilidade, para a primeira requisição da lista $A L$, de obter 0 recurso.

C. Caso não haja a quantidade suficiente de recurso, porém existe a possibilidade de obter o recurso, considerando a quantidade reservada e a quantidade alocada pelas requisições que estão no processo de committing.

O Servidor Recurso, no estado Verifica_Rec_AL, segue para o estado Mantém_AL, preservando a primeira requisição da lista $A L$, deixando a 
requisição aguardar, com prioridade em relação a novas requisições. A situação de espera persiste enquanto requisições que obtiveram reserva ou requisições que aguardam a conclusão do workflow, finalizem suas operações sobre o recurso. Caso estas requisições finalizem suas operações permite ao Servidor Recurso, no estado Verifica_Rec_AL, oferecer, para a primeira requisição da lista $A L$, a situação $A$ ou $B$ desta lista de possibilidade, seguindo para o estado Rem_Req_AL quando há recurso suficiente ou seguindo para o estado Neg_Rec_AL quando não há recurso suficiente. Esta abordagem é empregada para que as requisições da lista $A L$ não realizem reenvio, o qual pode implicar em um atendimento injusto ou a situação de starvation através de reenvio infinito.

No terceiro cenário, quando a lista $W L$ e a lista $A L$ não possuem requisições, o Servidor Recurso, no estado Verifica_WL, constata que a lista WL está vazia, seguindo para o estado Verifica $A L$, constatando que a lista $A L$ está vazia. Finalizando este cenário, o Servidor Recurso segue para o estado FIM, indicando que o procedimento para verificar a disponibilidade de recurso foi concluído, ficando liberado para reiniciar o procedimento.

\subsubsection{DEMONSTRAÇÃo dA JUSTIÇA NO ATENDIMENTO}

Sejam as requisições $R E Q_{1}$ e $R E Q_{2}$, tal que $R E Q_{1}$ foi solicitada em $T_{R E Q 1}$ e $R E Q_{2}$ em $T_{R E Q 2}$, sendo que $T_{R E Q 1<T} T_{R E Q 2}$. Seja também um site $S_{1}$, possuindo os recursos que são solicitados por $R E Q_{1}$ e $R E Q_{2}$, possuindo valor de tempo $T_{\text {s1 }}$, onde TS1<TREQ1

Então, aplicando-se as estratégias propostas para o atendimento com justiça entre as requisições, $R E Q_{1}$ terá prioridade no atendimento em relação a $R E Q_{2}$.

\section{Prova:}

Caso $R E Q_{1}$ seja recebida e logo após $R E Q_{2}$ seja recebida, cada uma das requisições serão atendidas e inseridas na lista $A L$ (linhas 1 a 3 da Figura 4.27). Caso haja a quantidade disponível suficiente para cada requisição, estas conseguem efetuar reserva e são inseridas na lista RL (linhas 17 a 19 da Figura 4.22).

Caso $R E Q_{2}$ seja recebida antes de $R E Q_{1}$, e se houver a quantidade disponível de recursos, o procedimento descrito no parágrafo anterior será realizado, efetuando- 
se a reserva e inserindo-a na lista $R L$. Porém, ao receber $R E Q_{1}$ após $R E Q_{2}, 0$ atendimento não será realizado através do procedimento regular, uma vez que a condição apresentada na linha 1 da Figura 4.27 será falsa, pois TREQ1 é menor que $T_{R E Q 2}$, ou seja, $R E Q_{1}$ foi solicitada em um tempo anterior ao de $R E Q_{2}$.

Então, uma segunda condição (linha 5 da Figura 4.27) é analisada. Caso haja requisições na lista $R L$ com tempos maiores que $R E Q_{1}$, estas são retiradas da lista $R L, R E Q_{1}$ é inserida na lista $W L$ e em seguida as requisições com $T$ maiores são inseridas na lista WL (linhas 6 a 10 da Figura 4.27). Este procedimento faz com que $R E Q_{1}$ e $R E Q_{2}$ sejam ordenadas de maneira crescente na lista WL, através do valor $T$ de cada requisição, organizando a prioridade no atendimento.

Dessa maneira, REQ1 será atendida antes de REQ2 (linhas 5 a 7 da Figura 4.22), sendo removida da lista $W L$ e inserida na lista $R L$, obtendo a reserva para a solicitação.

\section{Restrição:}

Seja um cenário em que uma $R E Q_{2}$ é solicitada em um instante $T_{R E Q 2}$ e $R E Q_{1}$

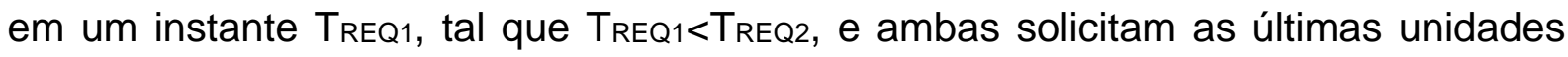
disponíveis de recurso em um site $S_{1}$. Caso $S_{1}$ receba a solicitação $R E Q_{2}$ e efetue a alocação das unidades disponíveis, antes da chegada da solicitação REQ1, REQ1 não será atendida.

\subsubsection{DemonstraçÃo da NÃo OcorRÊNCIA dE DEADLOCK}

Seja uma requisição $R E Q_{1}$ composta de duas solicitações, $R E Q_{1}$ s1 $_{\text {e }} R E Q_{1}$, e uma requisição $R E Q_{2}$ composta de duas solicitações, $R E Q_{2 S 1}$ e $R E Q_{2 S 2}$, tal que REQ1 é solicitada em $T_{R E Q 1}$ e REQ2 é solicitada em $T_{R E Q 2}$, e $T_{R E Q 1}<T_{R E Q 2}$. Seja também um site $S_{1}$ e um site $S_{2}$, cada um possuindo recursos distintos, bem como, $S_{1}$ possui representação de tempo $T_{s 1}$ e $S_{2}$ possui $T_{s 2}$, onde $T_{s 1<} T_{R E Q 1}$ e $T_{S 2}<T_{R E Q 1}$.

Caso $R E Q_{1}$ e $R E Q_{2}$ façam requisições simultaneamente, onde $R E Q_{1}$, por meio de $R E Q_{1}$ 1, obtém o recurso em $S_{1}$ e $R E Q_{2}$, por meio de $R E Q_{2}$, obtém o recurso em $\mathrm{S}_{2}$, fica configurada a situação de deadlock, uma vez que REQ1s2 não obtém o recurso em $S_{2}$, em razão de que foi alocada para $R E Q_{2 S 2}$ e $R E Q_{2 S 1}$ não obtém o recurso em $S_{1}$, em razão de que foi alocada para $R E Q_{1} s_{1}$. Esta situação impede que $R E Q_{1}$ e $R E Q_{2}$ 
concluam suas solicitações, uma vez que cada requisição necessita que suas duas solicitações sejam atendidas.

Então, aplicando-se as estratégias proposta, $R E Q_{1}$ terá prioridade no atendimento em relação a $R E Q_{2}$, possuindo o privilégio de consumir os recursos, impedindo a situação de deadlock.

\section{Prova:}

Considere um cenário em que REQ1 e $R E Q_{2}$ façam requisições simultaneamente. Caso em $S_{1}, R E Q_{1 S 1}$ é recebida antes de $R E Q_{2} s_{1}$, então $R E Q_{1} s_{1}$ será atendida e inserida na lista $A L$, considerando que o valor TREQ1 é maior que TS1 (linhas 1 a 3 da Figura 4.27). Verifica-se se há quantidade disponível (QTD - BUFFER) para $R E Q_{151}$. Caso a quantidade disponível seja suficiente, a quantidade solicitada por $R E Q_{1 s 1}$ é incrementada no BUFFER de $S_{1}$ e $R E Q_{1 S 1}$ é inserida na lista $R L$ (linhas 17 a 19 da Figura 4.22), caso contrário verifica-se se a quantidade total é suficiente. Caso seja suficiente, aguarda pela disponibilidade do recurso (linhas 21 a 25 da Figura 4.22) e caso não haja quantidade suficiente a requisição é removida da lista $A L$ e terá o recurso negado (linhas 26 e 27 da Figura 4.22).

Prosseguindo em $S_{1}, R E Q_{2 S 1}$ será atendida e inserida na lista $A L$, considerando que o valor TREQ2 é maior que Ts1 (linhas 1 a 3 da Figura 4.27). Verifica-se que há quantidade disponível (QTD - BUFFER), porém REQ1s1 obteve o recurso disponível em $S_{1}$, mas ainda não alocou, uma vez que a quantidade solicitada foi alocada em BUFFER (linha 18 da Figura 4.22). Porém, neste instante, ainda há a possibilidade de REQ2s1 obter o recurso uma vez que o recurso ainda não foi alocado. Então verifica se a quantidade total (QTD) é suficiente para $R E Q_{251}$. Caso seja suficiente, $R E Q_{2 s 1}$ aguarda na lista AL (linhas 21 e 22 da Figura 4.22). Caso contrário, verifica se a quantidade alocada pelas requisições que estão no processo de committing é suficiente para atender $R E Q_{251}$. Caso seja suficiente, $R E Q_{2 S 1}$ aguarda na lista $A L$ (linhas 24 e 25 da Figura 4.22). Caso contrário, remove REQ2S1 da lista $A L$ e nega o recurso (linhas 26 e 27 da Figura 4.22).

Para que REQ 1 s1 aloque a quantidade obtida em $S_{1}$, necessita da indicação que $R E Q_{1 s 2}$ obteve sucesso ao solicitar o recurso em $S_{2}$.

Em $S_{2}, R E Q_{2}$ 2 é recebida antes de REQ1S1. Então $R E Q_{2}$ 2 é atendida, e inserida na lista $A L$, considerando que o valor TREQ2 é maior que Ts2 (linhas 1 a 3 da 
Figura 4.27). Verifica-se se há quantidade disponível (QTD - BUFFER) para REQ2s2. Caso seja suficiente a quantidade solicitada por $R E Q_{2 S 2}$, o BUFFER de $S_{2}$ é incrementado e REQ2s2 é inserida na lista $R L$ (linhas 17 a 19 da Figura 4.22), caso contrário verifica-se se há quantidade total (QTD) é suficiente. Caso seja suficiente, aguarda pela disponibilidade do recurso (linhas 20 a 22 da Figura 4.22). Caso contrário, verifica se a quantidade alocada pelas requisições que estão no processo de committing é suficiente para atender REQ2s2. Caso seja suficiente, $R E Q_{252}$ aguarda na lista AL (linhas 24 e 25 da Figura 4.22). Caso contrário, remove REQ2s2 da lista $A L$ e nega o recurso (linhas 26 e 27 da Figura 4.22).

Prosseguindo em $\mathrm{S}_{2}, \mathrm{REQ} 1 \mathrm{~s} 2$ será atendida. Neste instante $\mathrm{T}_{\mathrm{REQ} 1}$ é menor que Ts2, e a condição apresentada na linha 1 da Figura 4.27 será falsa. Então verifica-se se na lista $R L$ há requisições com $T$ maior que $T_{R E Q 1}$, e será constatado que REQ2s2 foi atendido obtendo a pré-alocação do recurso (linha 5 da Figura 4.27). Como REQ2s2 possui TREQ2 maior que $T_{R E Q 1}, R E Q_{2 S 2}$ é removida da lista $R L$, o valor pré-alocado é desfeito, decrementando o BUFFER em $\mathrm{S}_{2}$ com a quantidade solicitada por REQ $2 \mathrm{~S}_{2}$, inserindo $R E Q_{152}$ e em seguida $R E Q_{252}$ na lista WL (linhas 6 a 11 da Figura 4.27). Verifica-se se há quantidade disponível (QTD - BUFFER) para REQ1s2. Caso haja quantidade suficiente a quantidade solicitada por REQ1s2 é incrementada no BUFFER de $S_{2}$ e $R E Q_{1}$ s2 é inserida na lista $R L$ (linhas 5 a 7 da Figura 4.22) obtendo a préalocação do recurso. Em seguida $R E Q_{252}$ será atendida novamente, verificando-se se há quantidade disponível (QTD - BUFFER) suficiente para a sua solicitação (linha 5 da Figura 4.22). Porém, REQ1s2 obteve o recurso em $S_{2}$ mas ainda não confirmou esta solicitação, indicando a possibilidade de REQ2s2 obter o recurso novamente. Então verifica-se se a quantidade total (QTD) é suficiente para REQ2s2. Caso seja suficiente, REQ2s2 aguarda na lista WL (linhas 8 a 10 da Figura 4.22). Caso contrário, verifica se a quantidade alocada pelas requisições que estão no processo de committing é suficiente. Caso seja suficiente REQ2s2 aguarda na lista WL (linhas 11 a 13 da Figura 4.22). Caso contrário, remove $R E Q_{2 s 2}$ da lista $W L$ e nega o recurso (linhas 14 e 15 da Figura 4.22).

Concluindo, REQ1 confirma as solicitações realizadas, confirmando a solicitação $R E Q_{1 S 1}$ em $S_{1}$ e REQ 1 s2 em $S_{2}$ através do algoritmo da Figura 4.25, alocando os recursos obtidos. 


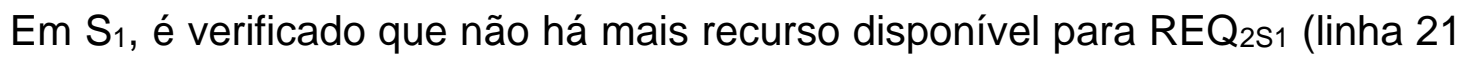
da Figura 4.22), também não há requisições no processo de committing (linha 24 da Figura 4.22) e terá a solicitação negada (linha 27 da Figura 4.22). Em S2, também é verificado que não há mais recurso disponível para REQ2S2 (linha 9 da Figura 4.22), não há requisições no processo de committing (linha 12 da Figura 4.22)e REQ2s2 terá a solicitação negada (linha 15 da Figura 4.22).

Desta maneira, garante-se a não ocorrência de deadlock, e as solicitações realizadas por $R E Q_{1}$ terão prioridade em relação as solicitações de $R E Q_{2}$.

\subsubsection{DEMONSTRAÇÃo da NÃo OCORRÊNCIA de StaRVATION}

Seja uma requisição $R E Q_{i}$ que solicita no instante $T_{R E Q i}$, que requisita no recurso $\mathrm{S}$, onde $\mathrm{Ts}$ é a marca de tempo do recurso.

Então, tem-se que, aplicando-se as estratégias propostas não ocorrerá uma situação de starvation.

\section{Prova:}

Serão considerados os cenários possíveis em que possam ser geradas situações de starvation:

1 o cenário - TREQi $>$ Ts e não há quantidade de unidades do recurso disponíveis, mas há uma quantidade de unidades já pré-alocadas (reservadas) para requisições com prioridades maiores do que REQi suficiente para o atendimento.

Neste caso, REQi é inserida na lista AL (linhas 1 a 3 da Figura 4.27) e se mantem aguardando a disponibilidade do recurso na lista AL (linhas 20 a 22 da Figura 4.22) sem a necessidade de realizar reenvio, com prioridade em relação a novas requisições realizadas em instantes $T>T_{\text {REQi, dado que as requisições são inseridas }}$ em ordem crescente na lista AL, conforme a condição da linha 1 na Figura 4.27.

20 cenário - TREQi $>$ Ts e há quantidade de unidades do recurso disponíveis e suficiente para o atendimento de REQ.

Neste caso, REQi pré-aloca o recurso e é inserida na lista RL (linhas 17 a 19 da Figura 4.22). Caso uma outra requisição $R E Q_{j}$ chegue no servidor de recurso $S$, realizada em instante $T_{R E Q j}$, onde $T_{R E Q j}<T_{R E Q i}$ e $T_{R E Q j}<T_{S}$, a condição da linha 1 na Figura 4.27 será falsa, então retira-se as requisições com T maior que $T_{R E Q j}$ da lista $R L$, atualiza o valor de BUFFER com as requisições retiradas da lista $R L$ e as 
requisições são inseridas na ordem crescente na lista WL (linhas 5 a 10 da Figura 4.27). Assim $R E Q_{j}$ tem prioridade em relação a $R E Q_{i}$, uma vez que $T_{R E Q j}<T_{R E Q i}$, então verifica-se se a quantidade disponível é suficiente para a quantidade de REQj. Caso seja suficiente, $R E Q_{j}$ pré-aloca o recurso incrementando BUFFER com a sua quantidade solicitada e inserida na lista RL (linhas 5 a 7 da Figura 4.22). Em seguida, esta mesma verificação é realizada para $R E Q_{i}$, onde caso não haja quantidade disponível, verifica-se se a quantidade total é suficiente para REQ. Caso não seja suficiente, mas há quantidade pré-alocada suficiente para o atendimento, REQi não necessita realizar a requisição novamente, uma vez que a requisição é suspensa, necessitando aguardar a disponibilidade do recurso, mantendo-se na lista WL (linhas 8 a 10 da Figura 4.22).

Caso outra requisição REQk solicite em instante $T_{R E Q k}$, onde $T_{R E Q k}>T_{s}, R E Q_{k}$ será inserida na lista $A L$, porém $R E Q_{k}$ será atendida somente após $R E Q_{i}$, uma vez que a lista WL possui prioridade em relação a lista $A L$, garantindo o privilégio de $R E Q_{i}$ (linha 4 e linha 16 da Figura 4.22).

Então, dadas essas considerações, pode-se concluir que se tem a garantia da não ocorrência de starvation.

\subsection{Considerações Sobre a Proposta}

Neste capítulo foram apresentadas as estratégias elaboradas para permitir a execução de workflows oriundos de múltiplos domínios, os quais realizam requisições em serviços providos por servidores distintos. Os workflows são executados de forma transacional, processando operações de maneira justa e impedindo situações de deadlock e starvation, sem a necessidade de um coordenador centralizador para realizar este gerenciamento.

Alguns autores recorrem a diferentes estratégias para resolver esta situação. Abortar a execução de um dos workflows (TURKER, HALLER, et al., 2005) quando a situação de deadlock é detectada, elegendo de maneira aleatória qual dos workflows irá ceder o recurso e reiniciar sua execução para que o outro workflow possa prosseguir a execução, pode resolver a situação de deadlock, porém não é um critério justo. A abordagem de desistir dos recursos obtidos caso não consiga obter todos os recursos da composição de serviço, realizando reenvio das requisições até que 
consigam todos os recursos (MACIEL e HIRATA, 2010), impede a situação de deadlock, porém pode permanecer em reenvio indefinido, configurando uma situação de starvation.

Considerar o instante proposto mantém a mesma ordem de prioridade para todos os pedidos de recursos, presente na composição da requisição. Isto impede que haja situações de deadlock e também mantém a justiça, uma vez que não há influência de fatores como a distância geográfica entre os servidores e o tráfego na rede.

Desse modo este trabalho define critérios para impedir deadlock e starvation entre workflows de diversos servidores através de uma execução justa das requisições nos múltiplos domínios. As estratégias adotadas mantêm a autonomia entre os serviços, uma vez que os servidores não necessitam de conhecimento prévio das entidades envolvidas, já que o protocolo fornece as informações necessárias para que tomem as decisões isoladamente. 


\section{SISTEMA PARA EXECUÇÃO JUSTA DE COMPOSIÇÃO DE SERVIÇOS REMOTOS ORIUNDOS DE DOMÍNIO DISTINTO}

Um sistema para prover execuções justas entre workflows provenientes de domínios distintos, que visam atender requisições que solicitam múltiplos recursos, oferecidos em servidores distintos, é apresentado neste capítulo.

Implementa-se aqui, as estratégias e mecanismos apresentados no capítulo 4, construindo-se, desta forma, um sistema de atendimento justo e com comportamento transacional na execução de composições de serviços, presentes no workflow, e com a garantia de impedir situações de deadlock e starvation.

As seções a seguir descrevem a arquitetura desenvolvida, o protocolo e as entidades que irão realizar a comunicação para atender as necessidades.

\subsection{A Arquitetura Desenvolvida}

A arquitetura desenvolvida está estruturada em duas entidades e o vínculo entre elas; Servidor Requisição (RQT), Servidor Recurso (RSC) e a comunicação entre os serviços, conforme a Figura 5.1.

Figura 5.1 - Arquitetura desenvolvida

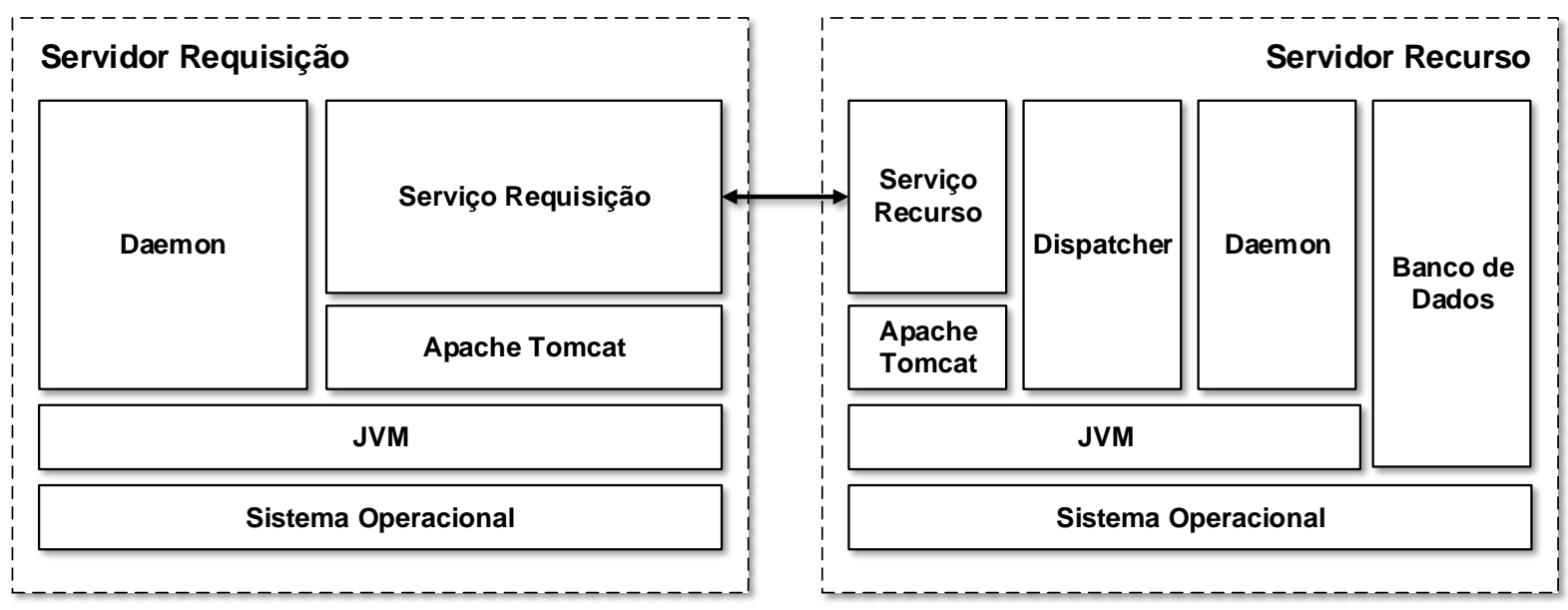

Fonte: O Autor (2015)

O sistema foi desenvolvido na linguagem Java, o qual utiliza a máquina virtual Java (JVM) versão 1.8.0_60 e os serviços Requisição e Recurso também foram desenvolvidos em Java, e disponibilizados no servidor Web Apache Tomcat versão 7.0.55. O sistema operacional, a máquina virtual Java, o servidor Web e o sistema 
gerenciador de banco de dados são a infraestrutura de sustentação para que o sistema entre em execução.

A atribuição do servidor Web é disponibilizar uma aplicação em Java através de uma interface de fácil utilização para o seu conjunto de operações. Nesta implementação os serviços foram utilizados como instancias de objetos remotos através da API Java para Web Services baseados em XML (JAX-WS 2.0). O serviço Recurso disponibiliza o método executeDispatcher, encaminhando a solicitação de operação para que seja executada pelo componente Dispatcher. O serviço Requisição disponibiliza o método receiveRequest, o qual irá decompor as composições de serviços em requisições individuais para que sejam executadas nos respectivos recursos.

Tabela 5.1 - Informações sobre os serviços disponibilizados

\begin{tabular}{|c|c|c|}
\hline Hostname & Atribuição & Serviço \\
\hline Suse01 & $\begin{array}{l}\text { Servidor } \\
\text { Recurso }\end{array}$ & http://192.168.56.101:8080/Suse01Resource/ \\
\hline Suse02 & $\begin{array}{l}\text { Servidor } \\
\text { Recurso }\end{array}$ & http://192.168.56.102:8080/Suse02Resource/ \\
\hline Suse03 & $\begin{array}{c}\text { Servidor } \\
\text { Requisição }\end{array}$ & http://192.168.56.103:8080/Suse03Request/ \\
\hline Suse04 & $\begin{array}{c}\text { Servidor } \\
\text { Requisição }\end{array}$ & http://192.168.56.104:8080/Suse04Request/ \\
\hline
\end{tabular}

O Servidor Requisição está incumbido de receber e atender as requisições, de maneira transparente, para executar as solicitações dos clientes. O serviço Requisição, através da operação receiveRequest, executa o workflow correspondente ao pedido do cliente, gerando as requisições individuais aos respectivos serviços Recurso, presentes nas composições.

O componente Daemon gerencia o relógio lógico local e as informações sobre o servidor. Essas informações são fornecidas ao serviço Requisição para que as requisições individuais possam ser encaminhadas ao respectivo recurso. Após as operações serem concluídas no Servidor Recurso, o serviço Requisição coordena as respostas, contendo o estado da operação, de modo que assegure o comportamento transacional de toda execução, e solicite a atualização do relógio lógico. 
O Servidor Recurso está encarregado de receber as requisições individuais, de maneira que execute as operações de forma justa, livre de deadlock e starvation. Para tanto, o serviço Recurso, através da operação executeDispatcher, encaminha a requisição para o componente Dispatcher.

O componente Dispatcher é responsável pela execução da operação solicitada, realizando o tratamento necessário para definir a prioridade no atendimento a requisição, solicitando ao Daemon a informação ou a atualização do relógio lógico. Após estas etapas, o Dispatcher permite que a requisição realize as operações necessárias no recurso (Banco de Dados). Ao finalizar a operação, o Dispatcher sinaliza o estado da operação, e o valor do relógio lógico local para que sejam encaminhadas como resposta para o serviço Requisição.

\subsection{Protocolo de Comunicação}

A comunicação entre Servidor Requisição e Servidor Recurso é realizada, utilizando uma estrutura de dados chamada Envelope como mensagem, através de requisições e respostas entre Servidor Requisição e Servidor Recurso. A requisição contém uma operação que o Servidor Requisição quer realizar no Servidor Recurso, a qual será executada de maneira justa. A resposta contém o estado gerado pela operação, no atendimento da requisição ao Servidor Recurso, para que o Servidor Requisição possa realizar o gerenciamento da execução do workflow, proporcionando o comportamento transacional. A estrutura de dados Envelope, descrita na Figura 5.2, contém os campos com os dados descritos a seguir:

Figura 5.2 - Envelope

\begin{tabular}{|c|c|}
\hline \multicolumn{2}{|c|}{ Header } \\
\hline Operation & Status \\
\hline \multicolumn{2}{|c|}{ Body } \\
\hline
\end{tabular}

Fonte: O Autor (2015)

- Header: estrutura de dados contendo as informações fornecidas pelo gerenciador do Servidor Requisição de origem.

- Operation: informação sobre a operação solicitada pelo Servidor Requisição para o Servidor Recurso. 
- Status: informação do Servidor Recurso para o Servidor Requisição sobre a situação da operação solicitada.

- Body: estrutura de dados contendo as informações sobre uma requisição.

O campo Header é uma estrutura de dados fornecida pelo componente Daemon, contendo as informações de controle do Servidor Requisição, ilustrado na Figura 5.3 a seguir, composto pelos seguintes campos:

Figura 5.3 - Header

\begin{tabular}{|c|c|c|c|}
\hline ID & TS & IP & HostName \\
\hline
\end{tabular}

Fonte: O Autor (2015)

- ID: número de identificação local de uma requisição.

- TS: marca de tempo do relógio lógico.

- IP: identificação do número ip da máquina local.

- Hostname: nome da máquina local.

O campo Body é uma estrutura de dados fornecida pelo componente Provide Requests, o qual está descrito na seção 5.3.1, contendo as informações sobre uma requisição, ilustrado na Figura 5.4, composto pelos seguintes campos:

Figura 5.4 - Body

\begin{tabular}{|l|l|}
\hline Resource ID & Value \\
\hline
\end{tabular}

Fonte: O Autor (2015)

- Resource ID: identificação do recurso no Servidor Recurso.

- Value: é um valor que indica a quantidade de um recurso. Este valor, dependendo do contexto, pode representar a quantidade solicitada caso a operação seja a requisição de reserva, ou pode representar a quantidade disponível caso a operação seja a consulta sobre a disponibilidade do recurso.

O Servidor Requisição é responsável em atribuir uma operação no campo Operation, do Envelope a ser enviado ao Servidor Recurso, para que este possa executar a operação solicitada. O Servidor Recurso, no término da operação, retorna o Envelope, contendo o estado da execução da operação no campo Status. 


\subsection{SERVIDOR REQUISIÇÃo}

O Servidor Requisição disponibiliza o serviço Requisição implementado utilizando a API Java para Web Services baseados em XML (JAX-WS 2.0), possuindo workflows que descrevem uma composição de serviços, gerenciando o estado final da execução de cada requisição individual, proporcionando o comportamento transacional da execução. A arquitetura do serviço Requisição está ilustrada na Figura 4.18. O componente Provide Requests (Trata Requisição) recebe a lista de quantidades desejada para cada recurso. O componente Daemon (Informação Local) fornece e gerencia as informações da máquina local. O componente Execute Workflow (Gerencia Requisições) recebe do componente Provide Requests uma lista contendo as quantidades e os respectivos recursos, criando requisições individuais para executar o workflow, gerenciando o retorno de cada requisição. A Figura 5.5, ilustra esses componentes com as denominações utilizadas na implementação.

Figura 5.5 - Organização Servidor Requisição
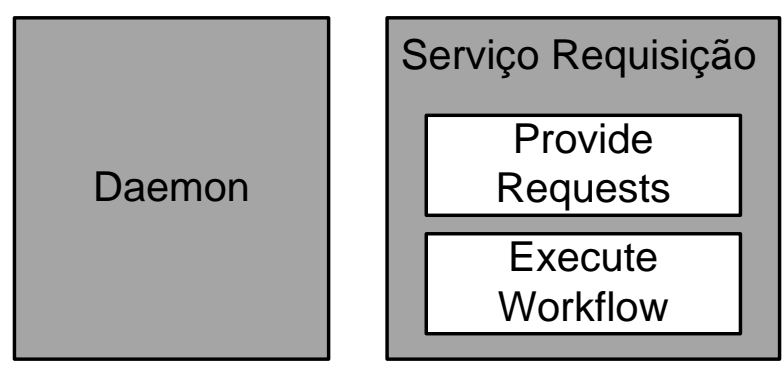

Fonte: O Autor (2015)

\subsubsection{SERVIÇO REQUISIÇÃo}

O serviço Requisição, por meio da operação receiveRequest executa o workflow correspondente a solicitação do cliente. Para esta tarefa utiliza dois componentes, Provide Requests e Execute Workflow, descritos a seguir.

\subsubsection{Provide Requests}

O componente Provide Requests recebe uma lista de quantidades desejada de cada recurso, montando uma nova lista com as quantidades e os respectivos recursos. Desse modo, o componente organiza cada elemento da lista em objetos do tipo Body, descrito na seção 5.2, fornecendo uma lista de Body para que o componente Execute Workflow possa executar a composição de serviço. 


\subsubsection{Execute Workflow}

Neste componente são definidos a ordem e condições para a execução de uma composição de serviços, coordenando as execuções individuais para proporcionar o comportamento transacional da execução. Para cada elemento da composição, gera requisições individuais de maneira que realize a operação solicitada em cada Servidor Recurso. Para realizar estas tarefas o componente, conforme a ilustração da Figura 5.6, está estruturado em quatro módulos.

Figura 5.6 - Arquitetura Execute Workflow

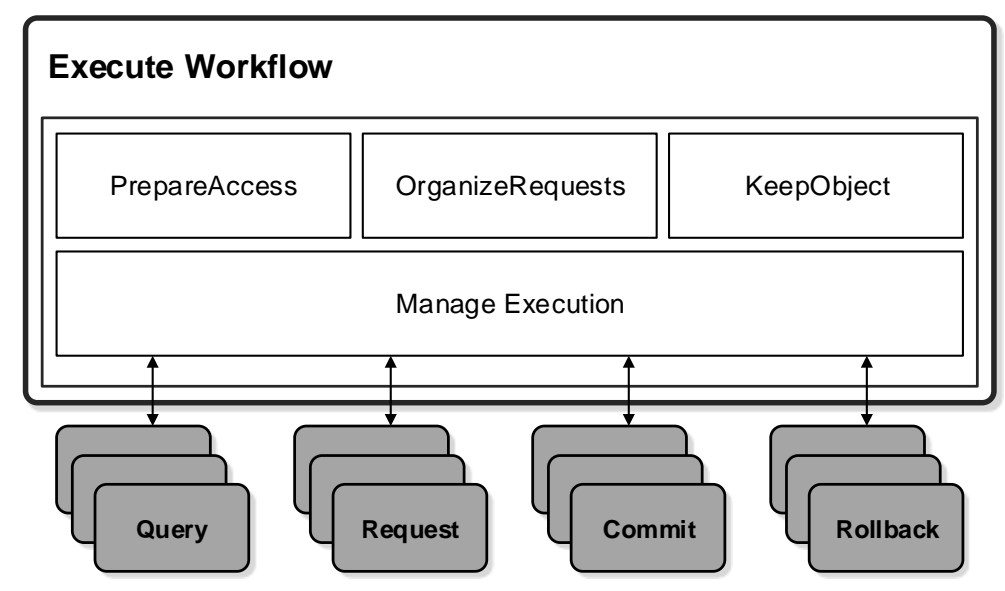

Fonte: O Autor (2015)

O módulo Prepare Access organiza para que uma requisição possa executar operações no Servidor Recurso. Para tanto, ele solicita ao Daemon um objeto Header contendo as informações da máquina local, atribuindo-a a um objeto do tipo Envelope, construindo a mensagem necessária para a comunicação entre Servidor Requisição e Servidor Recurso, a qual será fornecida para o módulo Organize Requests para que anexe o objeto Body ao Envelope.

O módulo Keep Object irá armazenar ou restaurar o estado original de uma requisição, possuindo para isso dois métodos. O método save irá receber um objeto do tipo Header e persistir suas informações em arquivo. O método restore realiza a leitura de um arquivo, retornando um objeto Header com as informações do estado inicial de uma requisição.

O módulo Organize Requisitions recebe uma lista de Body para decompor a lista em requisições individuais. Para tanto solicita ao módulo Prepare Access um Envelope para cada requisição, anexando o Body em cada um deles, gerando uma lista de Envelopes. Esta lista de Envelopes terá o estado original de cada elemento 
persistido utilizando o módulo Keep Object e encaminhando a lista para o módulo Manage Execution.

O módulo Manage Execution, a partir de uma lista de Envelopes, permite a execução de quatro operações, descritos na seção 4.2.4.1. As operações Query_Resources, Request_Resources, Commit_Resources e Rollback_Resources obedecem ao protocolo de execução descrito na seção 4.2.4.3, as quais fornece informações que são gerenciadas para proporcionar o comportamento transacional da execução.

Cada uma das operações do módulo Manage Execution possui funções específicas, descritas na seção 4.2.4.3, as quais foram implementadas na forma de threads em Java. Cada uma das threads recebe um Envelope da lista para executar uma requisição no Servidor Recurso especificado. A função req_resource foi nomeada como RequestThread, providenciando a reserva de uma quantidade indicada. A função que_resource foi nomeada como QueryThread, a qual realiza o procedimento de consulta sobre um recurso. A função rol_resource foi nomeada como RollbackThread, a qual desfaz a reserva obtida por uma requisição. A função com_resource foi nomeada como CommitThread, confirmando uma reserva realizada sobre o recurso indicado. A função rev_resource foi nomeada como RevokeThread, devolvendo um recurso que foi alocado. A função fin_commit foi nomeada como FinalizeThread, a qual retira uma requisição da lista $\mathrm{CL}$, indicando que o processo de committing foi concluído para todas as requisições que compõem o workflow

\subsubsection{DAEMON}

O componente Daemon, ilustrado na Figura 5.7, é responsável pelo gerenciamento do relógio lógico local e a identificação para cada requisição individual. Outra atribuição deste componente é fornecer informação da máquina local, gerando um objeto do tipo Header, ilustrado na Figura 5.3, com esses atributos.

O componente é o mesmo apresentado na Figura 4.18 e Figura 4.20, o qual está nomeado como Informação Local. Foi desenvolvido como um processo servidor em Java, e é executado em segundo plano, aguardando por solicitações na porta 50500 , as quais utilizarão os seus métodos. 
Figura 5.7 - Arquitetura Daemon

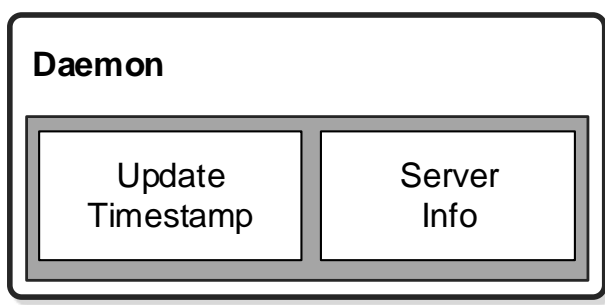

Fonte: O Autor (2015)

O método UpdateTimeStamp realiza a atualização do relógio lógico local, a partir de um objeto Header que é recebido como parâmetro. O método ServerInfo coleta as informações local, por ele gerenciadas, retornando um objeto Header.

\subsection{SerVidor RECURSO}

O Servidor Recurso é o local onde está disponibilizado o serviço Recurso, implementado utilizando a API Java para Web Services baseados em XML (JAX-WS 2.0). Promove a execução justa das requisições recebidas, seguindo o critério de prioridade definido na seção 4.2.2, impedindo a situação de deadlock e starvation. A arquitetura do serviço Recurso está ilustrada na Figura 4.20. O Execute Dispatcher é uma chamada do serviço Recurso o qual irá encaminhar uma requisição ao componente Dispatcher (Gerencia Operação). O componente Dispatcher seleciona a operação solicitada para que seja efetuada a execução. Para esta execução é necessário o componente Handle Data Base (Gerencia Recurso), o qual manipula diretamente o Data Base (Banco de Dados), e em seguida atualiza o relógio lógico local utilizando o componente Daemon (Informação Local). Ao final da execução, retorna à situação da operação. A Figura 5.8 ilustra os componentes implementados, com as denominações utilizadas no desenvolvimento.

Figura 5.8 - Organização Servidor Recurso
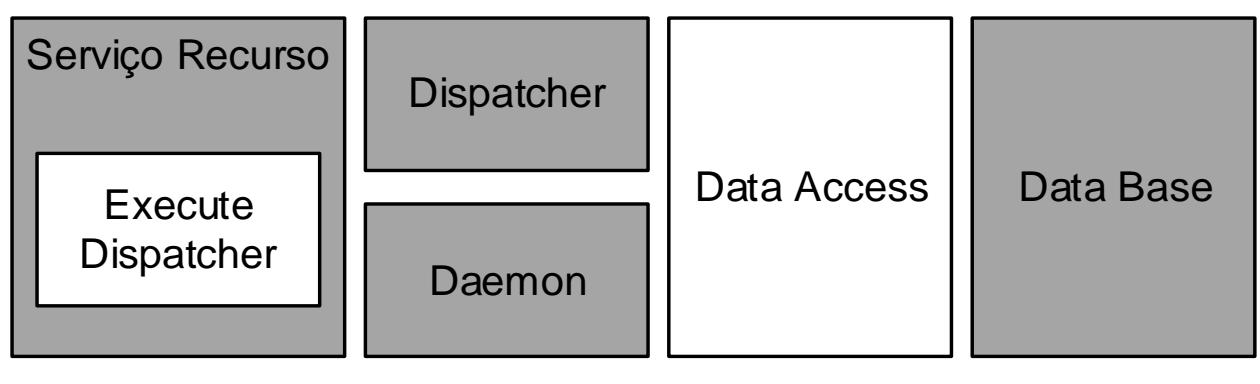

Fonte: O Autor (2015) 


\subsubsection{SERVIÇO RECURSO}

O serviço Recurso contém a operação executeDispatcher, que envia uma requisição para o componente Dispatcher, solicitando uma operação especificada no Envelope da requisição.

\subsubsection{DAEMON}

O componente Daemon é o mesmo componente apresentado na seção 5.3.1.2, utilizado pelo Servidor Requisição para o gerenciamento de identificação da requisição, e do relógio lógico local. No Servidor Recurso o Daemon é utilizado para atualizar e coletar o valor do relógio lógico de maneira que o critério de prioridade seja atendido. O componente é um processo servidor que está executando em segundo plano, aguardando solicitações para executar suas operações na porta 50500 .

\subsubsection{DATA ACCESS}

O componente Data Access é uma camada de software para separar o componente Dispatcher e o componente Data Base, funcionando como uma interface comum entre os componentes. Possui duas classes, a Access Data Base que realiza a conexão com o banco de dados, e a classe Handle Data Base a qual efetua operações para manipular o banco de dados. A Figura 5.9 ilustra o componente.

\section{Figura 5.9 - Arquitetura Data Access}

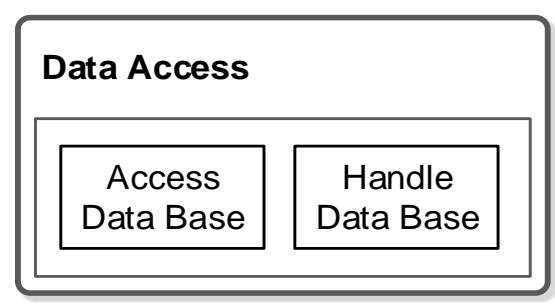

Fonte: O Autor (2015)

\subsubsection{DATA BASE}

O componente Data Base é o local onde os registros do recurso são persistidos. Para tanto utilizou-se o SGBD MariaDB versão 10.0.21.

\subsubsection{DISPATCHER}

O componente Dispatcher gerencia as listas de alocação de recursos e coordena a execução das operações sobre o recurso, descritas na seção 4.2.4.2. As listas 
adotadas são ferramentas para proporcionar o acesso e a manipulação do recurso de maneira justa seguindo o critério de prioridade definido neste trabalho. Para proporcionar a execução das operações, através do critério de prioridade, o componente está organizado em dois módulos, ilustrado na Figura 5.10, os quais compartilham as listas e são executados simultaneamente.

Figura 5.10 - Arquitetura Dispatcher

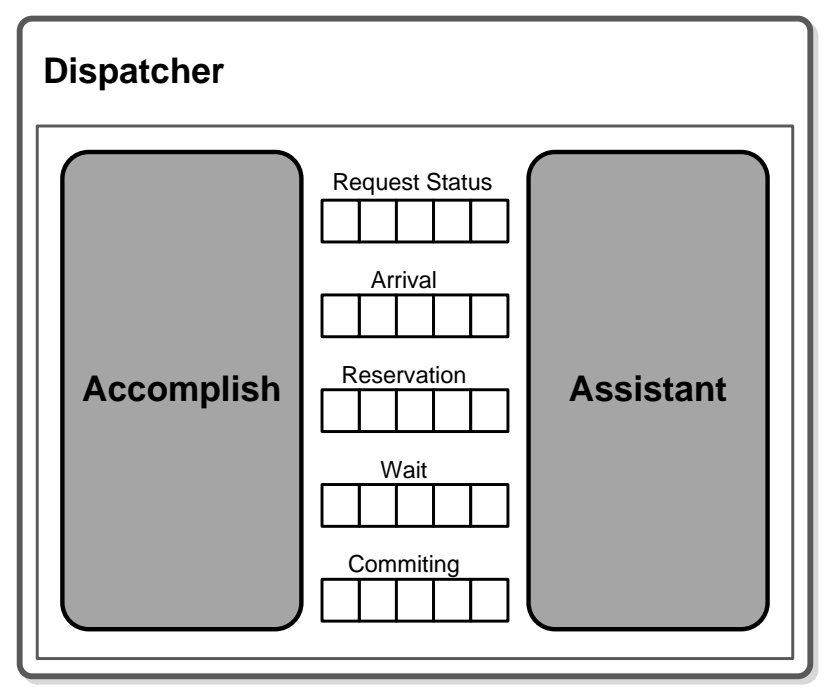

Fonte: O Autor (2015)

O componente foi implementado como um processo servidor e aguarda o envio de requisições, no formato do Envelope, pelo componente Execute Dispatcher na porta 60600. Esta estratégia foi adotada no intuito de haver somente uma instancia do componente Dispatcher para cada recurso, possibilitando o controle concorrente no uso do recurso para que não haja inconsistência de dados.

Além das listas descritas na seção 4.2.4.2 (Arrival, Reservation, Wait e Committing), foi incorporada uma quinta lista, chamada de Request Status, para verificar o estado de uma requisição. A lista armazena duas informações de cada elemento; o Envelope da requisição, e o status da requisição. O status é representado pelos seguintes estados:

- IN_ARRIVAL: requisição que está na lista Arrival, indicando que aguarda pela disponibilidade do recurso.

- IN_RESERVATION: requisição que está na lista Reservation, indicando que a reserva foi concluída e está aguardando a confirmação da reserva. 
- IN_WAIT: requisição que está na lista Wait, indica que aguarda pela disponibilidade do recurso, porém possui uma prioridade maior as requisições que estão na lista Arrival.

- IN_COMMITTING: requisição que está na lista Committing, indicando que a requisição está em processo de confirmação, concluindo a alocação do recurso.

- DECLINED: requisição que não está em nenhuma lista, indicando que não há recurso disponível.

A seção 4.2.6.4 apresenta como as operações são realizadas por este componente.

A thread Executa Operação está nomeada como Accomplish, recebe o Envelope da requisição, executa a operação solicitada, indicando na lista Request Status em qual lista a requisição está neste instante. Ao encerrar a operação, atribui um status de execução no Envelope da requisição que será utilizada como retorno para o Servidor Requisição.

A thread Auxilia Execução está nomeada como Assistant, auxilia a execução da thread Accomplish, liberando-a para receber novas requisições sem que fique bloqueada até finalizar o tratamento de cada requisição. A thread Assistant fica suspensa, aguardando que a thread Accomplish realize uma ação nas listas. Caso ocorra a ação, a thread Assistant realizará a transferência de requisições entre as listas, conforme a disponibilidade do recurso, alterando a indicação de status da respectiva requisição na lista Request Status. 


\section{RESULTADOS E ANÁLISES}

Neste capítulo são apresentados os testes, com o objetivo de verificar o comportamento das estratégias propostas, utilizando o sistema implementado e cenários apropriados para observar o atendimento dos aspectos de justiça e não ocorrência de deadlock e starvation. É descrita a metodologia utilizada para a realização dos testes, descrevendo qual a finalidade de cada cenário, o objetivo de cada plano de teste e o ambiente utilizado. Em seguida são apresentados os resultados obtidos, as respectivas análises e considerações sobre o comportamento das estratégias verificado nos testes.

\subsection{Metodologia Utilizada nos Testes}

Para realizar os testes foram utilizadas quatro máquinas virtuais, duas foram designadas como Servidores Requisição (Suse03 e Suse04) e duas como Servidores Recurso (Suse01 e Suse02), e as requisições originadas de um computador interligado a rede virtual. A Figura 6.1 ilustra a topologia utilizada nos testes. Os computadores são virtualizados pelo VirtualBox 5.0.10 e utilizam o sistema operacional Linux OpenSuse 13.2.

Figura 6.1 - Topologia de testes

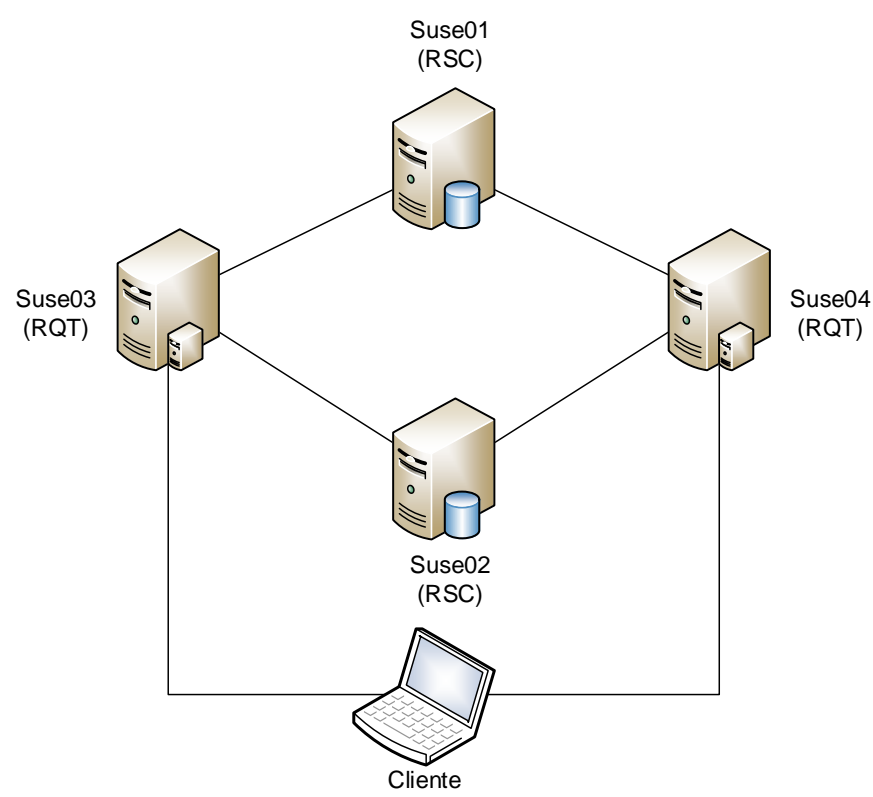

Fonte: O Autor (2015) 
Os testes possuem o propósito de verificar o comportamento da proposta apresentada neste trabalho. Os testes visam verificar se os mecanismos atendem ao critério de prioridade, garantindo a não ocorrência de deadlock e starvation.

Para tanto, cenários foram elaborados com o intuito de provocar o problema. A seguir é apresentada a descrição de cada um destes cenários.

\subsection{Descrição dos Cenários de Teste}

Dois cenários foram elaborados para a realização dos testes. O primeiro cenário visa proporcionar um ambiente de testes para analisar o aspecto de justiça no atendimento das requisições. O segundo tem como objetivo provocar uma situação que poderia gerar deadlock. A verificação de não ocorrência de starvation pode ser efetuada, considerando o comportamento dos testes nos dois cenários.

\subsubsection{CenÁRIO 1}

O primeiro cenário foi elaborado no intuito de verificar se o critério de justiça é atendido. Para tanto é apresentada a seguinte situação:

- dois Servidores Recurso com reservas atribuídas que estão aguardando a confirmação para alocação ou cancelamento;

- antes destas reservas serem confirmadas, uma nova requisição com maior prioridade, em relação a estas, será realizada;

- Suse01 possui em sua lista Reservation três reservas efetuadas pelos ID's 33, 35 e 37 de Suse03, possuindo valor de TS, respectivamente, 38, 40 e 42, onde cada requisição reservou 5 unidades do recurso;

- Suse02 possui em sua lista Reservation três reservas efetuadas pelos ID's 33, 35 e 37 de Suse03, possuindo valor de TS, respectivamente, 38, 40 e 42, onde cada requisição reservou 10 unidades do recurso;

- Suse04, possui TS com valor 36 e irá produzir requisições com ID 7, solicitando 5 unidades em Suse01 e 10 unidades em Suse02.

O cenário é apresentado na Figura 6.2. 
Figura 6.2 - Cenário 1

\begin{tabular}{|c|c|c|c|}
\hline \multicolumn{4}{|c|}{$\underline{\text { Reservation }}$} \\
\hline 33 & SUSE03 & 38 & 5 \\
\hline 35 & SUSE03 & 40 & 5 \\
\hline 37 & SUSE03 & 42 & 5 \\
\hline \multicolumn{4}{|c|}{ Reservation } \\
\hline 33 & SUSE03 & 38 & 10 \\
\hline 35 & SUSE03 & 40 & 10 \\
\hline 37 & SUSE03 & 42 & 10 \\
\hline
\end{tabular}
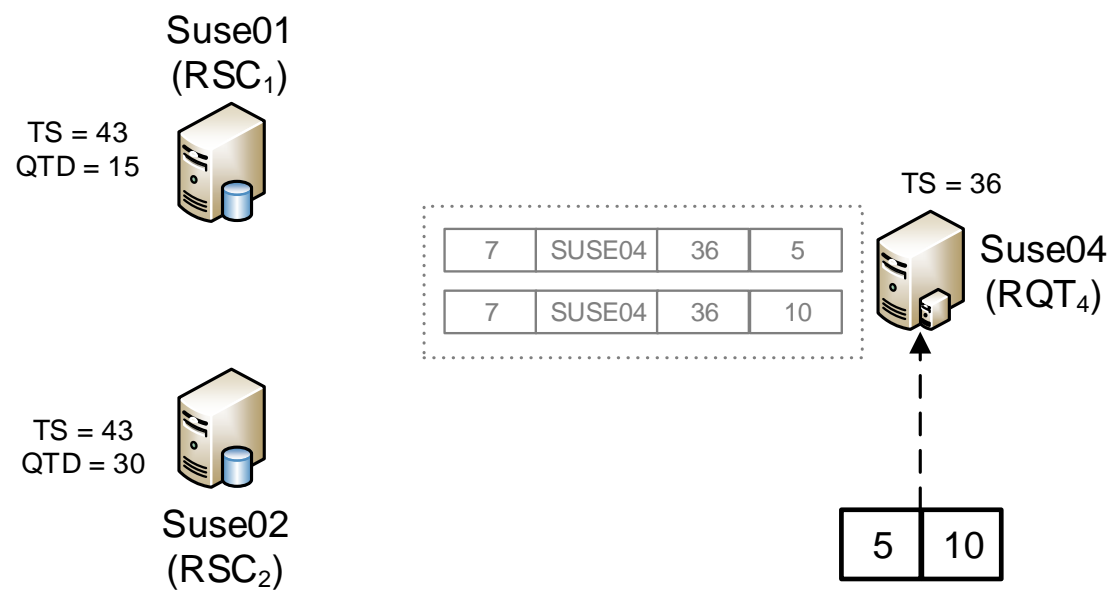

Fonte: O Autor (2015)

\subsubsection{CenáRIO 2}

O segundo cenário tem o objetivo de proporcionar um ambiente de teste que provoca uma situação de possível ocorrência de deadlock. Visa mostrar o impedimento da ocorrência de deadlock e starvation nos testes aplicados no sistema implementado, utilizando os mecanismos propostos.

A situação de deadlock não ocorre com frequência, necessitando sincronizar algumas etapas para que ocorra. Dessa forma, foi construída uma situação específica, onde Suse03, na execução de sua composição faz a requisição para Suse01 e instantes depois realiza a requisição em Suse02. Suse04 processa sua composição, sem manipular a execução, realizando a requisição simultaneamente para Suse01 e Suse02. O atraso de tempo entre as execuções das requisições em Suse03 é o elemento necessário para ocorrer a situação de deadlock entre os Servidores Requisição, possibilitando que Suse04 realize a requisição no recurso que Suse03 ainda não realizou, incidindo em estado de posse e espera. O relógio lógico de Suse03 está adiantado em relação ao relógio lógico de Suse04, para que, a requisição de Suse04 tenha maior prioridade em relação as requisições provenientes de Suse03.

O estado inicial deste cenário, ilustrado na Figura 6.3, assume a seguinte configuração:

- Suse01 possui 7 unidades do recurso disponível, TS com valor 79 e as listas vazias; 
- Suse02 possui 12 unidades do recurso disponível, TS com valor 79 e suas listas vazias;

- Suse03 possui TS com valor 80 e irá produzir requisições com ID 69, solicitando 5 unidades em Suse01 e 10 unidades em Suse02;

- Suse04 possui TS com valor 74 e irá produzir requisições com ID 69, solicitando 6 unidades em Suse01 e 12 unidades em Suse02.

\section{Figura 6.3 - Cenário 2}

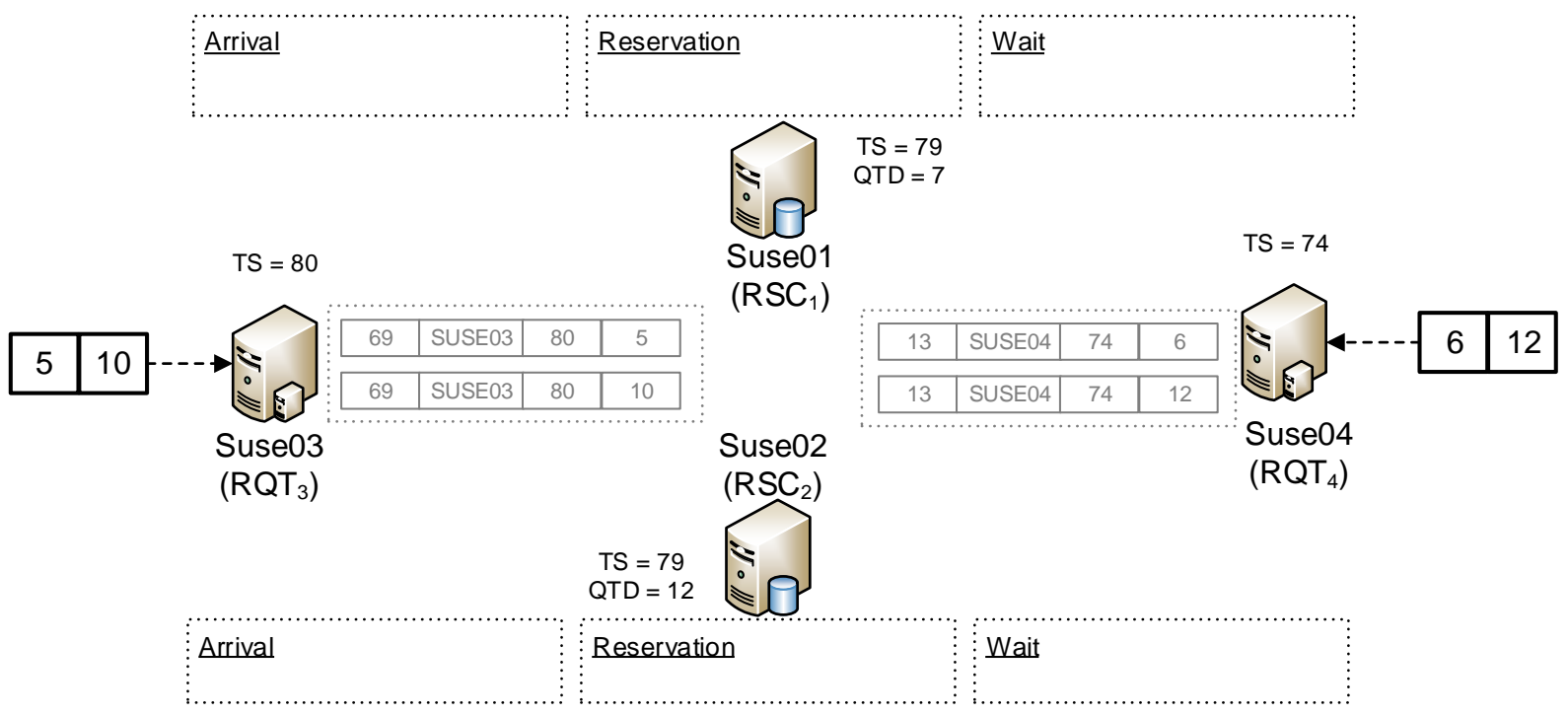

Fonte: O Autor (2015)

\subsection{Testes Realizados}

Para os testes realizados foram desenvolvidas aplicações que executam o workflow de requisição para consumir os recursos disponíveis. $O$ ambiente foi configurado, conforme apresentado na seção 6.2.

Segue a descrição da execução para cada cenário.

\subsubsection{Teste no CenáRIO 1}

O cenário apresenta a seguinte situação: Os Servidores Recurso Suse01 e Suse02 possuem respectivamente 15 e 30 unidades de recurso, tem valor de relógio lógico em 43 e os dois servidores possuem três requisições na lista Reservation, identificadas respectivamente pelo ID 38, 40 e 42, solicitadas pelo Servidor Requisição Suse03. Neste instante, Suse04 realiza requisições para Suse01 e Suse02, e possui o seu relógio local com 36, conforme ilustrado na Figura 6.4. 


\section{Figura 6.4 - Requisição com TS menor}

\begin{tabular}{|c|c|c|c|}
\hline \multicolumn{4}{|c|}{ Reservation } \\
\hline 33 & SUSE03 & 38 & 5 \\
\hline 35 & SUSE03 & 40 & 5 \\
\hline 37 & SUSE03 & 42 & 5 \\
\hline \multicolumn{4}{|c|}{ Reservation } \\
\hline 33 & SUSE03 & 38 & 10 \\
\hline 35 & SUSE03 & 40 & 10 \\
\hline 37 & SUSE03 & 42 & 10 \\
\hline
\end{tabular}

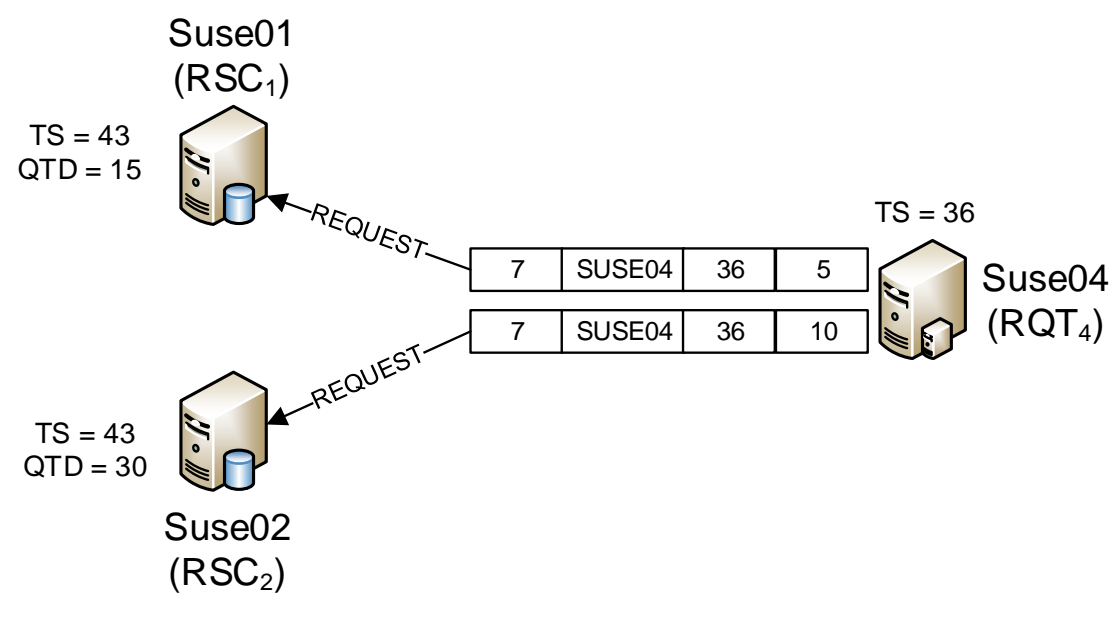

Fonte: O Autor (2015)

Seguindo o critério de prioridade, Suse01 e Suse02, ao receber a requisição de Suse04, dão preferência a nova requisição, movendo-a para a lista Wait e em seguida todas as requisições que estão na lista Reservation, com menor prioridade, são retiradas e inseridas para lista Wait. Desse modo, a requisição que possui o valor de ID 7, enviado por Suse04, possui prioridade em relação a todas as requisições que estavam na lista $R L$ devido ao valor do seu TS ser o menor, conseguindo efetuar a reserva, tornando-se o primeiro da lista Reservation. As outras requisições, também, são transferidas da lista Wait para a lista Reservation, conforme a disponibilidade do recurso para a reserva. Porém, a requisição com ID 37, enviada por Suse03, permanece na lista Wait, pois não há disponibilidade da quantidade necessária de recurso. Observe que o valor de QTD é 15 em Suse01, e a quantidade de recursos reservados, se somados, também é 15 . Mas ainda há a possibilidade de que alguma reserva não seja efetivada e o recurso não seja alocado, possibilitando que a requisição com ID 37 de Suse03 consiga o recurso que está solicitando. A mesma situação ocorre em Suse02, o qual possui valor de QTD em 30, mas a quantidade de reserva também é 30. Esta situação está ilustrada na Figura 6.5.

Caso alguma requisição desfaça a reserva obtida, a requisição com ID 37 de Suse03 terá prioridade em relação a novas requisições que venham a ser recebidas, caso estas tenham um valor de TS maior, pois está na lista Wait. 
Figura 6.5 - Promovendo justiça

\begin{tabular}{|c|c|c|c|}
\hline \multicolumn{4}{|c|}{ Reservation } \\
\hline 7 & SUSE04 & 36 & 5 \\
\hline 33 & SUSE03 & 38 & 5 \\
\hline 35 & SUSE03 & 40 & 5 \\
\hline \multicolumn{4}{|l|}{ Wait } \\
\hline 37 & SUSE03 & 42 & 5 \\
\hline \multicolumn{4}{|c|}{ Reservation } \\
\hline 7 & SUSE04 & 36 & 10 \\
\hline 33 & SUSE03 & 38 & 10 \\
\hline 35 & SUSE03 & 40 & 10 \\
\hline \multicolumn{4}{|l|}{ Wait } \\
\hline 37 & SUSE03 & 42 & 10 \\
\hline
\end{tabular}

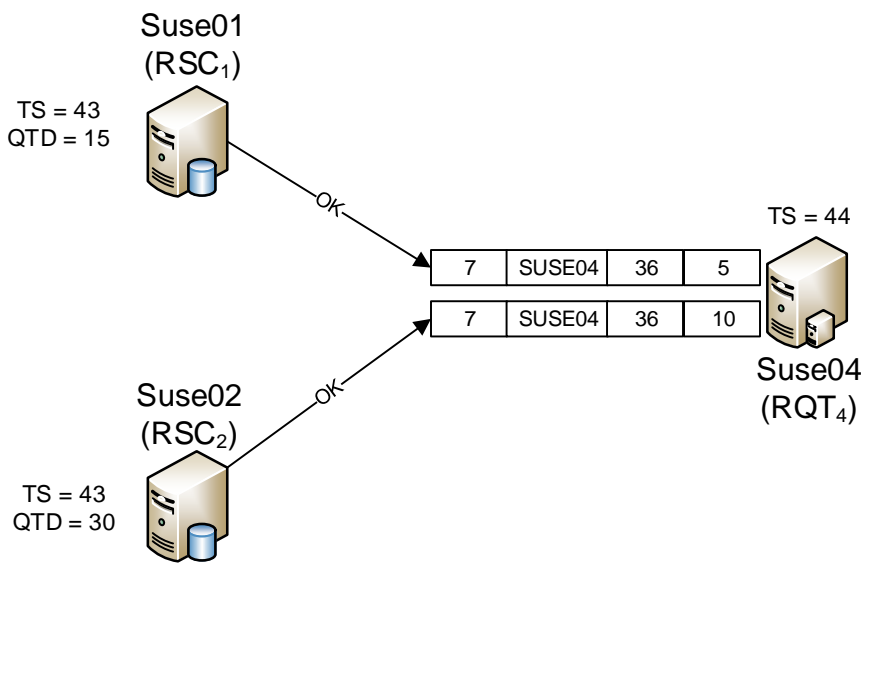

Fonte: O Autor (2015)

Prosseguindo a execução, a requisição ID 7 de Suse04 confirma a reserva, alocando 5 unidades em Suse01, restando 10 unidades de QTD, e alocando 10 unidades em Suse02, restando 20 unidades de QTD. Neste instante ainda há a possibilidade da requisição com ID 37 de Suse03 conseguir a reserva, pois ainda há reservas que não alocaram o recurso, permanecendo na lista Wait, conforme ilustrado na Figura 6.6.

\section{Figura 6.6 - Suse04 confirmando reserva}

\begin{tabular}{|c|c|c|c|}
\hline \multicolumn{4}{|c|}{$\underline{\text { Reservation }}$} \\
\hline 33 & SUSE03 & 38 & 5 \\
\hline 35 & SUSE03 & 40 & 5 \\
\hline \multicolumn{4}{|l|}{ Wait } \\
\hline 37 & SUSE03 & 42 & 5 \\
\hline \multicolumn{4}{|c|}{ Reservation } \\
\hline 33 & SUSE03 & 38 & 10 \\
\hline 35 & SUSE03 & 40 & 10 \\
\hline \multicolumn{4}{|l|}{ Wait } \\
\hline 37 & SUSE03 & 42 & 10 \\
\hline
\end{tabular}

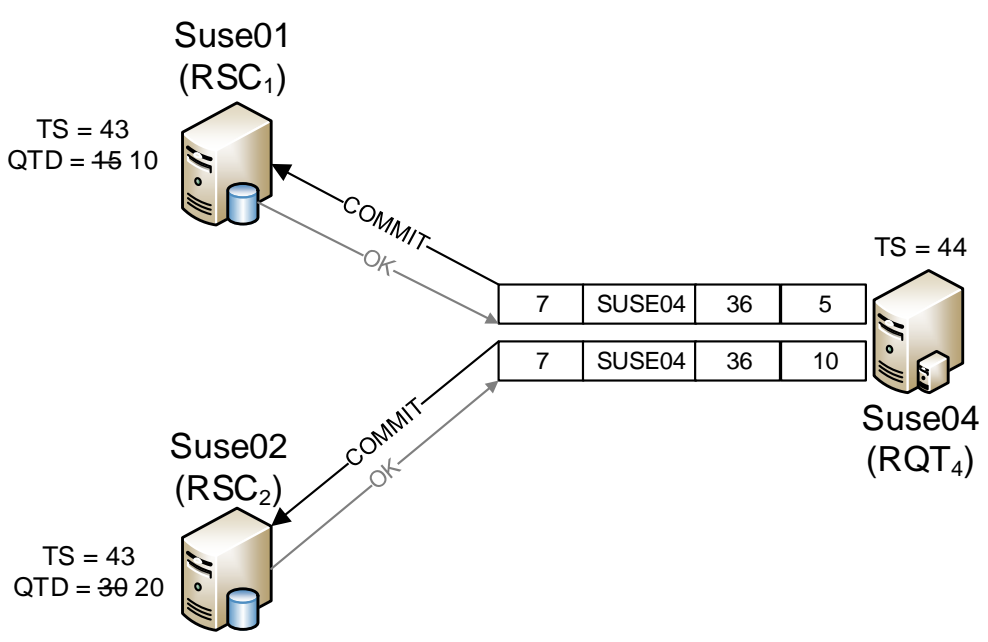

Fonte: O Autor (2015) 
A requisição com ID 33 de Suse03 desfaz a reserva obtida através da operação ROLLBACK, e ela é retirada da lista Reservation, disponibilizando a quantidade de recurso suficiente para que a requisição com ID 37 de Suse03 consiga o recurso novamente, já que estava suspensa aguardando na lista Wait. Desse modo, o critério de justiça é atendido, privilegiando uma requisição que já havia solicitado o recurso, obter, com prioridade, o recurso novamente. Esta situação está ilustrada na Figura 6.7 .

As execuções realizadas neste cenário possuem arquivo de log do processamento realizado em Suse01 e Suse02 apresentados, respectivamente, em Apêndice A e Apêndice B.

Figura 6.7 - Suse03 desistindo de reserva

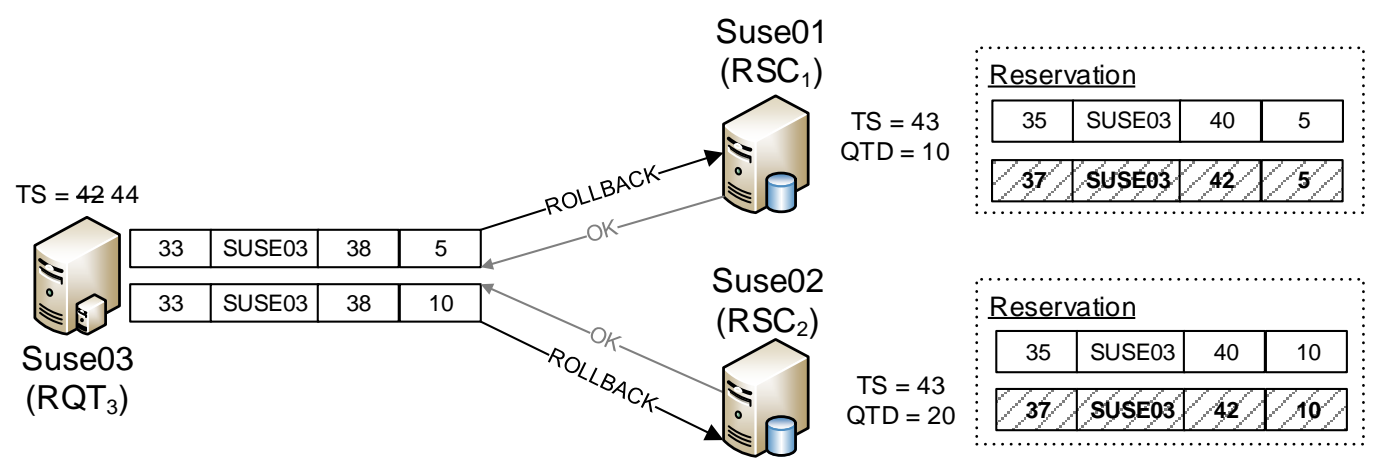

Fonte: O Autor (2015)

\subsubsection{TESTE NO CENÁRIO 2}

Ao executar ambas as requisições, Suse03 tem sua requisição recebida em Suse01 antes da requisição de Suse04, mas em Suse02 sua requisição chega após a requisição de Suse04. Nesta última situação, mesmo com a requisição de Suse04 possuindo um TS menor que o TS de Suse02, devido a todas as listas estarem vazias, esta requisição recebida terá prioridade, sendo então encaminhada para a lista Arrival. A configuração desta situação está ilustrada na Figura 6.8 . 
Figura 6.8 - Requisições em tempos distintos

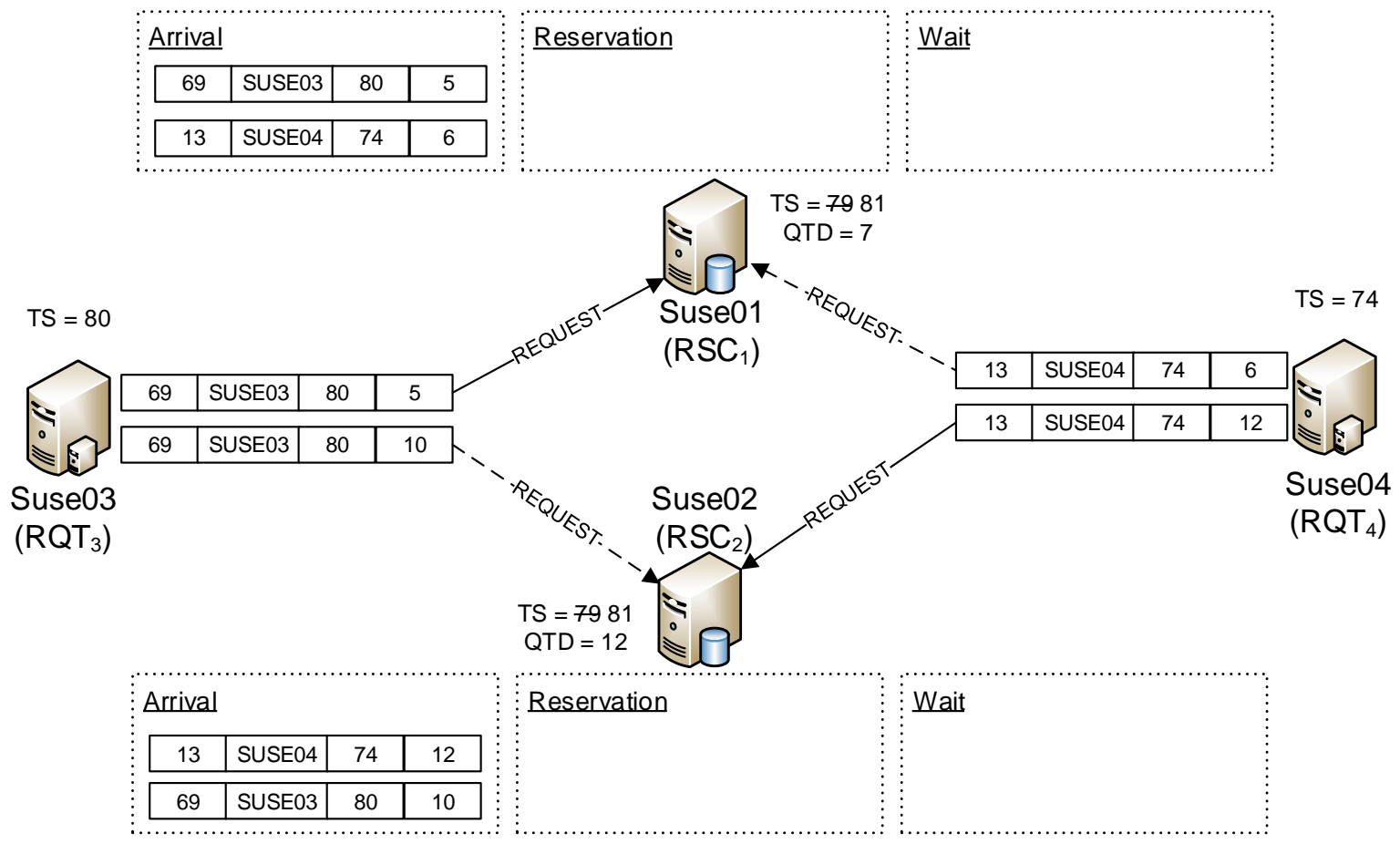

Fonte: O Autor (2015)

Esta situação configura o deadlock entre as execuções de Suse03 e Suse04, devido a Suse03 obter o recurso em Suse01 e aguardar por Suse02, e Suse04 obter o recurso em Suse02 e aguardar por Suse01, configurando uma espera circular ilustrado na Figura 6.5.

Figura 6.9 - Configuração de deadlock

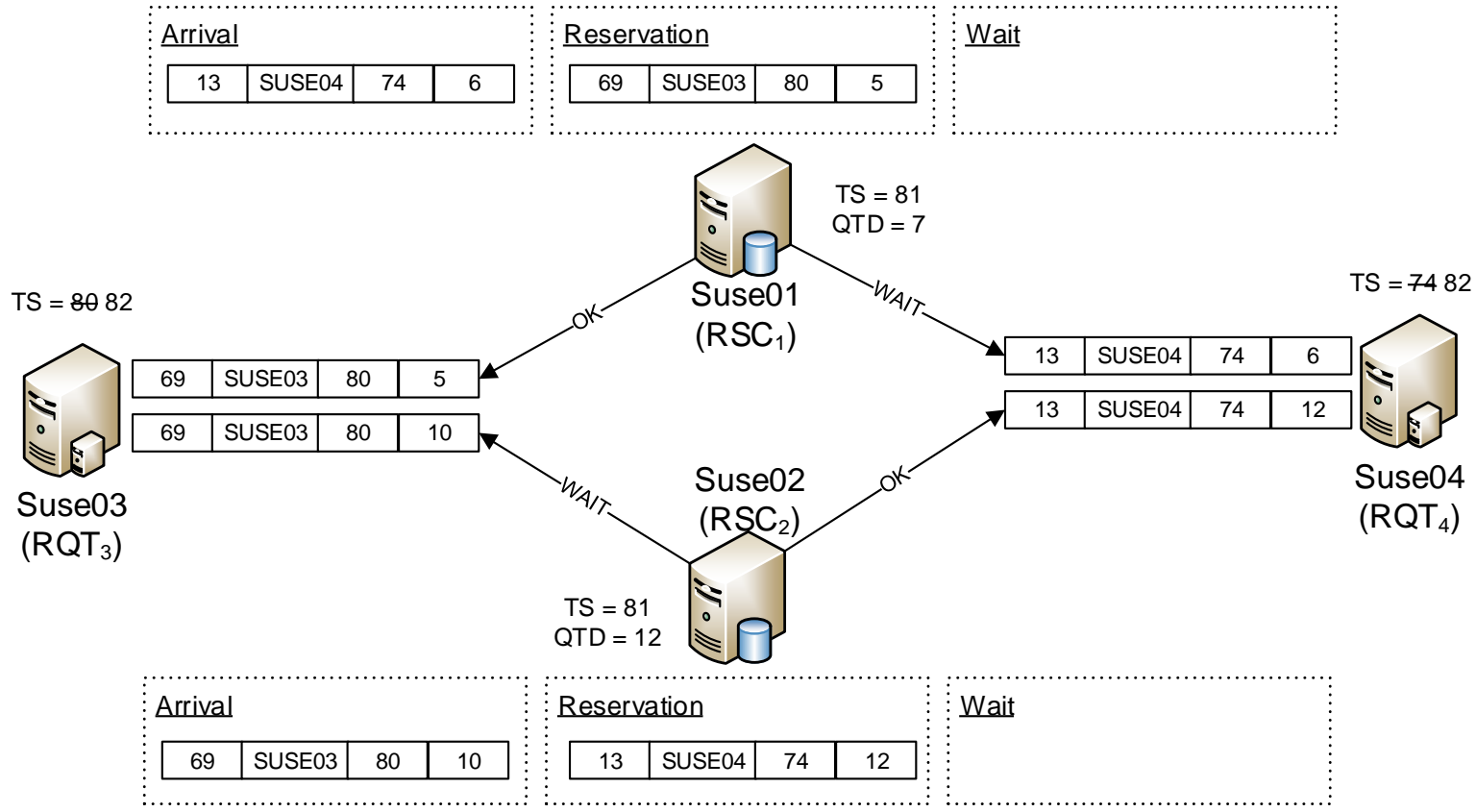

Fonte: O Autor (2015) 
Aplicando o critério de prioridade em Suse01, ambas as requisições irão para a lista Wait e como a requisição com ID 13 de Suse04 tem prioridade em relação a requisição ID 69 de Suse03, será concedida a reserva para a requisição de Suse04, resolvendo a situação de deadlock. A requisição de Suse03 fica na lista Wait, uma vez que terá prioridade, caso Suse04 desfaça sua reserva. A Figura 6.10 ilustra o impedimento para a ocorrência de deadlock. A transferência da requisição de Suse03 para a lista Wait, considerando sua prioridade garante a não ocorrência de starvation caso haja a disponibilidade de recursos devido a cancelamentos de alocação ou reserva.

Figura 6.10 - Resolvendo deadlock

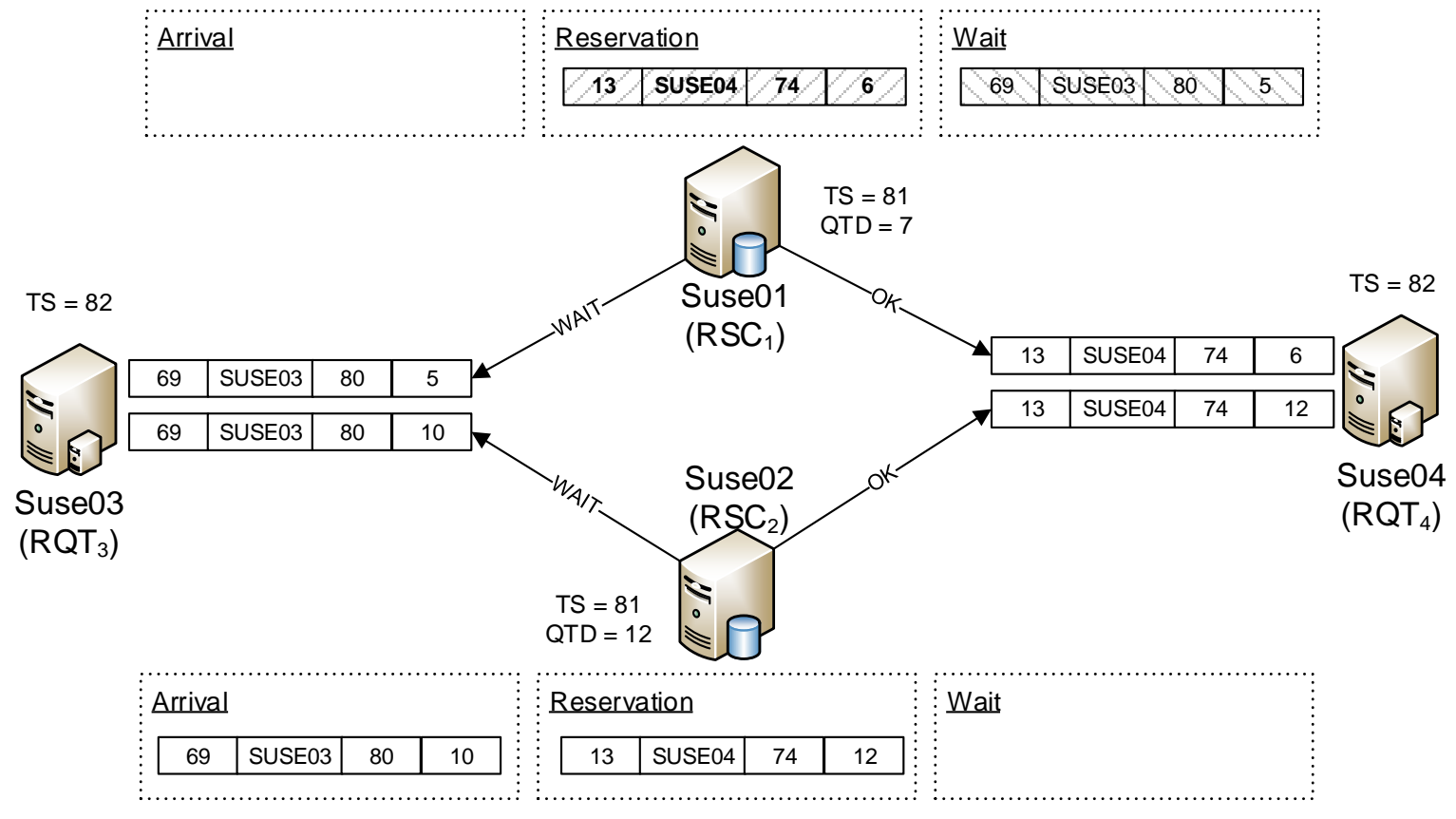

Fonte: O Autor (2015)

A partir desta etapa duas situações são possíveis.

$\mathrm{Na}$ primeira situação, Suse04 conseguiu realizar as reservas de suas requisições e confirmar as reservas, alocando os recursos. Desse modo, Suse01 decrementa 6 unidades, restando 1 e Suse 02 decrementa 12 unidades, restando 0 , e ambos os servidores retornando OK para indicar que a operação foi concluída com sucesso. Suse03 que estava aguardando a disponibilidade do recurso em Suse01, com a alocação do recurso para Suse04, recebe o retorno CANCEL de Suse01. Suse02 retorna DENY para Suse03 pois não há quantidade suficiente para atender a requisição. A ilustração desta situação é apresentada na Figura 6.11, e o detalhes do 
processamento deste teste podem ser verificados no Apêndice $C$ e Apêndice $D$ onde há os arquivos de log de execução para Suse01 e Suse02 respectivamente.

Figura 6.11 - Suse04 confirma e Suse03 tem requisição negada

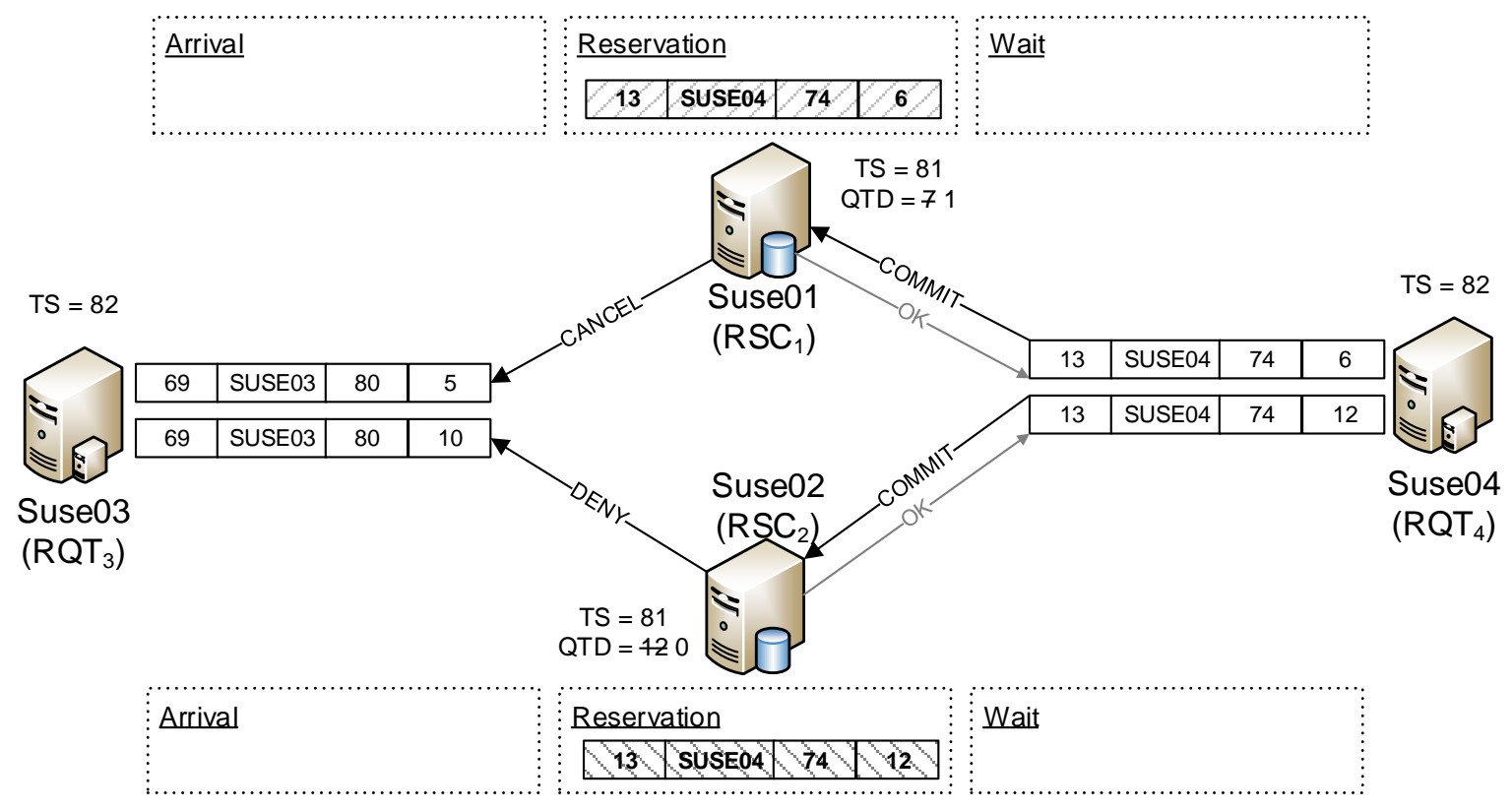

Fonte: O Autor (2015)

Na segunda situação, Suse04 desfaz suas reservas e Suse03, aguardando a disponibilidade na lista Wait, possui a prioridade para consumir os recursos. A Figura 6.12 ilustra esta situação. Suse04 requisita a operação ROLLBACK, desfazendo suas reservas em Suse01 e Suse02. As respectivas requisições de Suse03 em Suse01 e Suse02 obtém as suas reservas, o qual possui requisições na lista Wait de Suse01 e na lista Arrival de Suse02, apresentado na Figura 6.10. Suse03, com a disponibilidade dos recursos, confirma as reservas obtidas com a operação COMMIT, alocando os recursos. Suse 01 que possuía 7 unidades, decrementa 5 unidades que foi alocada para Suse03, restando duas unidades. Suse02, que possuía 12 unidades, decrementa 10 unidades, restando 2 unidades. Após alocar os recursos, os Servidores Recurso Suse01 e Suse02 retornam OK para Suse03, indicando que a operação foi concluída com sucesso. Os arquivos de log para este processamento são apresentados no Apêndice $E$ e Apêndice $F$ para as execuções realizadas respectivamente em Suse01 e Suse02. 
Figura 6.12 - Suse04 desfaz e Suse03 confirma

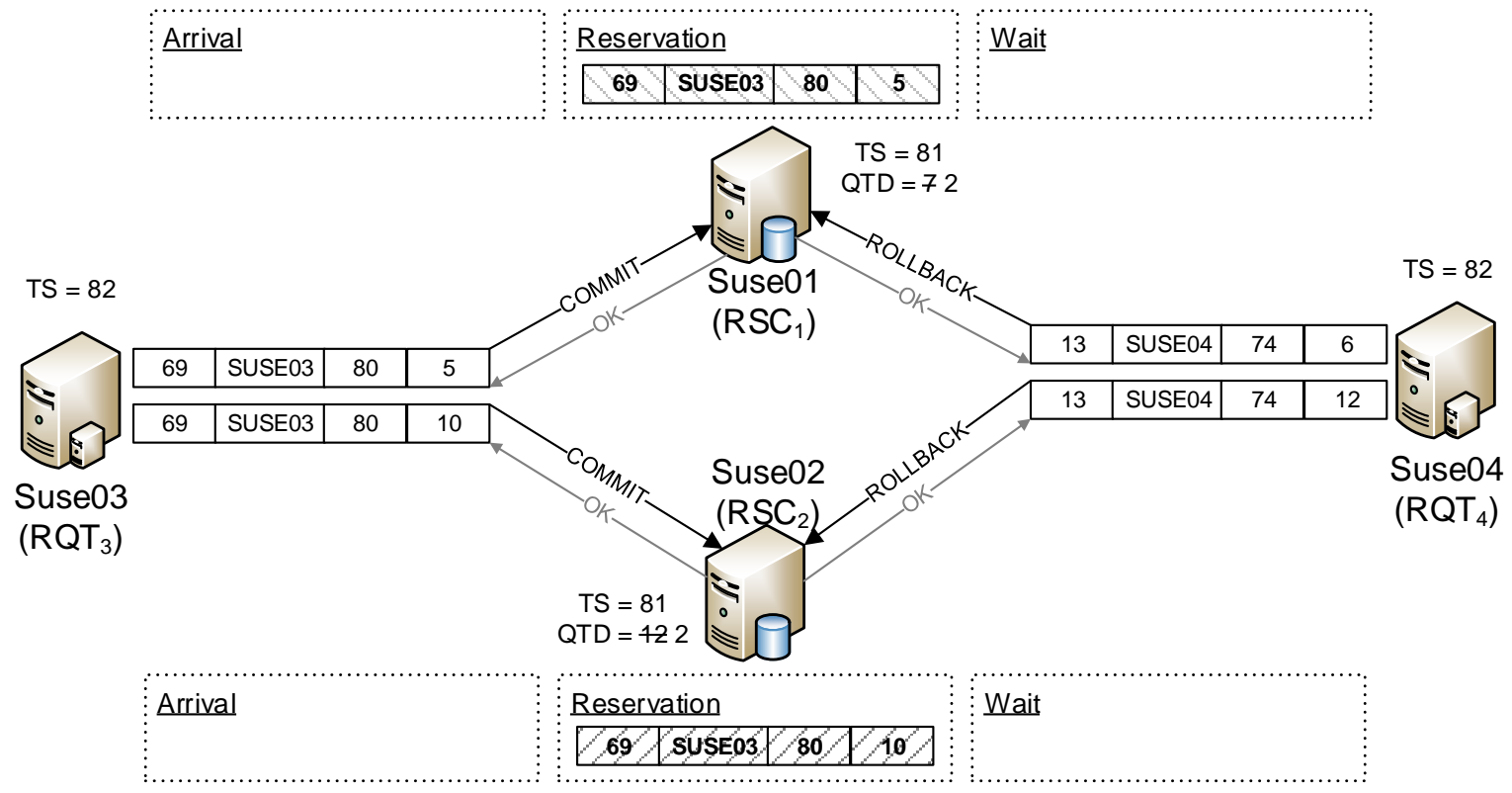

Fonte: O Autor (2015)

\subsection{Considerações Sobre os Resultados}

Os testes realizados mostram o controle de transação entre workflows executados em domínios diferentes através do resultado da operação solicitada ao serviço.

Os serviços realizam o gerenciamento de execução sobre o recurso, livre de deadlock, uma vez que a partir do critério de prioridade define qual requisição possui o privilégio de utilizar o recurso, mas possui prioridade para efetuar a reserva caso a requisição com prioridade desista da reserva efetuada. O critério adotado impede a situação de deadlock, sem a necessidade de abortar o processamento em Suse03 e Suse04 para liberar o recurso que cada um está em posse. A política de abortar o processamento necessita realizar reenvio de requisição entre as requisições que estão gerando o deadlock, o que pode permanecer de forma recorrente, implicando na situação de starvation.

Caso alguma requisição tenha que ceder uma reserva obtida, não necessita reiniciar o processo de requisição realizando novo reenvio, uma vez que será suspensa temporariamente no intuito de evitar situações injustas durante o processo de reenvio, bastando aguardar, pois caso haja a liberação do recurso este terá a prioridade no uso. A política de reenvio pode causar duas situações: 
- a situação de starvation, pois o processo de reenvio pode permanecer de maneira indefinida;

- uma situação injusta, onde caso haja a desistência de alguma reserva e uma nova requisição, realizada por outro, obtém a reserva antes da requisição que está realizando o reenvio. 


\section{CONCLUSÕES}

Neste trabalho foram analisadas diversas maneiras de realizar o controle transacional entre workflows oriundos de domínios distintos que executam composição de serviços entre múltiplos servidores. Existem esforços e pesquisas que procuram resolver o problema utilizando um coordenador centralizador, ou situações distribuídas que podem gerar deadlock na execução dos workflows e resolvendo com políticas que não são justas para prosseguir a execução, ou políticas que podem configurar na situação de starvation.

O desafio é aplicar estratégias para execução de workflows distintos, que utilizam serviços em múltiplos servidores, de maneira autônoma entre os servidores. Nesta estratégia, as entidades que proveem os recursos devem receber informações para determinar a prioridade de cada requisição para utilizar o serviço. As entidades que realizam as requisições devem oferecer informações para que a requisição seja atendida de forma justa e receber informações para que gerencie a execução da composição de maneira transacional.

A definição do critério de prioridade, através da política baseada no instante de solicitação de uma requisição e não no instante que um serviço recebe a requisição foi o elemento base para o desenvolvimento do trabalho.

O uso do relógio lógico se mostrou adequado para que o critério de prioridade fosse atendido. O valor do relógio conseguiu representar o instante de envio entre as requisições. Este critério permite definir a prioridade de atendimento no uso do recurso.

A utilização de estágios para efetuar o consumo de recurso é apropriada, pois com a utilização de múltiplas listas no atendimento ao recurso permite refazer um atendimento que foi realizado em um primeiro momento, mas durante a conclusão do processo houve a necessidade de reparo para promover uma condição justa. A política em promover justiça produziu um critério que em caso de impasse no atendimento de requisições haja como determinar a prioridade de uso do recurso impedindo a situação de deadlock.

O reparo realizado no atendimento da requisição, não elimina o privilégio que esta havia obtido em instante anterior, bastando aguardar a desistência de reservas 
para obter o privilégio novamente. O mecanismo de reparo faz com que a requisição fique temporariamente suspensa, sem a necessidade de realizar reenvio para obter 0 recurso novamente, impedindo a situação de starvation.

A notificação de estado para as operações solicitadas permite que a entidade que está executando a composição de serviços possa gerenciar cada operação solicitada de maneira que permita a execução transacional.

Os resultados mostram que é possível realizar o gerenciamento de forma transacional de workflows distintos, de maneira autônoma, onde os Servidores Requisição não precisam conhecer outros Servidores Requisição, e os Servidores Recurso não necessitem conhecer outros Servidores Recurso. O gerenciamento transacional para a execução dos workflows é realizado através de informações que estão contidas nas mensagens de request/reply que as entidades trocam, e as requisições são atendidas de maneira justa, impedindo a situação de deadlock e starvation.

\subsection{CONTRIBUIÇÕES}

No desenvolvimento deste trabalho, diversos aspectos foram tratados na execução de composição de serviços de forma transacional, podendo-se mencionar as seguintes contribuições:

- realizar o gerenciamento transacional entre workflows oriundos de domínios distintos de maneira autônoma, sem a necessidade dos servidores envolvidos possuírem o conhecimento global das execuções;

- o critério de prioridade baseado no instante em que uma requisição é realizada e não no instante em que ela é recebida pelo serviço que possui o recurso. Esta política evita que haja situação de posse e espera entre requisições de workflows oriundos de domínios diferentes, mantendo a justiça no atendimento e impedindo situações de deadlock;

- a política em tratar as requisições baseada em listas, em especial a lista WL. Esta lista considera que uma requisição está temporariamente suspensa para alocar um recurso, e lhe atribui prioridade caso alguma alocação não seja realizada. Esta política proporciona uma execução justa, 
evitando o procedimento de reenvio, a qual pode acarretar em execução injusta ou starvation.

\subsection{Trabalhos Futuros}

A continuidade deste trabalho cria a oportunidade para o desenvolvimento de novos trabalhos. Diversas questões podem ser tratadas em trabalhos futuros. Seguem algumas destas questões:

- no gerenciamento transacional de workflow, um aspecto importante é a tolerância a falhas, que pode ser explorado através de mecanismos mais robustos para as aplicações que utilizam o ambiente;

- avaliar estratégias de regras de negócios as quais podem definir novas políticas de prioridades, podendo-se considerar situações de tempo limite para que requisições fiquem na lista $\mathrm{WL}$, ou novos critérios para mover requisições entre as listas. 


\section{REFERÊNCIAS BIBLIOGRÁFICAS}

ARMBRUST, M. et al. Above the Clouds: A Berkeley View of Cloud Computing. EECS Department, University of California, Berkeley. [S.I.], p. http://www.eecs.berkeley.edu/Pubs/TechRpts/2009/EECS-2009-28.html. 2009. (UCB/EECS-2009-28).

BERNSTEIN, A. J.; KIFER, M. Databases and Transaction Processing: An Application-Oriented Approach. Boston, MA, USA: Addison-Wesley, 2001.

COULOURIS, G. et al. Distributed Systems: Concepts and Design. 5. ed. [S.I.]: Addison-Wesley Publishing Company, 2011.

ELMAGARMID, A.; RUSINKIEWICZ, M.; SHETH, A. Management of Heterogeneous and Autonomous Database Systems. San Francisco: Morgan Kaufmann, 1999.

ELMASRI, R.; NAVATHE, S. Sistemas de Banco de Dados. 5. ed. [S.I.]: Pearson Addison Wesley, 2005.

ERL, T. SOA - Princípios de Design de Serviços. 1. ed. [S.I.]: Pearson/Prentice Hall, 2009.

FOSTER, I. et al. The Physiology of the Grid: An Open Grid Services architecture for Distributed Systems Integration, 2002.

FOSTER, I.; KESSELMAN, C. The Grid: Blueprint for a New Computing Infrastructure. San Francisco: Elsevier, 2004.

FREUND, T.; STOREY, T. Transactions in the World of Web Services. IBM Corporation. [S.I.]. 2002.

GARCIA-MOLINA, H.; SALEM, K. Sagas. Proceedings of the 1987 ACM SIGMOD International Conference on Management of Data, San Francisco, California, USA, v. 16, p. $249-259,1987$.

GEORGAKOPOULOS, D.; HORNICK, M.; SHETH, A. An overview of workflow management: from process modeling to workflow automation infrastructure. Distributed and Parallel Databases, v. 3, n. 2, p. 119--153, 1995.

GOTTSCHALK, K. et al. Introduction to Web Services Architecture. IBM Systems Journal, 41, 2002. 170-177.

GREFEN, P.; VONK, J. A Taxonomy of Transactional Workflow Support. International Journal of Cooperative Information Systems, 2006. 87-118.

JAX-WS 2.0. Java API for XML-based web services. Disponivel em: $<$ https://jcp.org/en/jsr/detail?id=224>. Acesso em: Novembro 2014.

LAMPORT, L. Time, clocks, and the ordering of events in a distributed system. Communications of the ACM, Julho 1978. 558-565. 
LIMTHANMAPHON, B.; ZHANG, Y. Web Service Composition Transaction Management. Proceedings of the 15th Australasian Database Conference, Dunedin, New Zealand, 2004. 171--179.

MACIEL, L. A. H. D. S.; HIRATA, C. M. A timestamp-based two phase commit protocol for web services using rest architectural style. Journal of Web Engineering, v. 9, n. 3, p. 266--282, Setembro 2010.

OASIS. OASIS Web Services Business Process Execution Language. World Wide Web Consortium W3C, Abril 2007a. Disponivel em: <http://docs.oasisopen.org/wsbpel/2.0/wsbpel-v2.0.pdf>. Acesso em: Julho 2013.

OASIS. OASIS Web Services Transaction (WS-TX) TC. OASIS - Advancing Open Standards for the Information Society, 2009b. Disponivel em: <https://www.oasisopen.org/committees/tc_home.php?wg_abbrev=ws-tx>. Acesso em: Julho 2013.

OASIS. Web Services Atomic Transaction 1.1. World Wide Web Consortium W3C, 2009c. Disponivel em: <http://docs.oasis-open.org/ws-tx/wstx-wsat-1.1-spec-errataos/wstx-wsat-1.1-spec-errata-os.html>. Acesso em: Julho 2013.

OASIS. Web Services Business Activity 1.1. World Wide Web Consortium W3C, 2009d. Disponivel em: <http://docs.oasis-open.org/ws-tx/wstx-wsba-1.1-spec-os/wstxwsba-1.1-spec-os.html>. Acesso em: Julho 2013.

OASIS. Web Services Coordination (WS-Coordination) Version 1.2. The World Wide Web Consortium - W3C, 2009e. Disponivel em: <http://docs.oasis-open.org/wstx/wstx-wscoor-1.2-spec.html>. Acesso em: Julho 2013.

OASIS. OASIS - Advancing open standards for the information society. OASIS Advancing open standards for the information society, 2013. Disponivel em: <https://www.oasis-open.org/>. Acesso em: Abril 2013.

OZSU, M. T.; VALDURIEZ, P. Principles of Distributed Database Systems. 2nd edition. ed. Englewood Cliffs: Prentice-Hall, 1999.

QI, Z. et al. Integrating X/Open DTP into Grid services for Grid transaction processing. Proceedings. 10th IEEE International Workshop on Future Trends of Distributed Computing Systems. FTDCS 2004., 2004. 128-134.

SHENG, Q. et al. Web services composition: A decade's overview. Information Sciences, 280, 2014. 218 - 238.

TANENBAUM, A. S.; STEEN, M. V. Sistemas Distribuídos - Principios e Paradigmas. 2a. ed. São Paulo: Pearson Education, 2007.

TURKER, C. et al. How can we support Grid Transactions? Towards Peer-to-Peer Transaction Processing. Proceedings of the Second Conference on Innovative Data Systems Research (CIDR). [S.I.]: [s.n.]. 2005. p. 174-185.

W3C. World Wide Web Consortium. World Wide Web Consortium, 2013. Disponivel em: <http://www.w3.org/>. Acesso em: Abril 2013. 
WANG, T. et al. A Survey on the History of Transaction Management: From Flat to Grid Transactions. Distributed Parallel Databases, Hingham, MA, USA, v. 23, n. 3, p. 235--270, Junho 2008.

ZARRAS, ; ISSARNY, V. A Framework for Systematic Synthesis of Transactional Middleware. Proceedings of the IFIP International Conference on Distributed Systems Platforms and Open Distributed Processing, London, 1998. 257--272. 


\section{ApÊndice A - CenáRIo 1, Log em Suse01}

\section{Log de execução em Suse01 para o teste da subseção 6.3.1.}

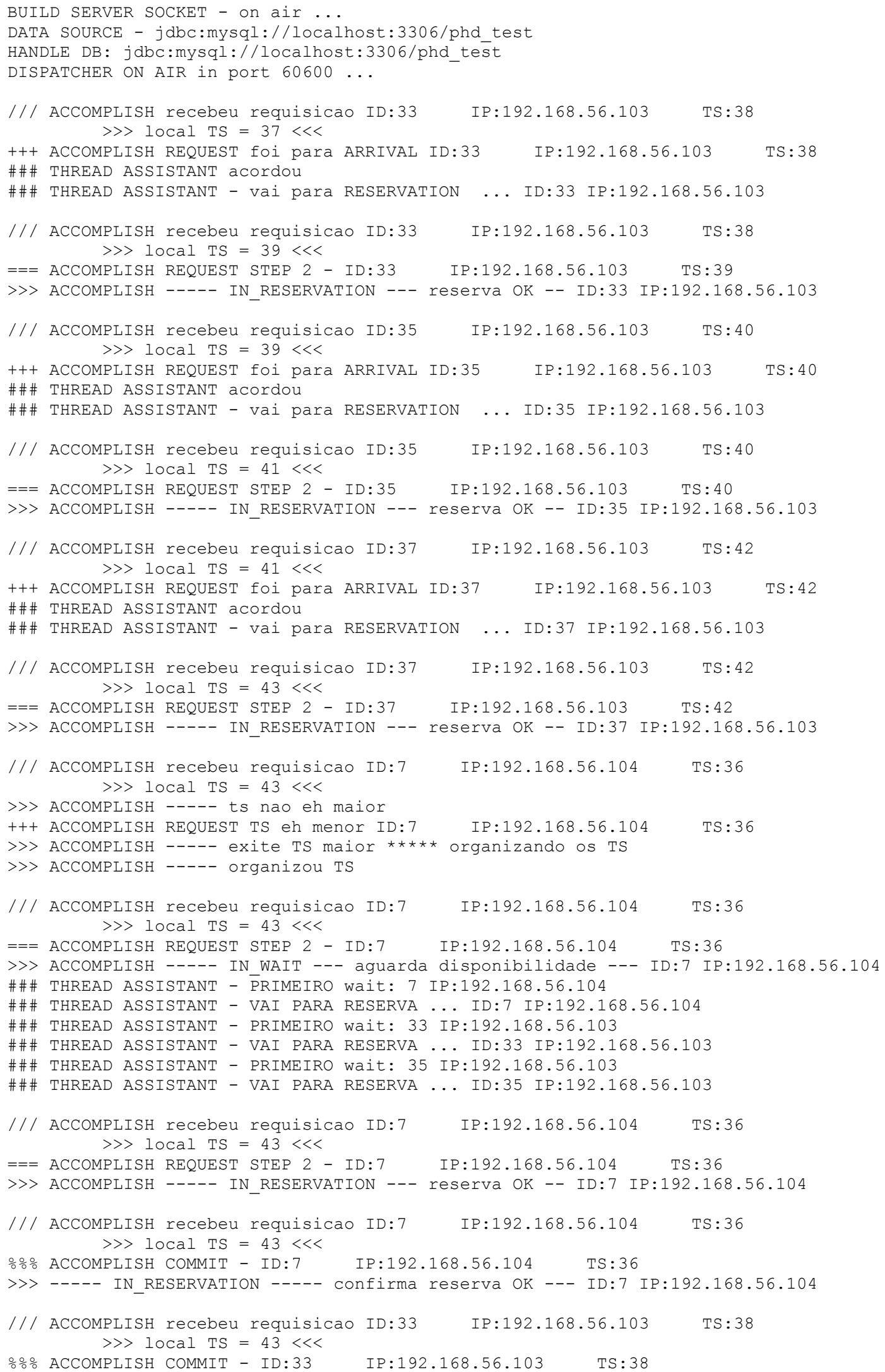


/// ACCOMPLISH recebeu requisicao ID:35

IP $: 192.168 .56 .103$

TS $: 40$

$$
>>\text { local TS }=43<<<
$$

(a@ ACCOMPLISH ROLLBACK - ID:35

IP $: 192.168 .56 .103$

TS $: 40$

>> ACCOMPLISH ROLLBACK - IN_RESERVATION - operacao OK --- ID:35 IP:192.168.56.103
\#\#\# THREAD ASSISTANT - PRIMEIRO wait: 37 IP:192.168.56.103

\#\#\# THREAD ASSISTANT - VAI PARA RESERVA ... ID:37 IP:192.168.56.103

/// ACCOMPLISH recebeu requisicao ID:37

IP: 192.168 .56 .103

TS $: 42$

$$
>>\text { local TS }=43<<<
$$

IP: 192.168 .56 .103
RVATION - operacao OK

TS: 42

a A ACCOMPI ISH ROIIBACK

ID:37 IP: 192.168 .56 .103

\#\#\# THREAD ASSISTANT - PRIMEĀRO wait: 39 IP:192.168.56.103

\#\#\# THREAD ASSISTANT - VAI PARA RESERVA ... ID:39 IP:192.168.56.103 


\section{APÊNDICE B - CenÁRIO 1, LOG EM SUSE02}

\section{Log de execução em Suse01 para o teste da subseção 6.3.1.}

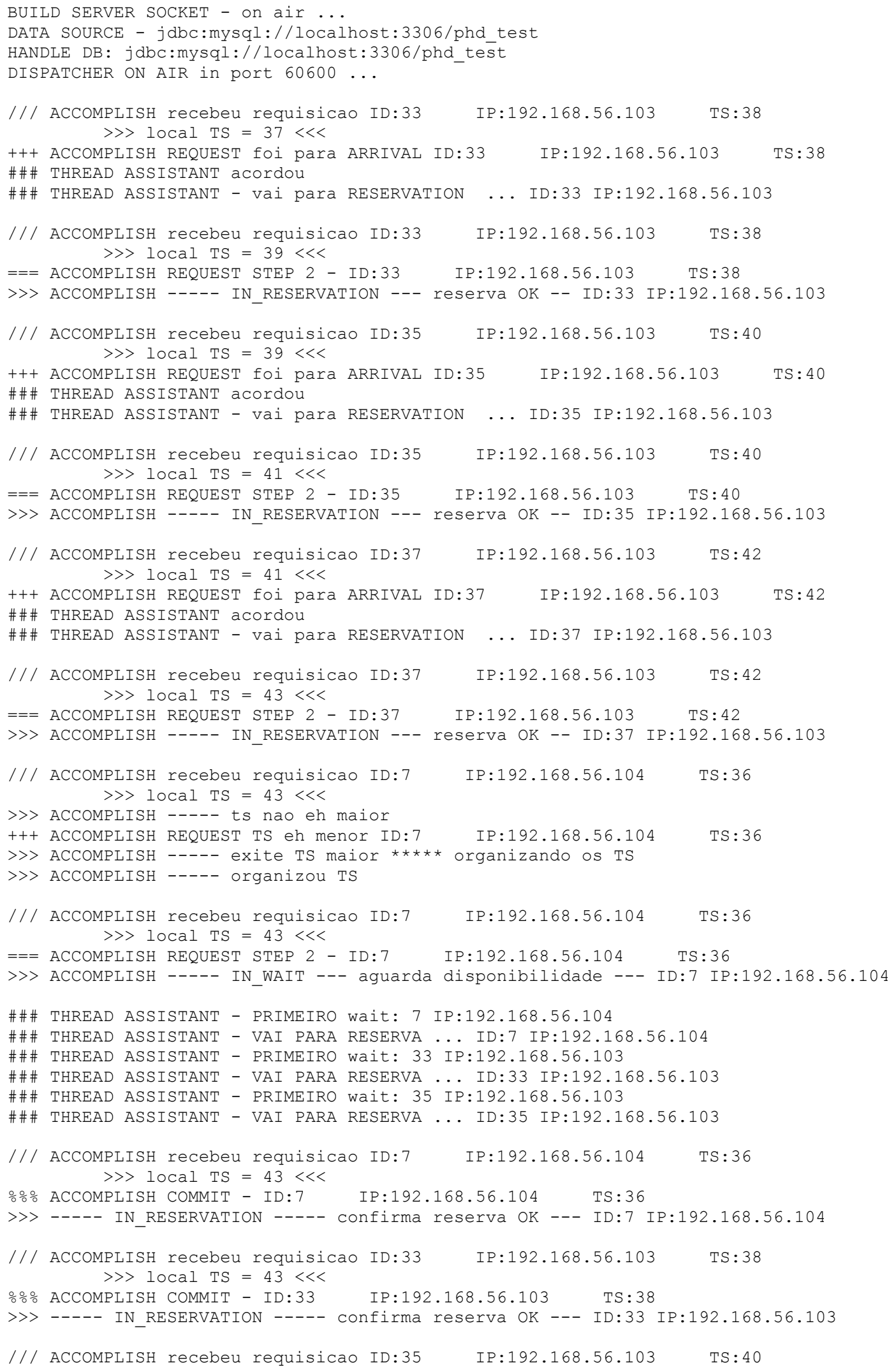




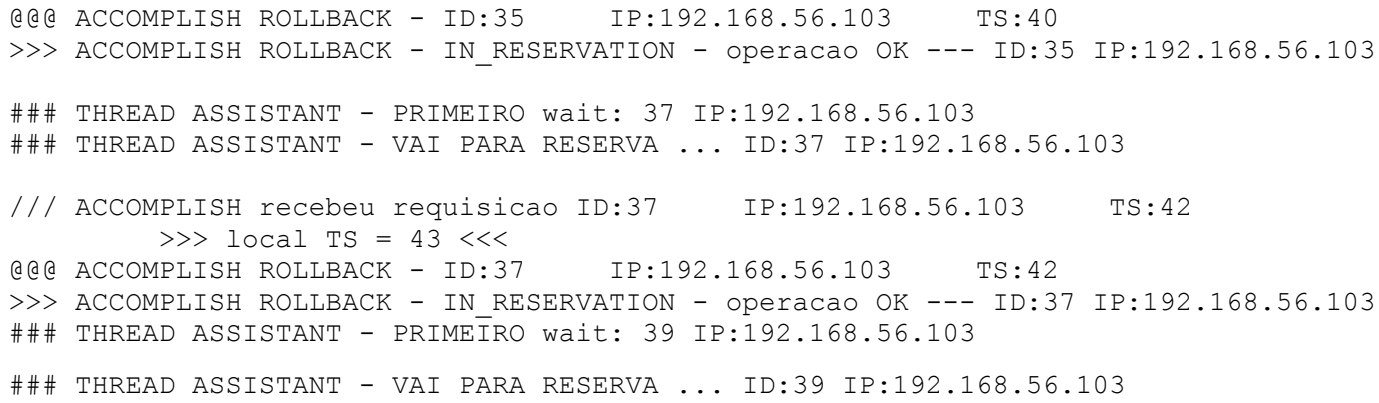




\section{ApÊndice C - Cenário 2, log em Suse01 para COMMIT de Suse04}

\section{Log de execução em Suse01 para o teste da subseção 6.3.2, onde Suse04 confirma reservas.}

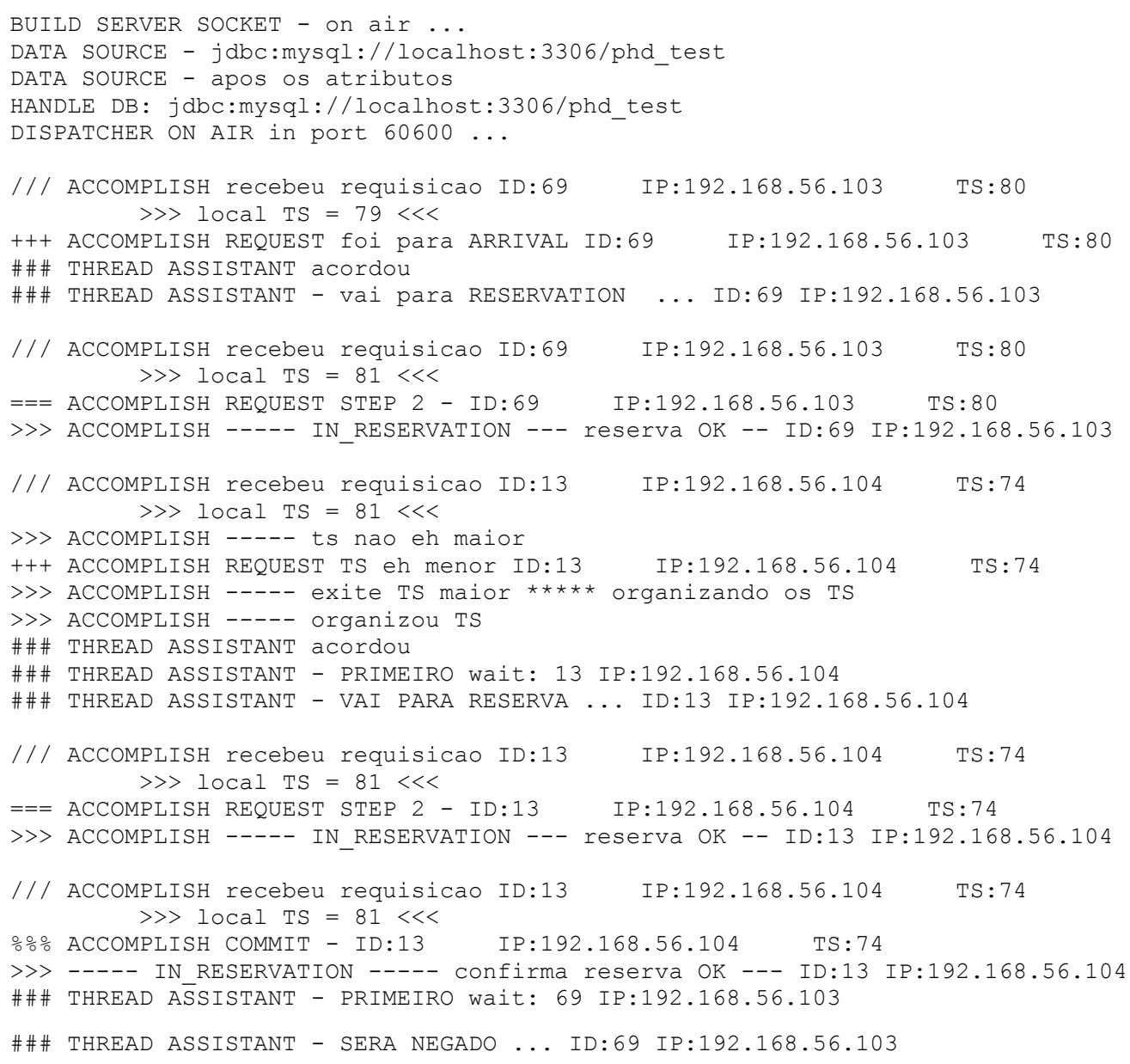




\section{ApÊndice D - Cenário 2, log em Suse02 para COMMIT de Suse04}

\section{Log de execução em Suse02 para o teste da subseção 6.3.2, onde Suse04 confirma reservas.}

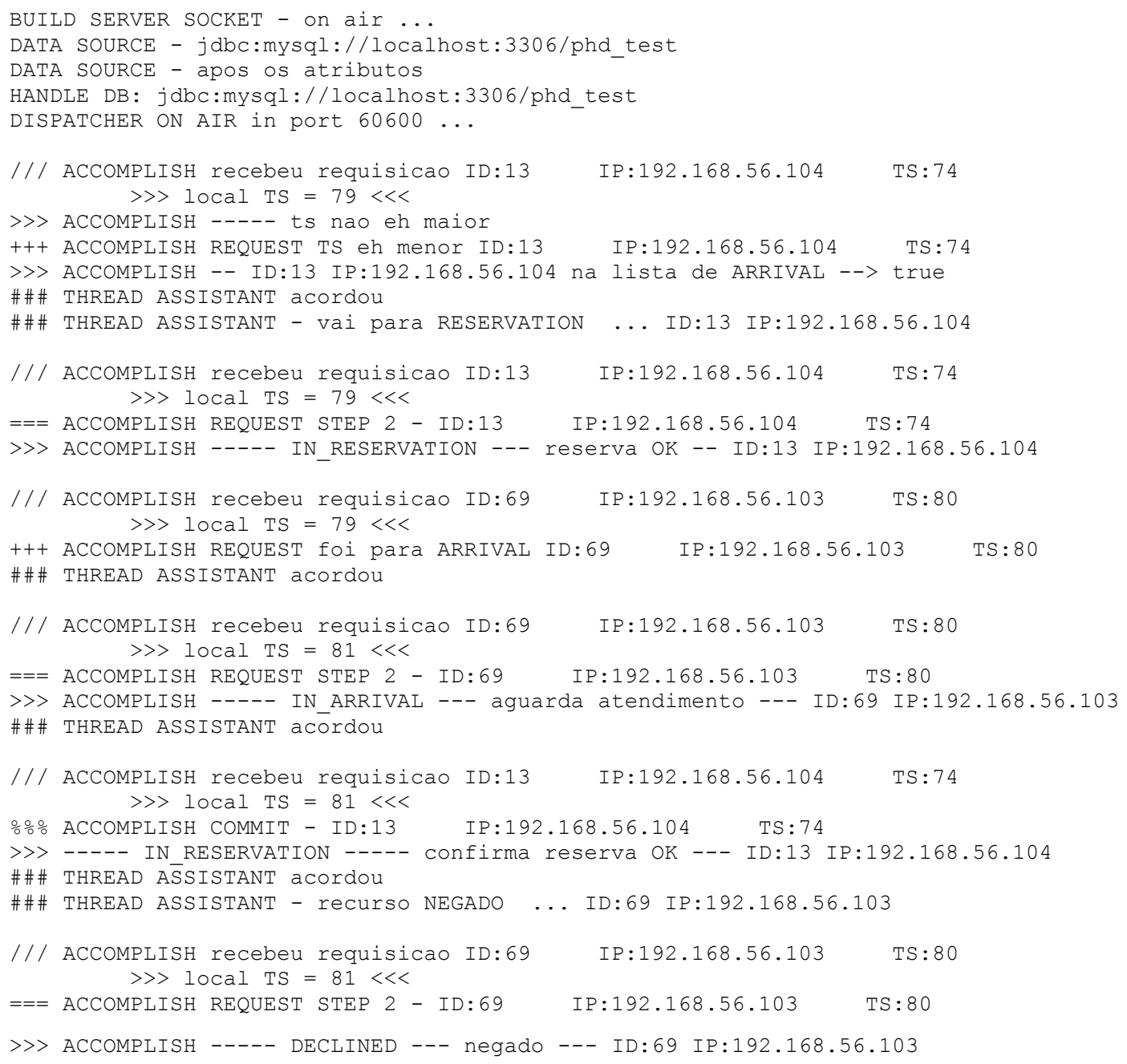




\section{ApÊndice E - Cenário 2, log em Suse01 Para ROLLBACK de Suse04}

\section{Log de execução em Suse01 para o teste da subseção 6.3.2, onde Suse04 desfaz reservas.}

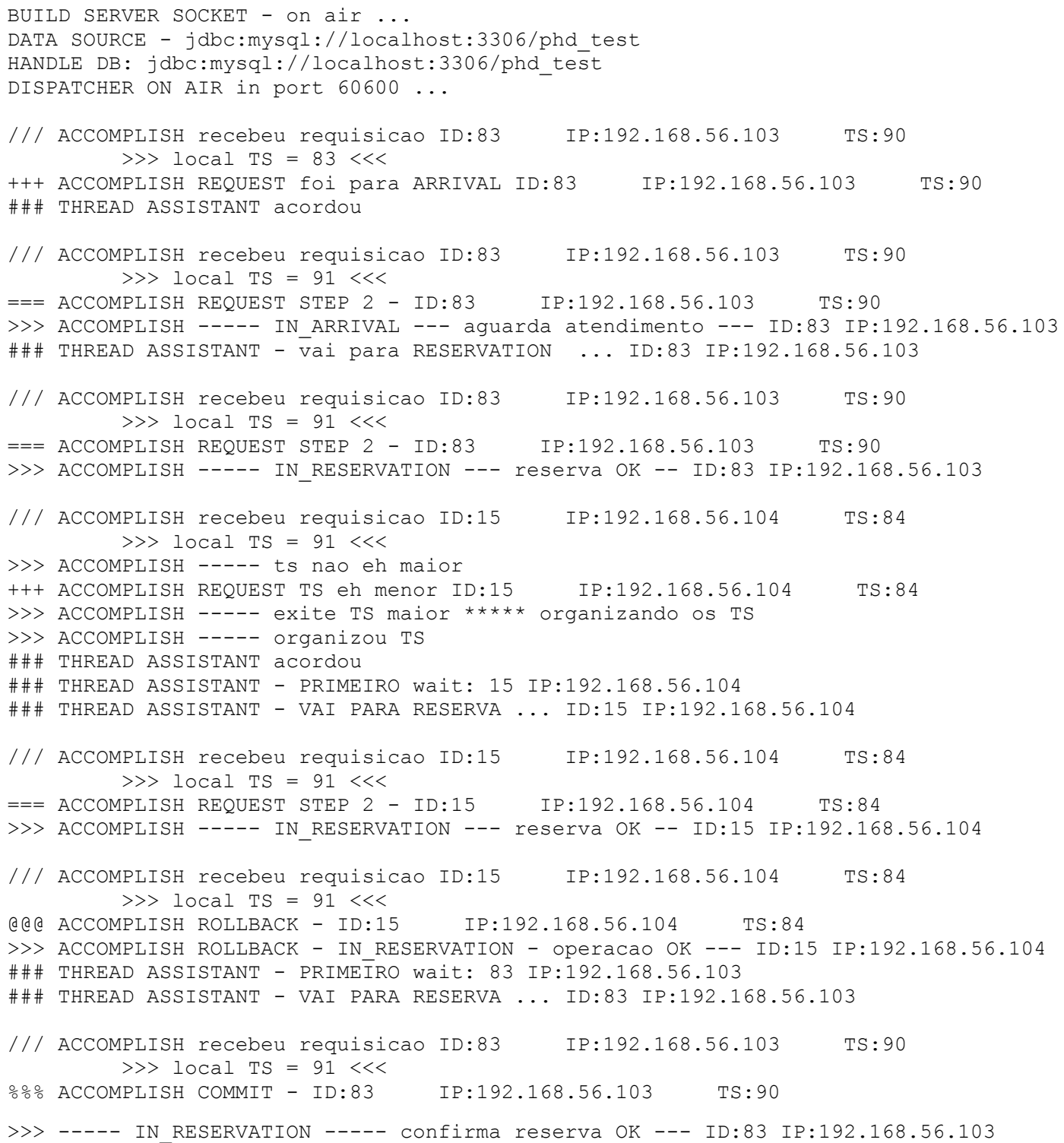




\section{ApÊndice F - Cenário 2, log em Suse02 PaRa ROLLBACK de Suse04}

\section{Log de execução em Suse02 para o teste da subseção 6.3.2, onde Suse04 desfaz reservas.}

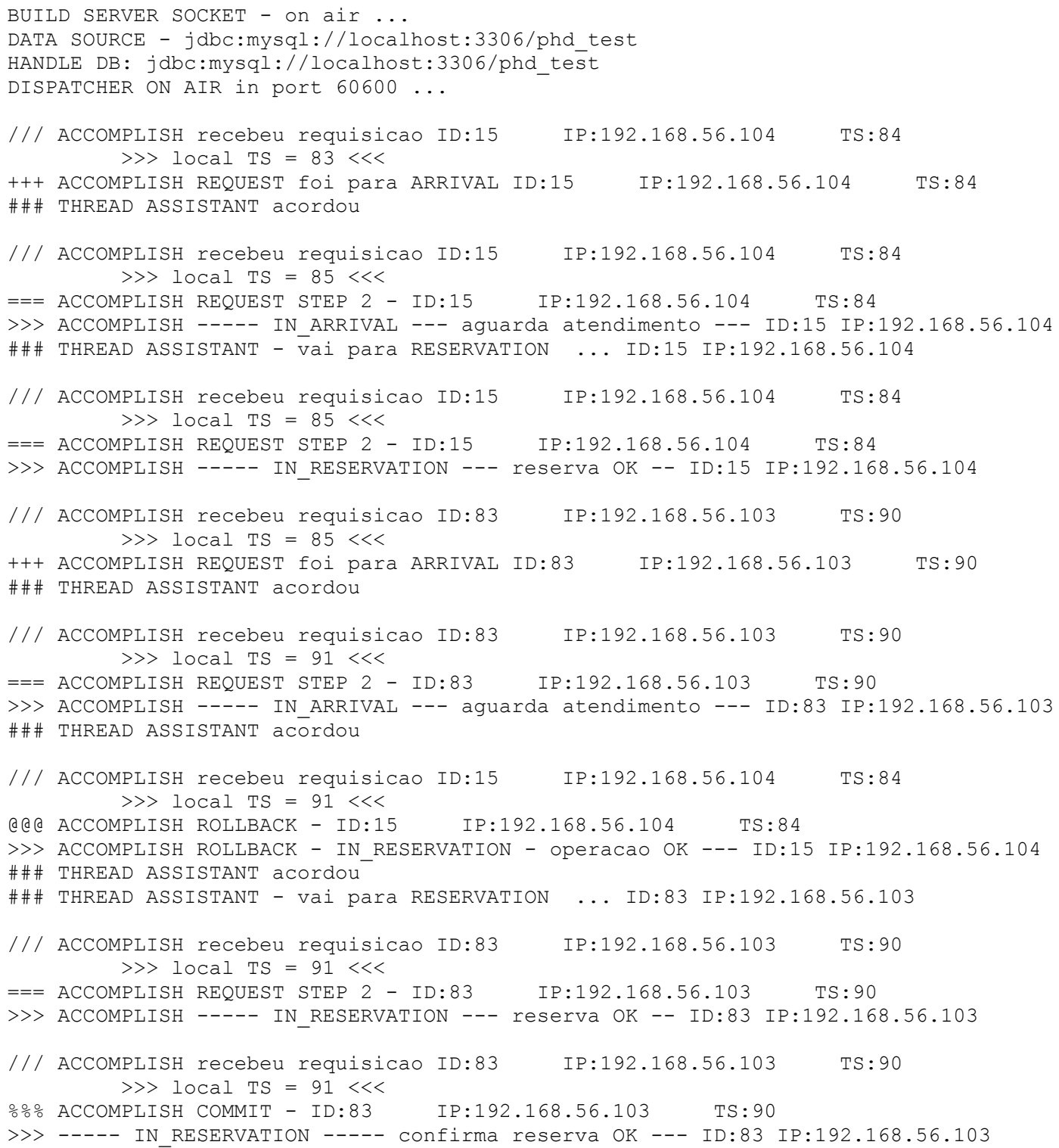

